Universidade de Brasília - UnB

Instituto de Geociências - IG

\title{
A Bacia Pull Apart do Gráben Água Bonita e o Lineamento Transbrasiliano
}

\author{
LAVOISIANE FERREIRA DE SOUZA
}

Programa de Pós Graduação em Geociências Aplicadas

Dissertação de Mestrado $\mathbf{N}^{\circ} 88$

Brasília-DF

Outubro, 2015 
Universidade de Brasília - UnB

Instituto de Geociências - IG

\title{
A Bacia Pull Apart do Gráben Água Bonita e o Lineamento Transbrasiliano
}

\section{Lavoisiane Ferreira de Souza}

\author{
Orientador: \\ Prof. ${ }^{\text {a }}$ Dra. Roberta Mary Vidotti \\ Dissertação de Mestrado \\ Programa de Pós Graduação em Geociências Aplicadas \\ Área de concentração: Geofísica Aplicada
}

Comissão Examinadora:

Prof. ${ }^{\text {a }}$ Dra. Roberta Mary Vidotti

Prof. Dr. David Lopes De Castro

Prof. Dr. Carlos Jorge de Abreu 
Ficha catalográfica elaborada automaticamente, com os dados fornecidos pelo(a) autor(a)

SS0729 Souza, Lavoisiane Ferreira

A Bacia Pull Apart do Graben Agua Bonita e 0 Lineamento Transbrasiliano / Lavoisiane Ferreira 2015.

$113 \mathrm{p}$.

Dissertação (Mestrado - Mestrado em Geociências Aplicadas) -- Universidade de Brasilia, 2015.

1. Gravimetria. 2. Magnetometria. 3. Matched Filter. 4. Euler 3D. 5. Modelagem Gravimétrica 2D. I. Vidotti, Roberta Mary, orient. II. Titulo. 
"Eis o meu segredo. É muito simples: só se vê bem com o coração.

O essencial é invisivel para os olhos."

Antoine de Saint-Exupéry

\section{Dedicatória}

À minha mãe Maria Ferreira de Araújo e ao meu irmão Lavousier Ferreira

Diniz de Souza, por sempre estar ao meu lado, apoiar minhas escolhas e me dar força para acreditar que desafios podem ser superados e que não devo temê-los. 


\section{Agradecimentos}

Agradeço à Prof. Dra. Roberta Mary Vidotti pela orientação, atenção e ter acreditado em meu potencial.

Ao Prof. Dr. Elton por toda atenção e paciência enquanto me ensinava a interpretar os dados geofísicos, geológicos e modelo geológico.

Ao Prof. Dr. Carlos Jorge de Abreu por todos os ensinamentos em sedimentologia e estratigrafia além toda atenção e ajuda durante o trabalho de campo.

Ao Prof. Dr. Giuliano Marotta pelos ensinamentos e ajuda durante a aquisição de dados gravimétricos e geodésicos.

A todos que participaram da aquisição de dados de gravimetria, Gabriela Alencar Vogado, Flávio Baldissera, Guilherme Ferreira, Hiago Faria, lago Souza, Kayke Bergamaschi e outros.

A todos da banca examinadora, Prof. ${ }^{a}$ Dra. Roberta Mary Vidotti, Prof. Dr. David Lopes De Castro e Prof. Dr. Carlos Jorge de Abreu pela revisão e críticas construtivas.

A todos os colegas, Luciane, Lucas, João Alberto, Marcelo e Elainy por todos os momentos compartilhados e ajuda.

Ao Instituto de Geociências da Universidade de Brasília por todo o suporte durante a realização do trabalho.

Agradeço ao suporte dado a este projeto pelo termo de cooperação FUB/Petrobras 0050.0053151.09.9.

Ao ESRI pela disponibilização do Pacote de ferramentas que compõem a Família ArcGis 10 por intermédio do contrato $N^{\circ} 2011$ MLK 8733 e a IMAGEM pelo apoio e viabilidade da concretização do termo de uso entre o IG-UnB e a ESRI e pelo suporte aos softwares.

A CPRM pelos dados aerogeofísicos do PGBC que foram fornecidos.

Ao INPE pelos dados fornecidos do TOPODATA.

A USGS pelo fornecimento das imagens de satélite do Landsat 8. 


\section{Sumário}

Resumo III

Abstract IV IV I I I I I I I I

Lista de Figuras V

Lista de Tabelas $\quad$ IX

1. Introdução

1.1. Objetivos 3

1.2. Localização 3

1.3. Hipóteses 5

1.4. Métodos 9

1.4.1. Dados Aerogeofísicos 10

1.4.2. Gravimetria Terrestre 12

1.4.3. Análise geológica 13

2. Contexto Geológico

2.1. Província Tocantins 14

2.1.1. Faixa Araguaia 16

2.1.2. Faixa Brasília 17

2.2. Ciclo Brasiliano e o Lineamento Transbrasiliano 19

2.2.1. Lineamento Transbrasiliano 21

2.3. Bacias Interiores 22

3. Geologia do Gráben Água Bonita e do Embasamento

3.1. Complexo Rio dos Mangues 25

3.2. Formação Xambioá 26

3.3. Formação Água Bonita 26

3.4. Interpretação geológica com base em Landsat e SRTM 33

4. Magnetometria Aérea

4.1. História e teoria do método 37

4.1.1. Campo Magnético Terrestre 39

4.1.2. Susceptibilidade magnética e magnetização 40

4.1.3. Magnetização induzida e remanente 42

4.2. Processamento dos dados 43

4.2.1. Micronivelamento 44

4.2.2. Redução ao Polo 46

4.2.3. Derivadas 47

4.3. Interpretação e integração dos dados magnéticos 54 
5. Gravimetria

5.1. História e teoria do método

5.1.1. Geóide

5.1.2. Densidade

5.2. Aplicações do método 63

5.3. Aquisição dos Dados $\quad 64$

5.4. Processamento dos Dados 68

5.4.1. Redução dos dados 68

5.4.1.1. Altitude Elipsoidal e Ortométrica 68

5.4.1.2. Correção de Drift 69

5.4.1.3. Correção de maré $\quad 69$

5.4.1.4. Correção de Latitude 70

5.4.1.5. Correção Ar-livre 72

5.4.1.6. Correção Bouguer $\quad 72$

5.5. Anomalias Ar-Livre e Bouguer 73

$\begin{array}{ll}\text { 5.5.1. Anomalia Ar-Livre } & 73\end{array}$

$\begin{array}{ll}\text { 5.5.2. Anomalia Bouguer } & 74\end{array}$

6. Análise de Profundidade e integração dos dados

6.1. Análise de Profundidade $\quad 77$

$\begin{array}{ll}\text { 6.1.1. Análise do Espectro de Potência } & 77\end{array}$

\begin{tabular}{ll} 
6.1.2. & Matched Filter \\
\hline 6.30
\end{tabular}

6.1.3. Deconvolução de Euler 86

6.2. Integração dos dados $\quad 92$

7. Modelagem Gravimétrica e Modelo Geológico

7.1. Modelagem Gravimétrica $\quad 95$

7.2. Modelo Geológico 98

8. Discussão Final e Conclusões 102

$\begin{array}{lr}\text { 9. Referências Bibliográficas } & 107\end{array}$ 


\section{Resumo}

O Lineamento Transbrasiliano (LTB) é uma das principais estruturas da Plataforma Sul-americana. É definido como uma faixa cataclasada de direção NE-SW com pelo menos $2700 \mathrm{~km}$ de extensão no Brasil, este lineamento exerceu grande influência, juntamente com outras estruturas do embasamento, na história deposicional das bacias sedimentares do Paraná e Parnaíba. A Formação Água Bonita (FAB) pode ter o mesmo aporte sedimentar que o de bacias paleozóicas, devido à posição intermediária em relação às bacias do Paraná, a sudoeste, e do Parnaíba, a nordeste, e do Amazonas, a noroeste. Dentro deste contexto este trabalho pode trazer informações importantes acerca da origem e evolução do gráben, além de sua correlação com o Lineamento Transbrasiliano e com as bacias sedimentares paleozoicas.

Este trabalho tem como objetivo principal fornecer o modelo geológico estrutural do Gráben Água Bonita utilizando dados geológicos, geofísicos aéreos e terrestres, além de trazer informações acerca da origem e evolução do gráben, sua correlação com o Lineamento Transbrasiliano e as bacias sedimentares paleozoicas brasileiras. O Graben Água Bonita está localizado nos estados de Tocantins e Goiás, entre o município de Araguaçu (TO), a oeste, e Novo Planalto (GO), a leste. Sua origem do pode estar associada a uma reativação do Lineamento Transbrasiliano na qual houve a deposição da Formação Água Bonita, com provável idade Siluriano-Devoniano.

A área de estudo é recoberta por dados aerogeofísicos de magnetometria adquiridos na década de 70 e foram utilizados para interpretação. Foram adquiridos dados terrestres gravimétricos e geodésicos em 498 estações e foram adicionados ao banco de dados 147 estações gravimétricas de trabalhos anteriores. A análise de afloramentos permitiu identificar associações de fácies sedimentares que ocorrem na superfície que adicionaram informações sobre a formação do gráben.

A partir da interpretação, integração, técnicas de análise de profundidade e modelagem gravimétrica $2 \mathrm{D}$ foi criado um modelo geológico com um rifte precursor, que pode ser relacionado ao Rifte Jaibaras, e que está associado ao baixo gravimétrico a aproximadamente $2,4 \mathrm{~km}$ e um duplex extensional num sistema strike slip com profundidade de até 1,6 km onde foram acomodados os sedimentos pré-existentes da $F A B$ e da fase rifte. A FAB é bordejada por falhas transcorrentes dextrais relacionadas ao Lineamento Transbrasiliano, na borda leste uma falha mais expressiva é subvertical com mergulho para oeste, na borda oeste a falha é menos íngreme. As falhas de borda são interceptadas por lineamentos perpendiculares à borda oeste. Ocorrem também falhas com direção N65E que separam o gráben em duas porções. A porção norte apresenta características diferentes da porção sul nos dados magnéticos, gravimétricos e geológicos. Na interpretação dos dados geofísicos e geológicos foram observados lineamentos primários com direção N55W, N70W e N35E e secundários E/W.

PALAVRAS-CHAVES: Gravimetria, Magnetometria, Matched Filter, Euler 3D, Modelagem Gravimétrica 2D, Inclinação do Sinal Analítico do Gradiente Horizontal, Espectro de Potência. 


\section{Abstract}

The Transbrasiliano lineament $(L T B)$ is one of the main structures of the South American Platform. It is defined as a cataclasitc belt trending NE-SW with at least $2700 \mathrm{~km}$ in length, this lineament had big influence, along with other structures, for the installation and depositional history of the sedimentary basins of Paraná and Parnaiba. Agua Bonita formation (FAB) may have the same sedimentation of Paleozoic basins due to its intermediate position relative to Paraná basin, southwest, Parnaiba basin, northeast, and Amazonas basin, northwest. Within this context, this work can provide important information about the origin and evolution of the graben, as well as its correlation with the Transbrasiliano lineament and the Paleozoic sedimentary basins.

This work aims to provide a structural geological model of the Agua Bonita Graben (GAB) using geological data, aero and ground geophysics, as well as to provide information about its origin and evolution, and its correlation with the Transbrasiliano lineament and Brazilian Paleozoic sedimentary basins. The Agua Bonita Graben is located in the Tocantins and Goias states, between the cities of Araguaçu (TO) to west and Novo Planalto (GO) to east. Its origin can be associated with a reactivation of the lineament Transbrasiliano in which there was the deposition of the Agua Bonita formation, suggested to be Silurian-Devonian.

The study area is covered by airborne geophysical magnetometry data acquired in the 70s wich were used for interpretation. Gravity and geodetic data in 498 terrestrial stations and were added to the database 147 gravity stations of previous work. The outcrops analysis identified sedimentary facies associations that occur on the surface and provided additional information about the graben formation.

A geological model was proposed for the GAB based on the interpretation, integration, depth analysis techniques and $2 D$ gravity forward modeling. A rift phase was included in the model, which may be related to Jaibaras rift. The rift section is associated with the 2.4 kilometers gravity low and an extensional duplex in a strike slip system is 1.6 kilometers deep, where preexisting sediments of the FAB and rift were accommodated. The FAB is bordered by dextral strike-slip faults related Transbrasiliano lineament, on the eastern edge a more significant fault is subvertical dipping to the west, the western edge fault is less steep. The graben border faults are intercepted by perpendicular faults at the western edge. Faults N65E trending separate the graben in two parts. The northern part has different characteristics from the southern portion in the magnetic, gravity and geological data. The geophysical and geological data interpretation provides primary lineaments trending N55W, N70W and N35E as well as secondary EW lineaments.

KEYWORDS: Gravity, Magnetics, Matched Filter, Euler 3D , 2D Gravimetric Modeling, Tilt Angle of the Total Horizontal Gradient, Power Spectrum. 


\section{Lista de Figuras}

Figura 1.1 - Mapa geológico simplificado da porção centro leste da Província Tocantins e localização da área de estudo (polígono verde) com os domínios tectônicos e principais estruturas associadas, segundo Pimentel et al. 2004.

.1

Figura 1.2 - Localização e principais cidades da área de estudo, vias de acesso utilizadas no trajeto de Brasília à área do projeto

Figura 1.3 - Mapa Geológico com a Geologia de Goiás 1:500.000 (Moreira et al. 2008) sobreposta a SD22, escala 1:1.000.000 (Lacerda Filho et al. 2004). Observa-se que a largura da Formação Água Bonita no estado de Goiás é menor do que no estado do Tocantins

Figura 1.4 - Etapas realizadas neste trabalho. Aquisição de dados de gravimetria, processamento dos dados magnéticos e gravimétricos, pesquisa de dados geológicos, seguidos pela interpretação e integração dos dados, modelagem gravimétrica e por último o modelo geológico do GAB......... 9

Figura 1.5 - Etapas realizadas utilizando os dados magnéticos. A partir do processamento dos dados foram gerados os produtos: Campo Magnético Anômalo (CMA), Campo Magnético Reduzido ao Polo (CMA-RDP), Derivada horizontal e vertical (dx, dy e dz), Amplitude do Gradiente Horizontal Total (AGHT), Amplitude do Sinal Analítico (ASA), Inclinação do Sinal Analítico (ISA) e Inclinação do Sinal Analítico do Gradiente Horizontal (TAHG). Estes produtos foram interpretados a partir da análise de profundidade, traçados de lineamentos e determinação dos domínios. 11

Figura 1.6 - Etapas realizadas utilizando os dados gravimétricos. Início com a aquisição dos dados seguido pelo processamento e interpretação.

Figura 2.1 - Províncias do Brasil (Bizzi et al. 2003), observar a Província Tocantins onde se localiza a área de estudo (em vermelho).

Figura 2.2 - Províncias Tectônicas da América do Sul (Cordani et al. 2000). Observar o Lineamento Transbrasiliano, de sul para norte, cortando a Bacia do Paraná, a área de estudo e a Bacia do Parnaíba.

Figura 2.3 - Alguns tipos de bacias interiores do Brasil (segundo Pedreira et al. 2003): bacias intracratônicas, strike-slip, de antepaís de retroarco e de riftes abortados (aulacógenos). .23

Figura 3.1 - Mapa geológico (Lacerda Filho et al. 2004) da área de estudos e embasamento adjacente. Localização dos pontos descritos neste capítulo, A, B e C, figuras 3.6, 3.8 e 3.9, respectivamente. .25

Figura 3.2 - Figura 3.2 - Perfil litológico vertical, onde se observa a Formação Água Bonita (SilurianoDevoniano ?) sobrepondo a Formação Xambioá (embasamento neoproterozoico). Observar conglomerados basais recobrindo o embasamento e sendo recoberto pelos arenitos possivelmente de barras de plataforma rasa, inicialmente com influência de marés e posteriormente com ações de ondas.

Figura 3.3 - Afloramento da associação de fácies A. Cruzadas de grande porte na altura da pessoa, cruzadas tabulares de menor espessura acima. Este pacote sobrepõe conglomerados, sob os pés da pessoa, que por sua vez assenta-se sobre o embasamento representado pela Fm. Xambioá (não mostrado na foto). 
Figura 3.4 - Perfil litológico vertical da associação de facies $B$, com ciclos de acamamento gradacional na base e truncamentos de baixo ângulo no topo, interrompido por siltito, representado por fácies de menor energia do ambiente (ação de ondas); segue-se uma camada de arenito com cruzada tabular, possivelmente depositada por correntes litorâneas (paleocorrentes para NE); ainda nesta fase, depositam ciclos de arenitos grossos a muito grossos mal selecionados com acamamento gradacional inverso, representando barras progradantes de plataforma. Finalmente, no topo são depositadas arenitos médios mal selecionados, sob ação de ondas, ao retrabalhar sedimentos previamente depositados, provavelmente por deltas de granulação grossa ou leques aluviais. 30

Figura 3.5 - Arenitos muito finos a médios, com estartificações onduladas truncadas de baixo ângulo (terço superior da foto) devido a ação de ondas de tempestades que retrabalharam depósitos arenosos de leques aluviais ou deltas de granulação grossa. Esta facies sobrepõe arenitos finos com estratificação cruzada tabular e base erosional (martelo), possivelmente depositados por correntes litorâneas dirigidas para NE.

Figura 3.6 - Foto fácies C, onde estão representados no topo as fácies de praia e na base as fácies de tempestade 32

Figura 3.7 - a) Fusão das bandas 564 do satélite Landsat 8, composição R5-G6-B4 e limites do GAB de acordo Lacerda Filho et al. 2004; b)Interpretação das principais drenagens interpretadas a partir da imagem de satélite Landsat 8 composição 5,6,4. 34

Figura 3.8 - Altimetria da área em estudo com 90 metros de resolução. A área de estudos apresenta pequena variação de elevação, aproximadamente, 130 metros...... .35

Figura 3.9 - a) Relevo sombreado; b) Principais lineamentos interpretados a partir do relevo sombreado. Em branco os lineamentos primários e os secundários em magenta. c) Roseta dos lineamentos traçados no relevo sombreado. Observam-se lineamentos de direção principal N35E, N55W, N70W e E/W 36

Figura 4.1- Campo magnético terrestre em junho de 2014 (European Space Agency, 2014). O Brasil encontrase numa região com uma baixa intensidade do campo magnético, denominada Anomalia Magnética do Atlântico Sul (AMAS). 39

Figura 4.2 - Vetor do campo magnético total: a) Definido em três componentes ortogonais; b) definido como um escalar com o ângulo de inclinação e declinação (Reeves, 2005). ..40

Figura 4.3 - Campo Magnético Anômalo onde se observa um trend NE referente à zona de influência do Lineamento Transbrasiliano e os limites do GAB que está inserido neste trend, em branco (de acordo Lacerda Filho et al. 2004).

Figura 4.4 - Campo magnético anômalo com a Redução ao Polo Diferencial onde se observa um trend NE referente à zona de influência do Lineamento Transbrasiliano e os limites do GAB que está inserido neste trend, em branco (de acordo Lacerda Filho et al. 2004).

Figura 4.5 - Derivada em z onde se observa um trend NE referente à zona de influência do Lineamento Transbrasiliano e os limites do GAB que está inserido neste trend, em branco (de acordo Lacerda Filho et al. 2004). .48

Figura 4.6 - Amplitude do Gradiente Horizontal Total onde se observa um trend NE referente à zona de influência do Lineamento Transbrasiliano e os limites do GAB que está inserido neste trend, em branco (de acordo Lacerda Filho et al. 2004). 
Figura 4.7 - Amplitude do Sinal Analítico 3D onde se observa um trend NE referente à zona de influência do Lineamento Transbrasiliano e os limites do GAB que está inserido neste trend, em branco (de acordo Lacerda Filho et al. 2004).

Figura 4.8 - Inclinação do Sinal Analítico onde se observa um trend NE referente à zona de influência do Lineamento Transbrasiliano e os limites do GAB que está inserido neste trend, em branco (de acordo Lacerda Filho et al. 2004).

Figura 4.9 - Curvas de da Inclinação do Sinal Analítico referente a $0^{\circ}$ para ajudar na interpretação considerando que no zero podem estar representadas as bordas (Verduzco et al. 2004).......52

Figura 4.10 - Inclinação do Sinal Analítico do Gradiente Horizontal onde se observa um trend NE referente à zona de influência do Lineamento Transbrasiliano e os limites do GAB que está inserido neste trend, em branco (de acordo Lacerda Filho et al. 2004).

Figura 4.11 - Lineamentos (em preto) traçados nos mapas magnéticos: a) CMA reduzido ao polo; b) AGHT; c) Dz; d) ISA; e) TAHG e f) ASA com os domínios magnéticos (em azul). Lineamentos cortam o GAB numa direção N65E, além de outros em toda a região de direção preferencialmente E/W e NE/SW. Estes lineamentos de direção NE/SW podem estar relacionados à zona de influência do Lineamento Transbrasiliano

Figura 4.12 - a) Integração das interpretações individuais dos produtos (em preto); b) roseta correspondente a integração dos produtos. Observam-se lineamentos que cortam o GAB numa direção N65E. Além de lineamentos em toda a região de direção E/W e NE/SW. 56

Figura 4.13 - Domínios interpretados com base na densidade e amplitude dos lineamentos. a)CMA reduzido ao polo; b) AGHT; c) ISA e d)TAHG.

Figura 5.1 - Geóide e elipsoide de referência demonstrado em uma escala continental (Reynolds, 1997)....62

Figura 5.2 - Mapa Geológico (Lacerda Filho et al. 2004) com a localização das 498 estações gravimétricas adquiridas neste trabalho e as 147 estações do trabalho de Carvalho (2011).

Figura 5.3 - Base gravimétrica localizada na Paroquia Imaculada Conceição de Araguaçu (TO). .66

Figura 5.4 - Exemplo de uma estação com aquisição de dados com Receptor GNSS/RTK simultaneamente a aquisição dos dados gravimétricos com o gravímetro CG5.

Figura 5.5 - Resultante da aceleração centrífuga e da aceleração devido à gravidade (Reynolds, 1997).......70

Figura 5.6 - Mapa de Anomalias Ar Livre e limites do GAB de acordo Lacerda Filho et al. 2004. .73

Figura 5.7 - Anomalia Bouguer Completa e limites do GAB de acordo Lacerda Filho et al. 2004. .75

Figura 5.8 - a) Efeito regional retirado da Anomalia Bouguer; b) Anomalia Bouguer Completa sem os efeitos regionais. Limites do GAB de acordo Lacerda Filho et al. 2004 76

Figura 6.1 - Espectro de Potência e a representação das fontes mais profundas, rasas e ruído (Whitehead, 2009). .78

Figura 6.2 - Espectro de Potência para os dados magnéticos e representação das fontes mais profundas, rasas, ruído e Nyquist. .79

Figura 6.3 - Espectro de Potência para os dados gravimétricos e representação das fontes mais profundas, rasas, ruído e Nyquist. .80 
Figura 6.4 - Exemplo de um resultado de matched filter (Phillips, 2001). Diferentes comprimentos de onda para 4 camadas a diferentes profundidades

Figura 6.5 - a) Espectro de potência para a magnetometria; b) Diferentes comprimentos de onda para 4 camadas a diferentes profundidades.

Figura 6.6 - Resultado de matched filter para a magnetometria: a) $28,206 \mathrm{~km}$; b) $8,642 \mathrm{~km}$; c) $1,620 \mathrm{~km} \mathrm{e} \mathrm{d)}$ 326 metros, equivalente ao ruído.

Figura 6.7 - Grid do Matched Filter a aproximadamente 8 km com a aplicação do: a) AGHT e b) TAHG Observa-se em ambos os mapas anomalias contínuas relacionadas à zona de influência do Lineamento Transbrasiliano.

Figura 6.8 - a) Espectro de potência para a gravimetria; b) Diferentes comprimentos de onda para 3 camadas a diferentes profundidades.

Figura 6.9 - Resultado do matched filter para a gravimetria: a) 2,608 km; b) 1,884 km e c) 427 metros. Nas figuras $a$ e $b$ observa-se um baixo gravimétrico na região do GAB.

Figura 6.10 - Mapa ao fundo é o AGHT com as soluções de Euler representadas por cículos coloridos : a) 200 a 480 metros, em verde; b) 480 a 1040 metros, em roxo e; c) 1040 a 9000 metros, em vermelho

Figura 6.11 - a) Todas as soluções de Euler: b) 200 a 480 metros, em verde; c) 480 a 1040 metros, em azul e; d) 1040 a 9000 metros, em vermelho.

Figura 6.12 - Integração da interpretação dos dados magnéticos (linhas pretas) com o resultado da deconvolução de Euler: a) fontes mais rasas e b) fontes mais profundas. .90

Figura 6.13 - Soluções de Euler para a gravimetria. Foram obtidos diferentes valores de profundidade que variam entre $1000 \mathrm{~m}$ e $2800 \mathrm{~m}$. .91

Figura 6.14 - Integração da interpretação dos dados geofísicos e geológicos com os mapa geológico e estruturas geológicas (em branco) de acordo o Lacerda Filho et al. (2004) e novos limites litogeofísicos.

Figura 6.15 - Afloramento de ortognaisse próximo à entrada sul da vila de Marilândia (Carvalho, 2011), onde se encontra o domínio 6 da integração.

Figura 6.16 - Mapa geológico da porção central do Graben de Água Bonita de acordo com Carvalho (2011).

Figura 7.1 - Anomalia Bouguer Completa com as estações gravimétricas, o perfil da modelagem gravimétrica (em vermelho) e as estruturas da folha SD22 em roxo (de acordo Lacerda Filho et al. 2004).

Figura 7.2 - Modelagem gravimétrica do perfil gravimétrico: a) Curva do dado modelado; b) Modelagem vista com profundidade até $4 \mathrm{~km}$; c) Modelagem com a profundidade até $8 \mathrm{~km}$

Figura 7.3 - Mapa e seção em perfil de um genérico sistema de falha strike slip, mostrando estrutura em flor e duplexes (Woodcock e Rickards, 2003)......

Figura 7.4 - Possível estrutura em flor no afloramento classificado como Fácies C. Esta estrutura pode ser encontrada em bacias strike slip. 
Figura 7.5 - Modelo geológico para o Graben Água Bonita onde um rifte precursor (que pode ser relacionado ao Grupo Jaibaras) formou uma calha preferencial de transporte com direção preferencial para $\mathrm{NE}$ e depois a deposição da Fm. Água Bonita (FAB) pode ter ocorrido ao mesmo tempo das bacias do Paraná e Parnaíba. A partir de reativações do LTB uma bacia pull-apart foi gerada acomodando os sedimentos pré-existentes da FAB e do rifte. A Faixa Araguaia em amarelo está a oeste do gráben que foi preenchido pela $F A B$, em verde claro; o rifte precursor em verde escuro; e a leste em contato com o gráben está o Complexo Rio dos Mangues do Arco Magmático de Goiás (rosa). Neste contato há um lineamento expressivo situado na zona de influência do LTB que tem um mergulho subvertical para oeste. A profundidade máxima do rifte é de $2,4 \mathrm{~km}$ e da FAB é de $1,6 \mathrm{~km}$. O GAB com suas falhas principais de direção principal N35E e perpendicular a borda oeste possui falhas de direção N55W, além disso, foi cortado com lineamentos de direção N65E que separa a parte norte da sul com características diferenciadas nos dados magnéticos, gravimétricos e geológicos. 101

\section{Lista de Tabelas}

Tabela 6.1- Índices estruturais para as diferentes geometrias de fontes do método magnético e gravimétrico (Reid et al. 1990; Withehead, 2010).

Tabela 7.1 - Diferentes profundidades encontradas com o espectro de potência e o Matched Filter para a análise de profundidade. 


\section{Introdução}

O Gráben Água Bonita (GAB) foi definido por Baptista e Cartner-Dyer (1966) como uma depressão alongada, com cerca de $9 \mathrm{~km}$ de largura por $90 \mathrm{~km}$ de extensão, delimitado por falhas normais, tendo sido formado a partir da reativação do Lineamento Transbrasiliano, sendo sua formação posterior a sua sedimentação, preservando assim os sedimentos pré-existentes. Localiza-se nos estados de Goiás e Tocantins (figura 1.1).

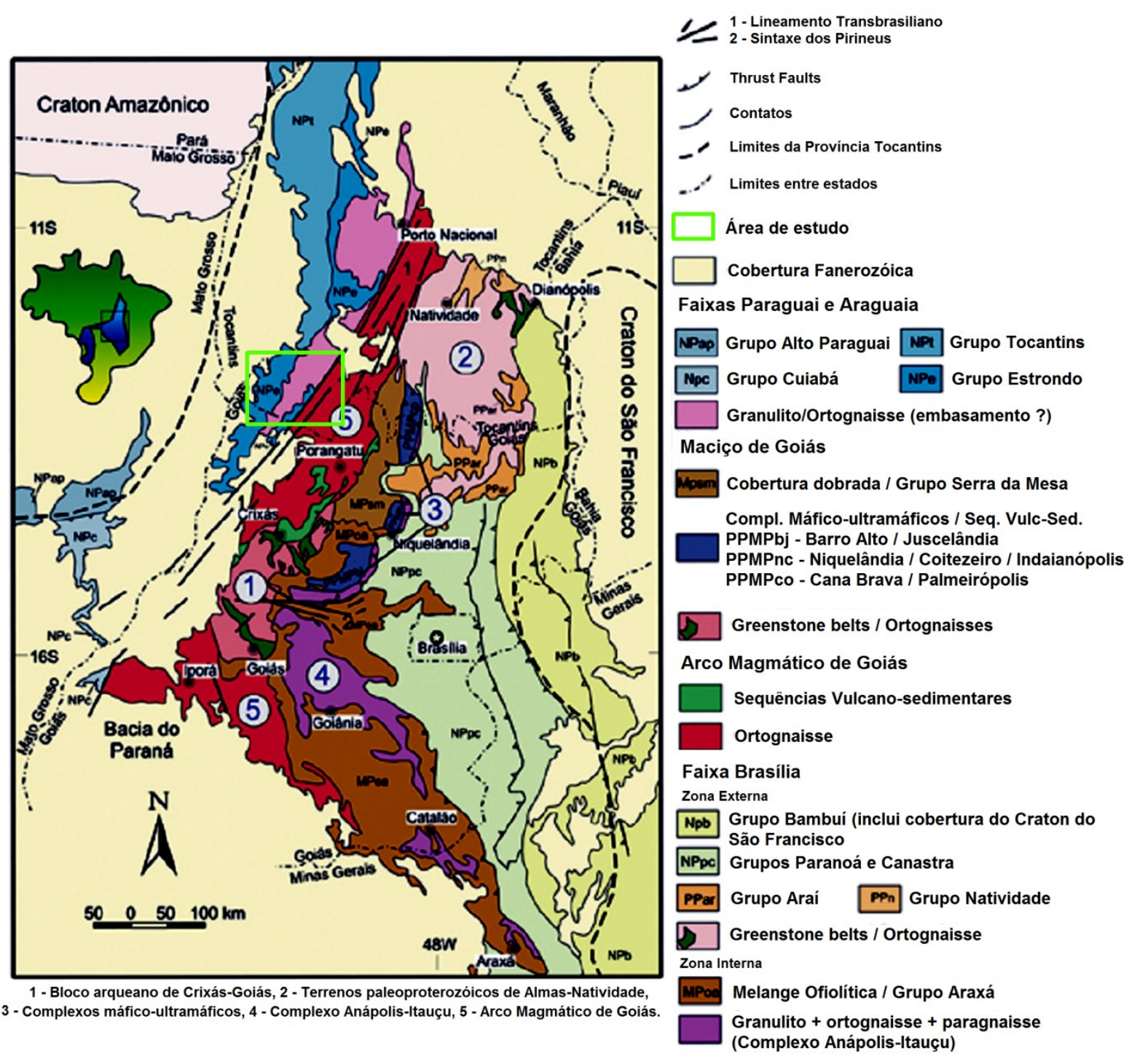

Figura 1.1 - Mapa geológico simplificado da porção centro leste da Província Tocantins e localização da área de estudo (polígono verde) com os domínios tectônicos e principais estruturas associadas, segundo Pimentel et al. 2004. 
O Lineamento Transbrasiliano (LTB) é definido como uma faixa cataclasada de direção NE-SW com pelo menos 2700 km de extensão, que atravessa o Brasil do Ceará ao Mato Grosso do Sul, adentrando o Paraguai e a Argentina, tendo também continuação no continente africano (Schobbenhaus et al. 1975). Na área de estudo, esta faixa tem cerca de $100 \mathrm{~km}$ de largura (Vidotti et al. 2012; Fuck et al. 2013). É uma das principais estruturas da Plataforma Sul-Americana, tendo sua instalação no Neoproterozoico, o lineamento sofreu diversas reativações, sendo que evidências geofísicas mostram que é constituído por uma importante descontinuidade litosférica (Schobbenhaus e Brito Neves 2003). Nas bacias sedimentares do Paraná e Parnaíba, este lineamento e outras estruturas do embasamento exerceram grande influência em sua história deposicional (Curto et al. 2014, Castro et al. 2014). De acordo com Brito Neves e Cordani (1991) o Lineamento Transbrasiliano é uma das principais suturas na gênese do Gondwana, onde foram unidos dois grandes domínios geotectônicos, sendo o primeiro o "Pré-Brasiliano", a noroeste e não afetado pelos eventos do Ciclo Brasiliano, e o outro, a sudeste, denominado "Brasiliano", onde os eventos deformacionais predominantes são relacionados a este ciclo.

O gráben está situado na Província Tocantins, bordejado a oeste pela Formação Xambioá, pertencente a Faixa Araguaia, e a leste pelo Complexo Rio dos Mangues, que está situado no Arco de Mara Rosa, que se encontra na porção norte do Arco Magmático de Goiás. O gráben é preenchido pela Formação Água Bonita, segundo Barbosa et al. (1966) de idade siluriano-devoniano, em que predominam arenitos intercalados com siltitos (Moreira et al. 2008). É delimitada a 
oeste por uma extensa faixa milonítica, onde existem paragnaisses e quartzobiotita-muscovita xisto, e a leste por anfibolitos ortognaisses (Carvalho, 2011).

\subsection{Objetivos}

Este trabalho tem como objetivo principal fornecer o modelo geológico estrutural do Gráben Água Bonita utilizando dados geológicos, geofísicos aéreos e terrestres, além de trazer informações acerca da origem e evolução do gráben, sua correlação com o Lineamento Transbrasiliano e as bacias sedimentares paleozoicas brasileiras.

\subsection{Localização}

A área de estudo localiza-se nos estados de Tocantins e Goiás, e compreende a região entre as latitudes $13,3^{\circ} \mathrm{S}$ e $12,4^{\circ} \mathrm{S}$ e as longitudes $49,1^{\circ} \mathrm{W}$ e $50,2^{\circ} \mathrm{W}$. A cidade de Araguaçu - TO foi escolhida como base de apoio para o trabalho de campo e está localizada a cerca de $500 \mathrm{~km}$ de Brasília. As principais cidades da área de estudos são Araguaçu, São Miguel do Araguaia, Novo Planalto e o povoado de Tataíra (figura 1.2). 


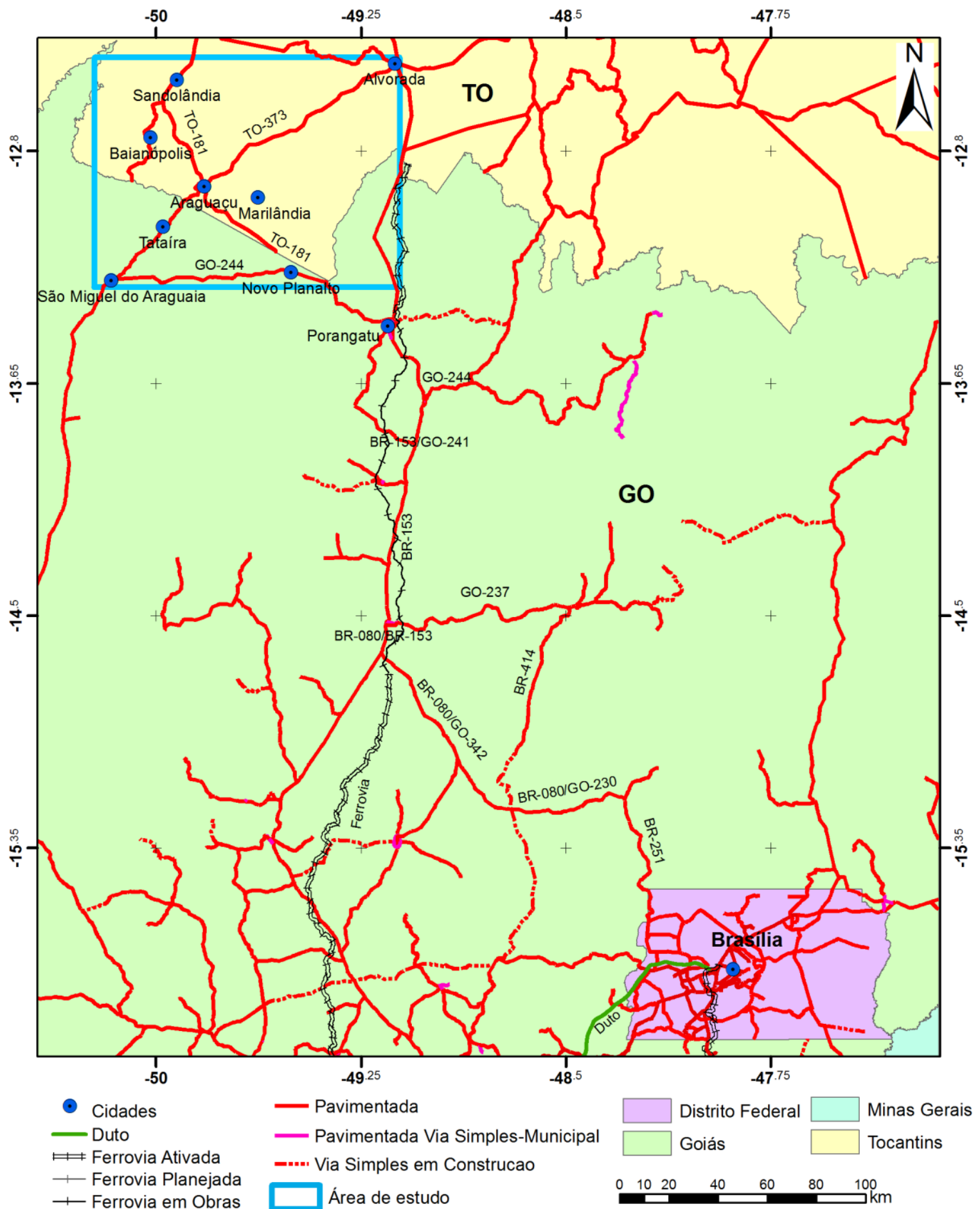

Figura 1.2 - Localização e principais cidades da área de estudo, vias de acesso utilizadas no trajeto de Brasília à área do projeto. 


\subsection{Hipóteses}

O mapa geológico de Goiás com escala de 1:500.000 (Moreira et al. 2008) e a folha SD-22 da Carta Geológica do Brasil ao Milionésimo (Lacerda Filho et al. 2004) foram utilizadas neste trabalho. Além do trabalho desenvolvido por Carvalho 2011, que aborda a região central do GAB.

A figura 1.3 é um recorte da área de estudos que apresenta a integração do mapa geológico do estado de Goiás (Moreira et al 2008) com a folha SD22 da carta geológica do Brasil ao Milionésimo (Lacerda Filho et al. 2004). Por meio desta integração nota-se que não há continuidade dos limites da Formação Água Bonita no estado de Goiás (Moreira et al. 2008) e o estado de Tocantins (Lacerda Filho et al. 2004) na borda oeste do GAB. Carvalho 2011, com base em dados de sensoriamento remoto, aerogeofísica, geologia estrutural e petrologia sugere que os limites da formação são definidos como zonas de cisalhamento, porém este trabalho foi limitado à porção central do $G A B$, desta forma, utiliza-se os limites publicados nos mapas citados, uma vez que compreendem toda a extensão do GAB. O contexto geológico regional será abordado no capítulo 2 e a geologia local no capítulo 3 . 


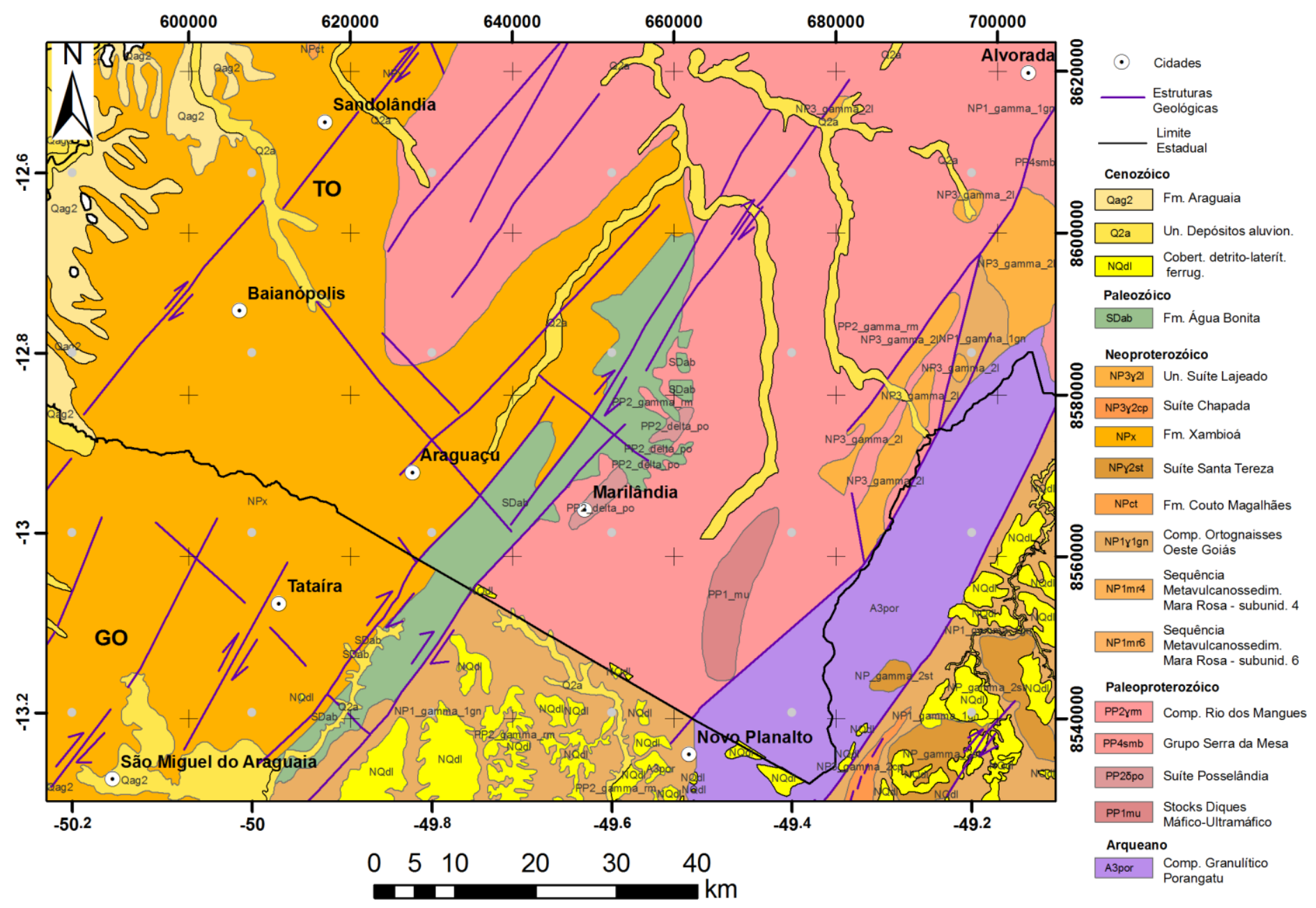

Figura 1.3 - Mapa Geológico com a Geologia de Goiás 1:500.000 (Moreira et al. 2008) sobreposta a SD22, escala 1:1.000.000 (Lacerda Filho et al. 2004). Observa-se que a largura da Formação Água Bonita no estado de Goiás é menor do que no estado do Tocantins.

A Formação Água Bonita (FAB) pode ter o mesmo aporte sedimentar de bacias paleozoicas, devido à posição intermediária em relação às bacias do Paraná, a sudoeste, e do Parnaíba, a nordeste, e do Amazonas, a noroeste (Barbosa et al. 1981). De acordo com Melo et al. (1987), a FAB pode ser correlacionada com o Grupo Serra Grande, Trombetas e a Formação Furnas a partir da similaridade litológica da seção basal , que sugere uma conexão entre estas bacias. De acordo com Milani et al. (2007) durante o Praguiano Eoemsiano ocorreu a primeira grande inundação do ciclo Devoniano. O segundo 
episódio de expansão marinha seria atingido no Mesodevoniano (transição Eifeliano/Givetiano) permitindo a conexão entre as bacias do Paraná e do Parnaíba, evidenciada por megafósseis e palinomorfos. Porém, Andrade e Camarço (1982) sugeriram que os arenitos fluviais da Formação Água Bonita teriam uma menor probabilidade de serem relacionados com os arenitos marinhos transicionais da Bacia do Paraná.

As informações oriundas de mapeamentos regionais, além de observações atuais, indicam que a região em que se insere o Gráben Água Bonita, esteve sujeita a movimentos regionais de caráter dextral (Delgado et al. 2003; Zalán, 1989) por ocasião das atividades tectônicas geradas pelas reativações do Lineamento Transbrasiliano.

Carvalho (2011) realizou mapeamento geológico e observou que a borda NW assim como a SE apresentam indícios de cisalhamento simples. As rochas não apresentam indícios macroscópicos de fósseis e exames micropaleontológicos nos siltitos não identificaram fósseis. Este autor propôs que o Gráben foi gerado a partir de combinação de mecanismo de cisalhamento puro e simples, sendo dominante o simples em um ambiente transtracional restrito. Dados gravimétricos e modelagem 2D apontaram um depocentro próximo ao contato oeste da FAB, com cerca de $4 \mathrm{~km}$ de profundidade.

O mesmo autor menciona ainda que não foi possível relacionar temporalmente a formação do gráben e a deposição das rochas sedimentares, sugerindo duas hipóteses. A primeira considera a subsidência do gráben posterior a sua sedimentação, como foi definido por Baptista e Cartner-Dyer (1966). A 
segunda sugere que primeiro teria acontecido a formação do gráben e depois o preenchimento pelos sedimentos.

Chamani et al. (2011), na Formação Água Bonita, descreve arenitos com falhas sinsedimentares escalonadas, gradando lateralmente para arenitos homogeneizados por liquefação, com restos dispersos da estratificação original. Este autor descreve medidas em paleocorrentes com orientações notavelmente paralelas à direção do Lineamento Transbrasiliano, afirmando que a bacia foi se instalando numa calha alongada condicionada pelo LTB.

Aguiar et al. (2011) realizou um estudo entre as falhas que limitam o GAB e o seu preenchimento sedimentar, caracterizando as principais litofácies e paleocorrentes dos depósitos sedimentares, além da obtenção de dados de paleocampos de esforços atuantes na geração/deformação das estruturas rúpteis. Concluiu que o GAB não representaria unicamente um gráben de preservação de rochas sedimentares nem seria uma bacia sedimentar do tipo rift, por não apresentar distribuição de fácies característica deste tipo de bacia. Sugeriu que a deposição da Formação Água Bonita teria ocorrido paralelamente à atividade tectônica fanerozóica ao longo do Lineamento Transbrasiliano. 


\subsection{Métodos}

Neste trabalho serão utilizados dados geofísicos aéreos (magnetometria) e terrestres (gravimetria), além de dados geológicos para a criação de um modelo geológico do Gráben Água Bonita (figura 1.4).

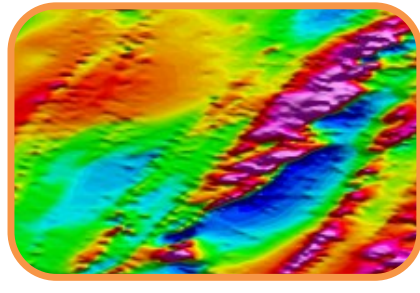

\section{Processamento da magnetometria}

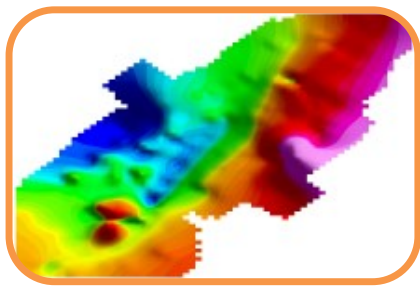

\section{Aquisição e processamento da gravimetria}

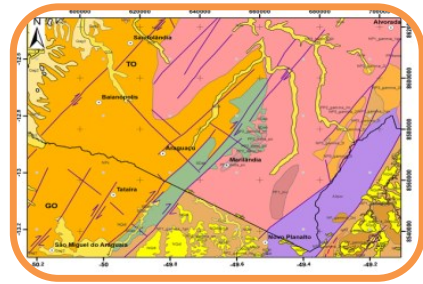

Dados geológicos
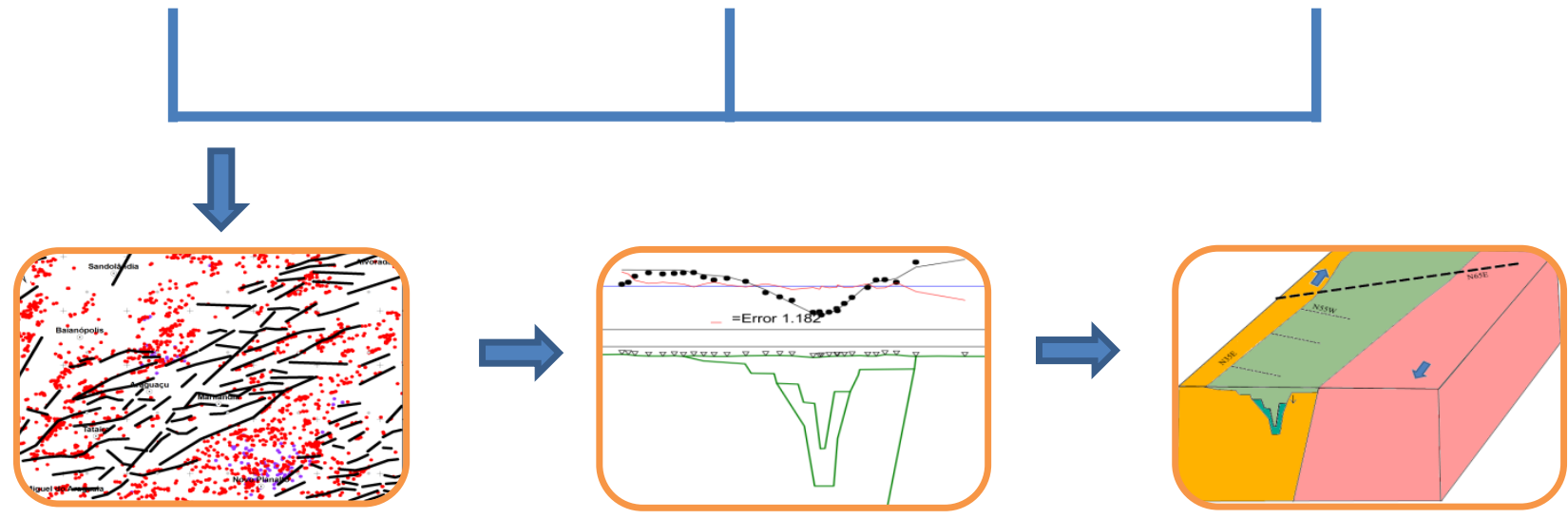

$$
\begin{aligned}
& \text { Análise de } \\
& \text { profundidade e } \\
& \text { Integração dos } \\
& \text { dados }
\end{aligned}
$$

Modelo Geológico

Figura 1.4 - Etapas realizadas neste trabalho. Aquisição de dados de gravimetria, processamento dos dados magnéticos e gravimétricos, pesquisa de dados geológicos, seguidos pela interpretação e integração dos dados, modelagem gravimétrica e por último o modelo geológico do GAB. 


\subsubsection{Dados Aerogeofísicos}

A área de estudos é recoberta pelo levantamento aerogeofísico do Projeto Geofísico Brasil - Canadá (PGBC) executado na década de 70 como parte de um levantamento dos recursos minerais da região Centro-Oeste do Brasil, sendo resultado de um acordo entre o Ministério de Minas e Energia do Brasil (MME) e a Agência Canadense para o Desenvolvimento Internacional (Canadian Internationmal Development Agency - CIDA). O projeto teve início em 1975 com uma produção de $184.139 \mathrm{~km}$ lineares que cobriram a área situada entre $5^{\circ}$ e $16^{\circ}$ sul e $48^{\circ}$ e $51^{\circ}$ oeste com a aquisição de dados de magnetometria e gamaespectrometria (DNPM, 1981). Estes dados estão disponíveis no Instituto de Geociências da UnB para uso em ensino e pesquisa, foram cedidos pelo Serviço Geológico do Brasil, CPRM. Deste projeto serão utilizados somente os dados de magnetometria aérea com altura de vôo de 150 metros, linhas de produção N-S espaçadas $2 \mathrm{~km}$ e linhas de controle na direção E-W de $14 \mathrm{~km}$. Estes dados foram processados e interpretados qualitativa e quantitativamente para gerar 0 conhecimento regional da área de estudo recobrindo toda a extensão do GAB (figura 1.5). 


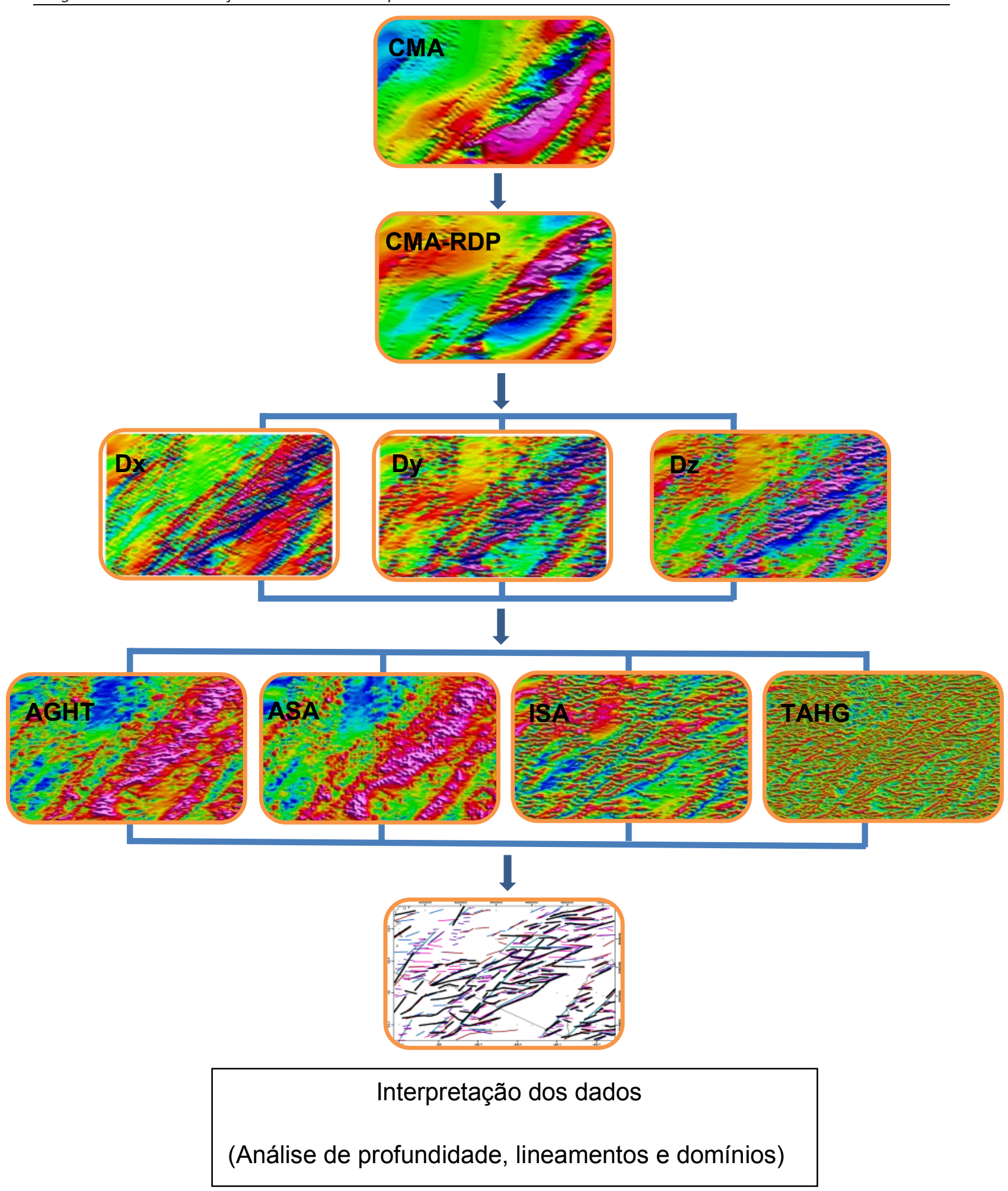

Figura 1.5 - Etapas realizadas utilizando os dados magnéticos. A partir do processamento dos dados foram gerados os produtos: Campo Magnético Anômalo (CMA), Campo Magnético Reduzido ao Polo (CMA-RDP), Derivada horizontal e vertical (dx, dy e dz), Amplitude do Gradiente Horizontal Total (AGHT), Amplitude do Sinal Analítico (ASA), Inclinação do Sinal Analítico (ISA) e Inclinação do Sinal Analítico do Gradiente Horizontal (TAHG). Estes produtos foram interpretados a partir da análise de profundidade, traçados de lineamentos e determinação dos domínios. 


\subsubsection{Gravimetria Terrestre}

Foram utilizadas neste trabalho os dados gravimétricos e geodésicos adquiridos no trabalho final de graduação de Vogado (2013) e Souza (2013), e ainda estações gravimétricas adquiridas por Carvalho em 2011 que foi integrado aos dados adquiridos em 2013. Foi realizado o processamento e redução para gerar as anomalias Ar Livre, Bouguer e Bouguer Completa. Estes dados serão interpretados quantitativamente e qualitativamente com objetivo de analisar a profundidade das fontes das anomalias, além da realização de modelagem 2D, acrescentando informações geológicas (figura 1.6).
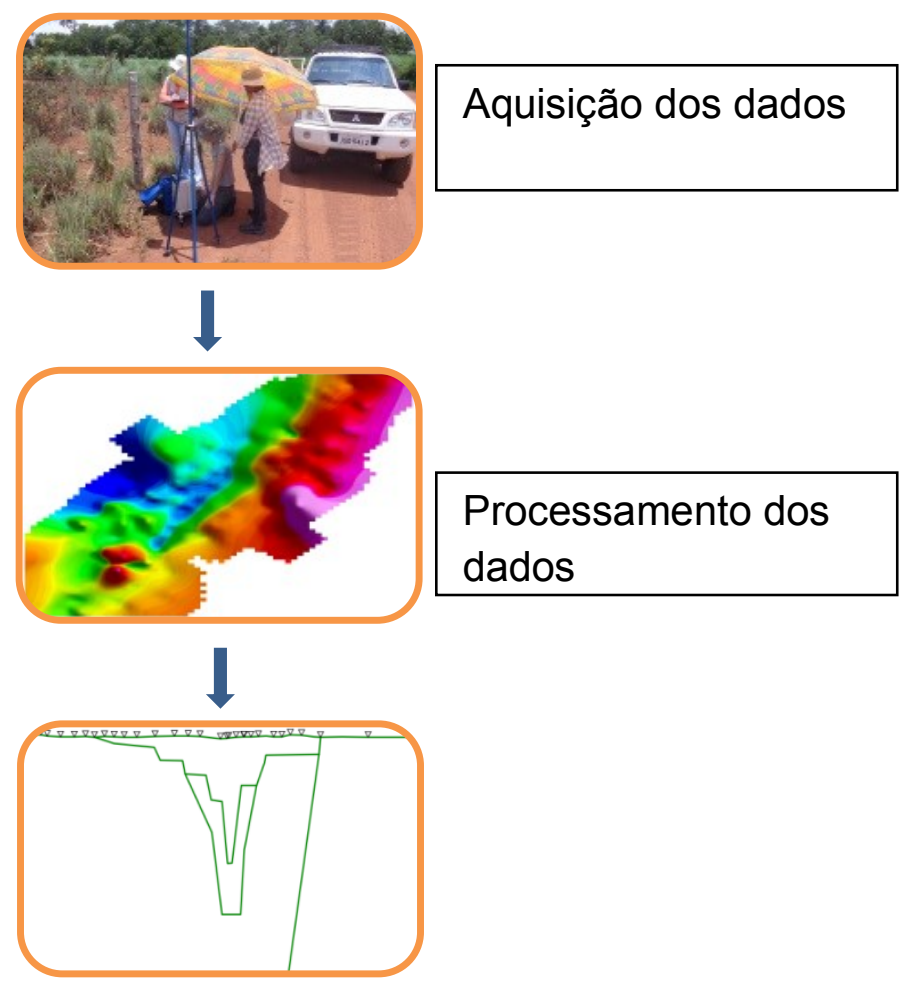

Interpretação dos dados

(Análise de profundidade e modelagem)

Figura 1.6 - Etapas realizadas utilizando os dados gravimétricos. Início com a aquisição dos dados seguido pelo processamento e interpretação. 


\subsubsection{Análise geológica}

Análise de informações geológicas trarão maiores informações sobre a origem e evolução tectônica do GAB. O conhecimento atual sobre o preenchimento sedimentar do gráben baseia-se em informações geológicas de superfície e poucos trabalhos de geofísica. O trabalho de Carvalho (2011) restringiu-se a região central do GAB. Neste trabalho, a análise de afloramentos permitirá identificar associações de fácies sedimentares que ocorrem na superfície podendo trazer mais informações sobre a Formação Água Bonita.

Para a análise geológica foi feita uma pesquisa bibliográfica, compilação de dados existentes, análise de imagens de satélite, dos mapas geológicos e relevo sombreado, sendo estes utilizados para interpretação e integração dos dados. As imagens de satélite utilizadas são do satélite norte-americano Landsat-8, que foi lançado em 2013 pertencendo ao programa Landsat (Land Remoting Sensing Satellite), iniciado na década de 70 . As imagens foram retiradas do site do United States Geological Survey (USGS). Para obter as informações sobre o relevo sombreado e altimetria foram utilizados dados proveniente do projeto Shuttle Radar Topographic Mission (SRTM). 


\section{Contexto Geológico}

Para se atingir o entendimento da geologia da área de estudo, abordou-se o contexto geológico regional, primeiramente, focando a Província Tocantins e as faixas que a compõem, Brasília, Paraguai e Araguaia, além do Lineamento Transbrasiliano, o qual engloba o Gráben Água Bonita a partir de sua reativação, de acordo Baptista e Cartner-Dyer (1966).

\subsection{Província Tocantins}

Bizzi et al. (2003) apresentam algumas modificações no limites das províncias conforme definidas por Almeida $(1977,1981)$. Províncias são regiões que apresentam feições estratigráficas, tectônicas, magmáticas, metamórficas e geomórficas próprias e diferentes das apresentadas pelas unidades confinantes tendo como limites escolhidos áreas de caráter geologicamente bem definido, representado por falhas e zonas de falhas, frontes metamórficas, zonas de antepaís, limites erosionais de áreas sedimentares; ou mal definido tais como limites transicionais ou arbitrários assumidos por falta de conhecimento adequado (Bizzi et al. 2003). De acordo estes autores divide-se o Brasil em 15 províncias estruturais (figura 2.1). 


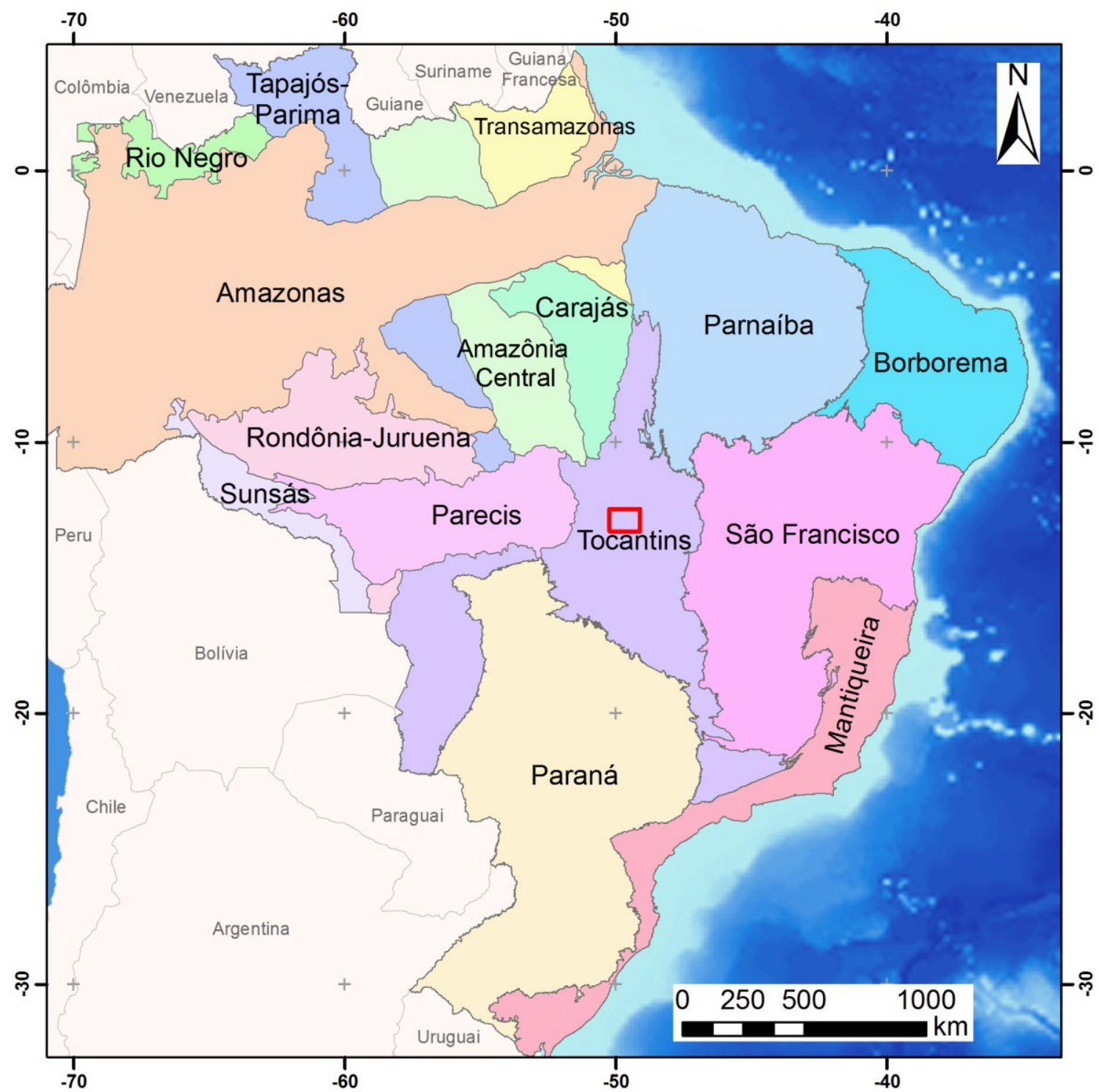

Figura 2.1 - Províncias do Brasil (Bizzi et al. 2003), observar a Província Tocantins onde se localiza a área de estudo (em vermelho).

A Província Tocantins (figura 2.1) é um sistema orogênico neoproterozoico situado entre os crátons Amazônico, São Francisco e Paranapanema sendo caracterizado por cinturões de dobramentos, com núcleos e fragmentos préBrasilianos, denominados de faixas Brasília, Araguaia e Paraguai, tendo sido resultantes da convergência dos crátons ao seu redor (Fuck et al. 2014). A 
província tem como embasamento terrenos arqueanos e paleoproterozoicos, que antes faziam parte do Maciço Mediano de Goiás (Almeida, 1967).

A Província de Tocantins é composta principalmente pelas faixas Araguaia, Paraguai e Brasília, sendo estes desenvolvidos durante as orogêneses do Pan/Africano Brasiliano. Sua evolução está relacionada aos mecanismos relacionados à tectônica de placas, sendo similar ao das modernas faixas orogênicas. Sua evolução foi marcada inicialmente por sedimentação de sequencias terrígenas e carbonáticas em ambientes plataformais; seguido da formação de crosta oceânica, e depois tendo a geração de arcos de ilhas e magmatismo associado no estágio orogênico acrescionário (Pimentel e Fuck, 1994; Fuck et al. 1993). Seu arcabouço estrutural é marcado por sistemas de cavalgamentos regionais, na qual há vergência para as zonas cratônicas e sistemas transcorrentes. A orogênese brasiliana causou uma deformação maior nas zonas internas dessas faixas, diminuindo em direção as zonas cratônicas. (Delgado et al. 2003).

\subsubsection{Faixa Araguaia}

Cinturão que ocorre desde o extremo norte do estado de Tocantins até a região de São Miguel do Araguaia, onde é recoberto pelos sedimentos da Bacia do Bananal. Possui uma direção geral N-S, medindo cerca de 1000 km de extensão com aproximadamente $150 \mathrm{~km}$ de largura (figura 2.1). Esta unidade limita o GAB à oeste.

Esta faixa é constituída principalmente por rochas metassedimentares pelítico-psamíticas, atribuídas ao Grupo Baixo Araguaia, a qual engloba a 
Formação Morro do Campo e Xambioá que compõem a zona interna. A zona externa é formada pelas formações Pequizeiro e Couto Magalhães com unidades metassedimentares com variação no grau metamórfico, de xisto-verde, a oeste, a anfibolito, porção leste. (Moraes Rego, 1933; Barbosa et al. 1966; Hasui et al. 1975, 1977; Sousa e Moreton, 1995; Frasca e Araújo, 2001; Alvarenga et al. 2000; Gorayeb et al. 2001).

Diferentes modelos foram propostos para a evolução da Faixa Araguaia desde a década de 70 (Kotschoubey et al. 2005) e de acordo com Almeida (1974) e Herz et al. (1989) corresponde a uma geosutura ensialica reativada. Uma fase distensiva formou um hemigraben assimétrico preenchido por uma sequência marinha transgressiva, seguido por uma inversão de movimentação de blocos, intensa deformação, aumento de temperatura e aumento de metamorfismo para leste, sendo que durante esta evolução, uma transferência de massa E/W e SE/NW que causou dobramento, cisalhamentos de baixo ângulo, cavalgamento e formação de nappes que transformaram a bacia num sistema imbricado (Hasui e Costa, 1990, Alvarenga et al. 2000, Herz et al. 1989,).

De acordo com Herz et al. (1989) esta faixa foi afetada fortemente pela Orogenia Brasiliana a partir da reativação de falhas transcorrentes do embasamento, intrusão de pequenos corpos graníticos, dobramentos na sequencia supracrustal e desenvolvimento de domos associados a falhas normais com a área abaixo do Grupo Estrondo sendo soerguida enquanto ocorria a deposição dos conglomerados do Rio Barreiras da área central. 


\subsubsection{Faixa Brasília}

A Faixa Brasília (figura 2.1) apresenta uma extensão de aproximadamente $1.000 \mathrm{~km}$ na direção geral N-S, estendendo-se desde o sul do estado de Tocantins, cruzando Goiás e chegando até a porção oeste de Minas Gerais, onde se interfere com os orógenos da Província Mantiqueira na região de Guaxupé. $\mathrm{Na}$ Inflexão dos Pirineus há a divisão da Faixa Brasília em Setentrional e Meridional (Schobbenhaus e Brito Neves, 2003).

De acordo com Pimentel et al (2004), a Faixa Brasília compreende a i) terrenos granito-greenstone arqueanos da região de Crixás-Goiás, ii) terrenos granito-gnáissicos e sequências vulcano-sedimentares paleoproterozóicas de Almas-Natividade-Cavalcante, iii) grandes complexos máficos-ultramáficos, iv) Complexo Granulítico de Anápolis-Itauçu e v) terrenos ortognáissicos e vulcanosedimentares neoproterozoicos juvenis (Arco Magmático de Goiás). Podem ser identificados dois segmentos distintos, um interno e outro externo, que se diferenciaram pela intensidade deformacional e pela polaridade metamórfica crescente em direção à zona da faixa.

O Arco Magmático de Goiás encontra-se da região oeste de Goiás e centrosul do estado do Tocantins, sendo separado em dois segmentos (norte e sul) e estende-se ao longo de uma faixa de aproximadamente $300 \mathrm{~km}$ de largura. Foi dividido em dois subdomínios (Arenopólis e Mara Rosa) pelos terrenos arqueanos granito greenstone de Crixás-Goiás, na qual foram interpretados como bloco continental alóctone (Melo, 2006). É considerado um sistema formador de arco de ilhas sendo que o Arco Mara Rosa representa o segmento norte enquanto o 
segmento sul é representado por uma série de arcos entre a cidade Bom Jardim de Goiás a Pontalina, no sul de Goiás. Compõe a borda leste do gráben Água Bonita com o Complexo Rio dos Mangues e se localiza no Arco de Mara Rosa.

\subsection{Ciclo Brasiliano e o Lineamento Transbrasiliano}

As províncias estruturais brasilianas resultantes do ciclo neoproterozoico (figura 2.2), na sua fase final de evolução deixaram importantes características ao continente como um todo. Por todo o fanerozoico, importantes fenômenos de herança tectônica estão vinculados ás estruturas e litologias geradas no Brasiliano em termos de alocação de coberturas, magmatismo, sismicidade entre outros (Schobbenhaus e Brito Neves, 2003). Cerca de 98\% da crosta continental da América do Sul estava composta ao final do brasiliano (Cordani e Sato, 1999).

De acordo Schobbenhaus e Brito Neves (2003), províncias brasilianas exibem uma série de características comuns: posição intercratônica, tipos de faixas móveis, granitogênese, importância dos shear belts de fase extrusional, entre outros, porém possuem suas características próprias. Província da Mantiqueira, Amazonas, São Francisco e Tocantins possuem um mosaico complexo de pequenos núcleos antigos pré-Brasilianos com faixas móveis sistematicamente ao redor. 


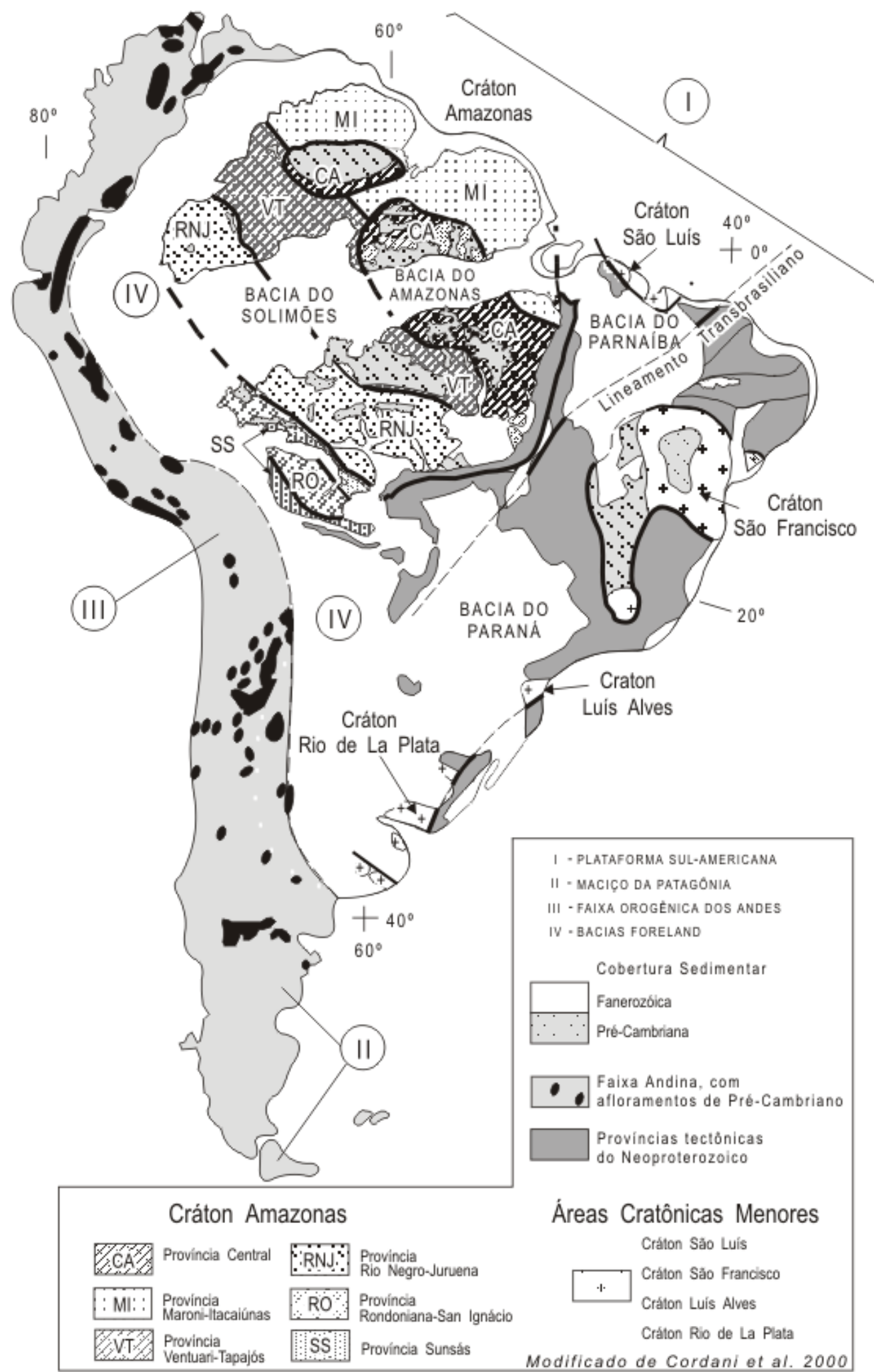

Figura 2.2 - Províncias Tectônicas da América do Sul (Cordani et al. 2000). Observar o Lineamento Transbrasiliano, de sul para norte, cortando a Bacia do Paraná, a área de estudo e a Bacia do Parnaíba. 
De acordo Schobbenhaus e Brito Neves (2003), no Brasiliano houve um grande predomínio de deformação, retrabalhamento, modelamento e processos afins, sobre acresção crustal, sendo que estes processos que deram praticamente a última forma ao substrato Pré-Cambriano da Plataforma. Há muitos elementos que enfatizam a potencialidade destes efeitos de ativação e regeneração, que atingiram diversos contextos pré-Brasilianos, zonas cratônicas (bordas e eventualmente zonas interiores, corredores de deformação), faixas móveis paleoproterozoicas e mesoproterozoicas e coberturas. Ainda de acordo com estes autores, o retrabalhamento variou de pouco intenso a completamente reestruturado, com a formação de intrafossas e de bacias pull apart (riftes transtracionais) que seguem shear belts ou lineamentos no interior das faixas móveis brasilianas.

\subsubsection{Lineamento Transbrasiliano}

O Lineamento Transbrasiliano (LTB) é definido como sendo uma faixa cataclasada de direção NE-SW com cerca de 2.700 km de extensão no Brasil, que atravessa o Brasil do Ceará ao Mato Grosso do Sul, adentrando o Paraguai e a Argentina, tendo também sua continuação no continente africano (Schobbenhaus et al. 1975). É uma das principais estruturas da Plataforma Sul-Americana, tendo sua instalação, no Neoproterozoico, o lineamento sofreu diversas reativações, sendo que evidências geofísicas mostram que este está constituído por uma importante descontinuidade litosférica. O Lineamento Transbrasiliano e outras estruturas do embasamento exerceram grande influência na instalação e história deposicional das bacias sedimentares (Vidotti et al. 2012, Curto et al. 2014). 
Zonas de fraqueza litosférica importantes, como o Lineamento Transbrasiliano, tendem a concentrar esforços remotos gerados na borda das placas, e dessa forma ser foco de atividade tectônica e sismicidade intraplaca (Fuck et al. 2013, Chamani, 2011).

De acordo com Brito Neves e Fuck (2014) o Lineamento Transbrasiliano é uma das principais suturas na gênese do Gondwana, onde foram unidos dois grandes domínios geotectônicos, sendo o primeiro o "Pré-Brasiliano", a noroeste e não afetado pelos eventos do Ciclo Brasiliano, e o outro, a sudeste, denominado "Brasiliano", onde os eventos deformacionais predominantes são relacionados a este ciclo. O "Pré-Brasiliano" no Neoproterozoico teria atuado como uma grande placa continental, enquanto o "Brasiliano" seria correspondente a uma série de fragmentos menores de microcontinentes, placas continentais, arcos magmáticos e terrenos alóctones (Brito Neves e Fuck, 2014).

\subsection{Bacias Interiores}

De acordo com Pedreira et al. (2003) bacias interiores do paleozoico e meso-cenozoico podem ser classificadas de acordo com o sistema de classificação de bacias de Kingston et al. (1983). Essas bacias estão representadas na figura 2.3 classificadas de quatro formas, como: a) Intracratônica, sua evolução consiste em diversos processos de formação, os quais incluem a extensão continental, subsidência termal sobre grande área e ajuste isostático superior (Klein, 1995); b) Strike-Slip, que se formam comumente a partir da alternância de transcorrência e falhamentos normais (Nilsen e Sylvester, 1995) e formando bacias de diversos tipos, incluindo as pull apart (Kearey e Vine, 
1996) e as bacias formadas inicialmente como bacias rifte desenvolvidas sob extensão regional, convertidas por strike-slip por transcorrência posterior (Nilsen e Sylvester, 1995); c) Bacias de Antepaís Retroarco que formam-se ao longo dos flancos de cinturões orogênicos de margem continental, no interior do continente podendo possuir sedimentação de depósitos não marinhos e marinhos rasos e muitas vezes, são relacionadas à tectônica thin-skinned, ou seja, sem envolvimento do embasamento; d) Aulacógenos e riftes: Quando ocorre a partir da fragmentação de um continente onde há a concatenação de uma série de junções triplas tipo rifte-rifte-rifte, onde o ramo não utilizado na ruptura fica preservado.

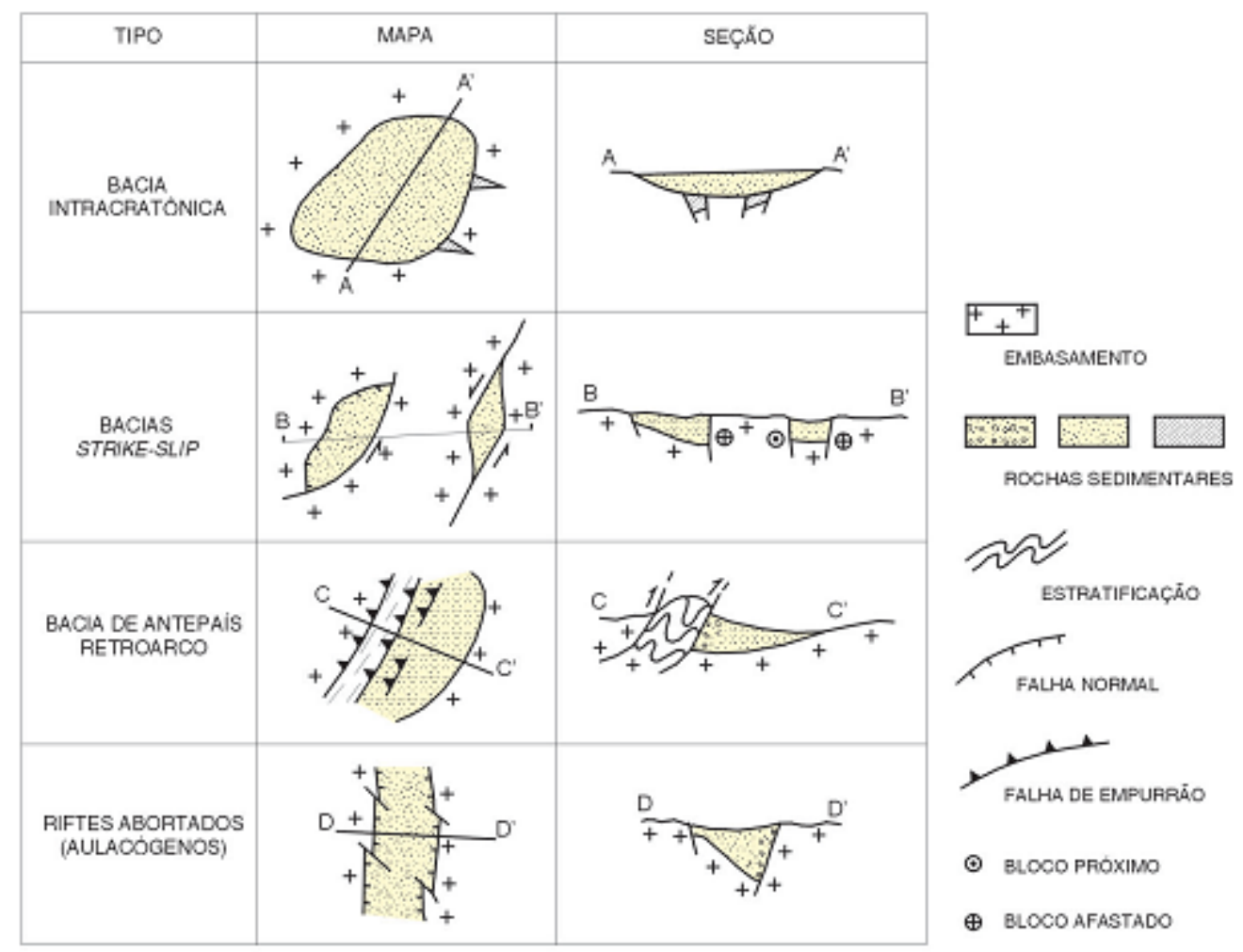

Figura 2.3 - Alguns tipos de bacias interiores do Brasil (segundo Pedreira et al. 2003): bacias intracratônicas, strike-slip, de antepaís de retroarco e de riftes abortados (aulacógenos). 


\section{Geologia do Gráben Água Bonita e do Embasamento}

O Graben Água Bonita está localizado nos estados de Tocantins e Goiás, próximo ao município de Araguaçu (TO), a oeste, e Novo Planalto (GO), a leste. Estende-se na direção $\mathrm{N} 35^{\circ}-40^{\circ} \mathrm{E}$ ocupando uma área descontínua de $550 \mathrm{~km}{ }^{2}$ (Lacerda Filho et al. 2004)

O Lineamento Transbrasiliano nessa região separa a Faixa Araguaia, a oeste, e o Arco Magmático de Goiás, a leste. A geologia local é composta pela Formação Xambioá, constituída por xistos aluminosos, grafita xistos e paragnaisses que foram consideradas neoproterozoicas; pelo Arco Magmático de Goiás, representado pelo Complexo Rio dos Mangues, composto por granitos e ortognaisses (Moreira et al. 2008) além da Suíte Posselândia, de formato alongado paralela ao gráben, composta principalmente por dioritos e gabros (Lacerda Filho et al. 2004); e pela Formação Água Bonita, estando inserida em uma faixa estreita de direção NE-SW, composta por arenitos intercalados com siltitos e conglomerados (Carvalho, 2011; Moreira et al. 2008). 


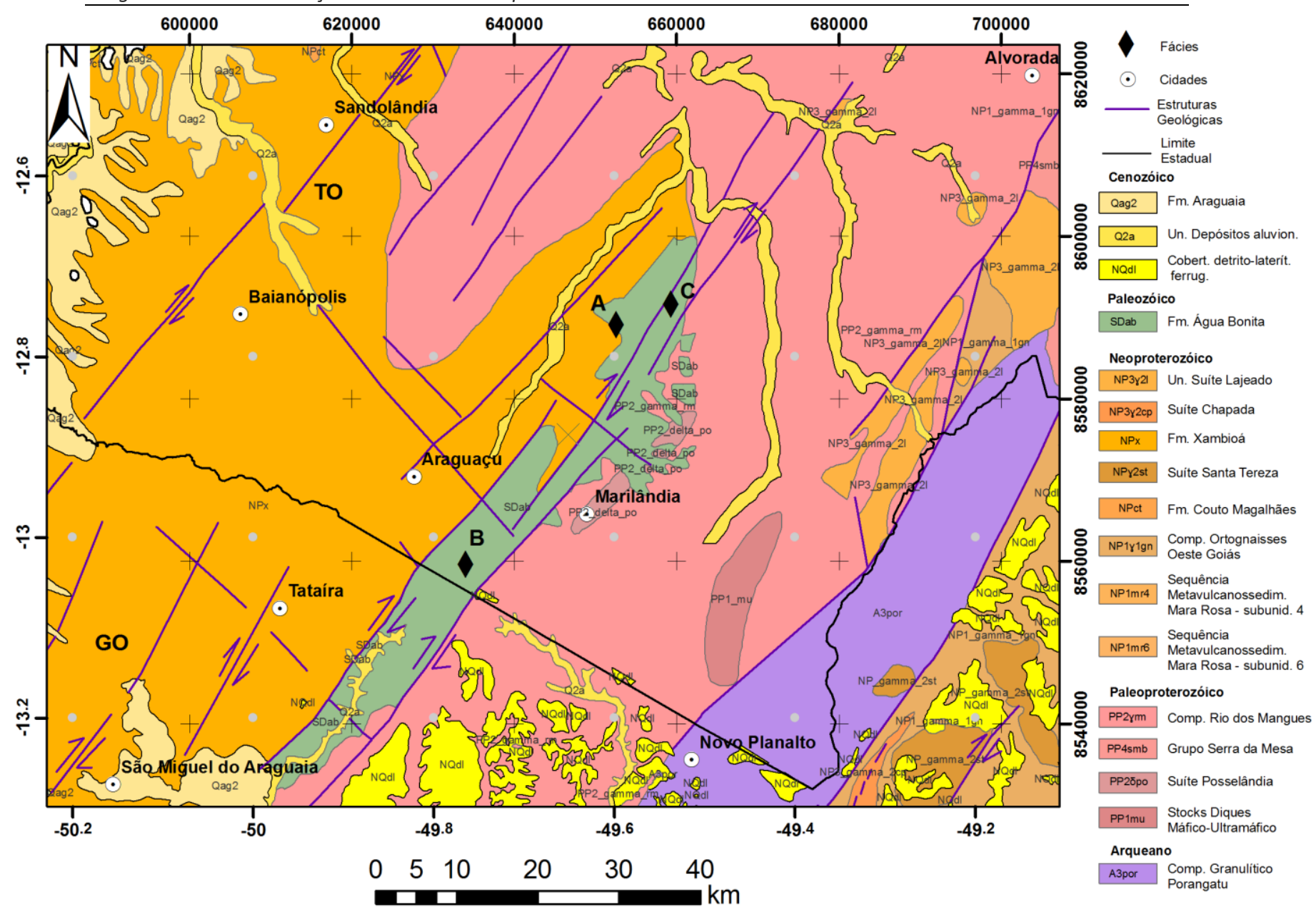

Figura 3.1 - Mapa geológico (Lacerda Filho et al. 2004) da área de estudos e embasamento adjacente. Localização dos pontos descritos neste capítulo, A, B e C, figuras $3.6,3.8$ e 3.9, respectivamente.

\subsection{Complexo Rio dos Mangues}

O Complexo Rio dos Mangues de idade paleoproterozoica é constituído por rochas metassedimentares, metaígneas félsicas e máficas, que foram metamorfizadas nas fácies anfibolito médio a alto resultando em gnaisses tonalíticos, granada quartzitos, gnaisses cálcio-silicáticos, quartzitos, anfibolitos e micaxistos subordinados (Costa et al. 1983). Encaixados em extensas rochas deste complexo, de 2,1 e 2,0 Ga (Moura e Souza, 1996), ocorrem suítes alcalinas, Monte Santo e Serra da Estrela, que segundo Alvarenga et al. (2000), parece 
estar associado ao rifteamento crustal, durante a formação da bacia Araguaia, que recebeu os sedimentos do Supergrupo Baixo Araguaia.

\subsection{Formação Xambioá}

A Formação Xambioá junto à Formação Morro do Campo compõem o Grupo Estrondo que forma a sequência basal do Cinturão Araguaia. A Formação Xambioá é sobreposta de forma concordante à Formação Rio Morro do Campo, sendo constituída de micaxistos variados, grafita xistos, xistos gnaissóides, xistos feldspáticos, e granatíferos, além de mármores e corpos de anfibolito, metamáficas-ultramáficas. Esta formação é a unidade que atinge relativamente um maior grau metamórfico e possui uma ampla distribuição ao longo de todo o Cinturão Araguaia (Alves, 2006).

\subsection{Formação Água Bonita}

O conhecimento atual sobre o preenchimento sedimentar do gráben baseiase em informações geológicas de superfície e de geofísica em subsuperfície, tendo em vista que não há perfuração de poços nessa bacia.

Carvalho (2011) descreveu o afloramento na Fazenda Água Bonita como ocupando aproximadamente $500 \mathrm{~m}^{2}$, tendo aproximadamente 3,8 metros de altura, cujas rochas apresentam uma tonalidade creme na rocha fresca e avermelhado a marrom na intemperizada tendo como a principal estrutura sedimentar primária a estratificação plano paralela centimétrica que mergulha aproximadamente $8^{\circ}$ para $305-330(\mathrm{NW})$ com granulometria variando de areia muito grossa a fina e silte em níveis milimétricos e alguns grãos com 
granulometria muito grossa. Observou gradação inversa, granocrescente ascendente, tendo na base areia fina e no topo areia grossa cuja composição é um quartzo arenito. Este mesmo autor sugeriu que a deposição ocorreu em ambiente fluvial.

A análise de afloramentos (A, B e C; figura 3.1) permitiu identificar pelo menos três associações de fácies sedimentares que ocorrem na superfície, um, na Fazenda Água Bonita e dois na rodovia que liga Araguaçu à Alvorada. Tais associações de fácies são apresentadas a seguir.

Associação de Fácies $\mathbf{A}$ : constituída por conglomerados em matriz arenosa avermelhada de aproximadamente $30 \mathrm{~cm}$ de espessura, contendo seixos e blocos de quartzito e quartzo, mica-xistos (figura 3.2 e 3.3 ). Sobrepondo os conglomerados há arenitos avermelhados, de seleção moderada, com estratificações cruzadas de base tangencial de grande porte, os quais gradam para cima para cruzadas tabulares em estratos de 30 a $40 \mathrm{~cm}$ de espessura. As estratificações indicam paleocorrentes para a direção oeste-sudoeste. Finalizando o perfil vertical, ocorrem no topo arenitos finos a muito finos também avermelhados e seleção boa a regular, com estratificações onduladas de poucos centímetros de comprimento. Toda a seção sedimentar repousa sobre o embasamento, representado pela Formação Xambioá, da Faixa Araguaia.

Interpretação: Esta associação de facies indica a possibilidade de ter havido o retrabalhamento de depósitos aluviais conglomeráticos, por ação de correntes, possivelmente de maré, em uma situação de mar transgressivo. Os arenitos de boa seleção laminados, sobrepostos representariam barras de plataforma cuja 
parte offshore estaria voltada para sul-sudoeste conforme indicação de paleocorrentes. Acima, os arenitos registram a ocorrência de ação de ondas, possivelmente já em uma plataforma intermediária, onde a pequena dimensão das marcas onduladas indicaria um menor alcance das ondas do que na parte mais proximal na zona de arrebentação (de ondas).

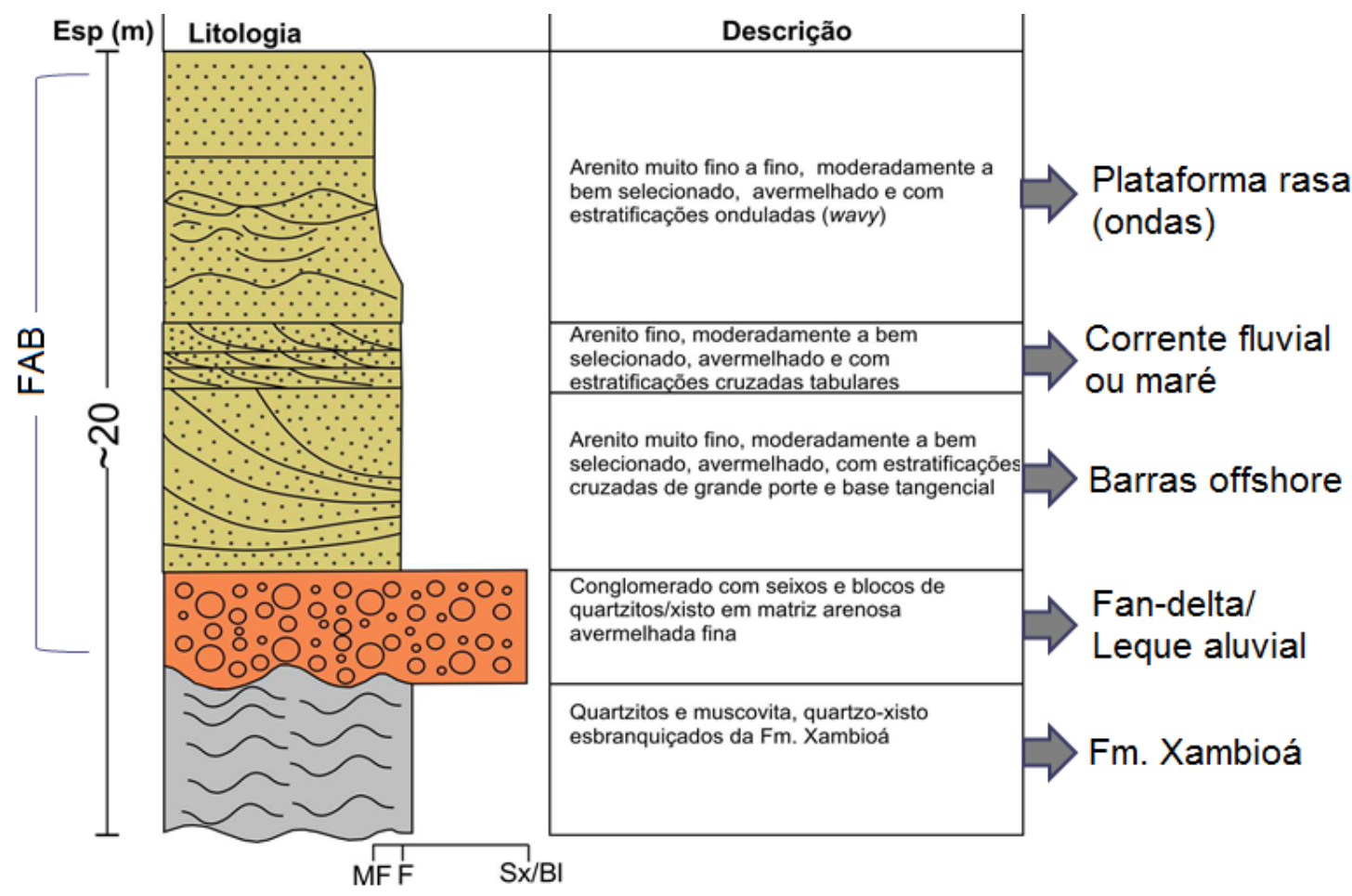

Figura 3.2 - Perfil litológico vertical, onde se observa a Formação Água Bonita (Siluriano-Devoniano ?) sobrepondo a Formação Xambioá (embasamento neoproterozoico). Observar conglomerados basais recobrindo o embasamento e sendo recoberto pelos arenitos possivelmente de barras de plataforma rasa, inicialmente com influência de marés e posteriormente com ações de ondas. 


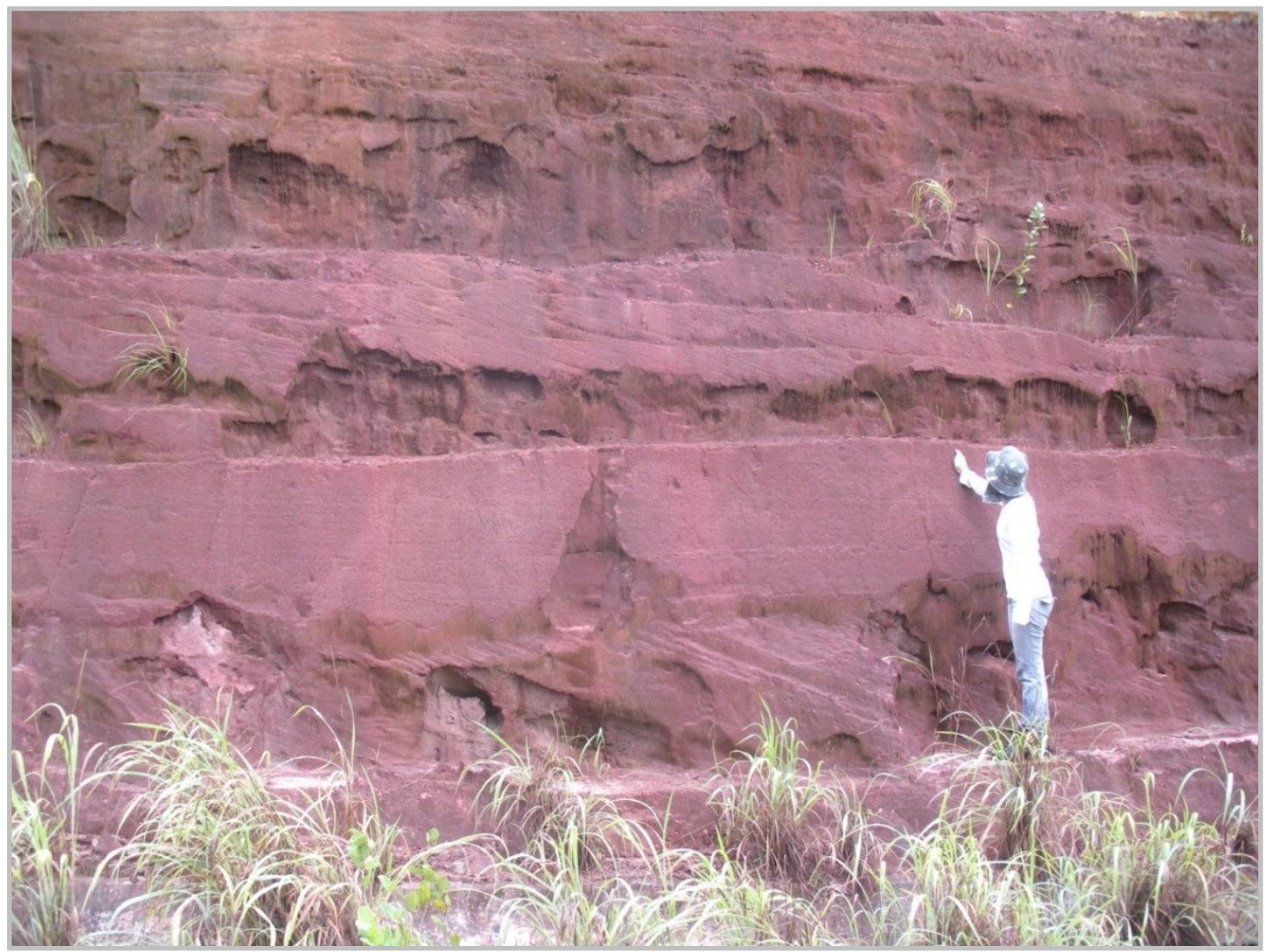

Figura 3.3 - Afloramento da associação de fácies A. Cruzadas de grande porte na altura da pessoa, cruzadas tabulares de menor espessura acima. Este pacote sobrepõe conglomerados, sob os pés da pessoa, que por sua vez assenta-se sobre o embasamento representado pela Fm. Xambioá (não mostrado na foto).

Associação de Fácies B: constituída por estratos com ciclos de acamamento gradacional normal de arenitos finos a médios, coloração creme, interrompidos por fácies de menor energia do ambiente, representado por siltitos (figura 3.4 e 3.5); segue-se uma camada de arenito com cruzada tabular, possivelmente depositada por correntes litorâneas (paleocorrentes para NE); ainda nesta fase, depositam ciclos de arenitos grossos a muito grossos mal selecionados com acamamento gradacional inverso, representando barras progradantes de plataforma. Finalmente, no topo ocorrem arenitos médios mal selecionados com estratificações onduladas truncadas muito suaves. 
Interpretação: O predomínio de estratificações onduladas, truncamentos suaves e rara estratificação cruzada tabular sugerem que a deposição de tais facies processou-se em plataforma rasa com ação de ondas de tempestades (q.v. Plint, 2010) que retrabalharam sedimentos previamente depositados, provavelmente por deltas de granulação grossa ou leques aluviais (q.v. Collela e Prior, 1990).

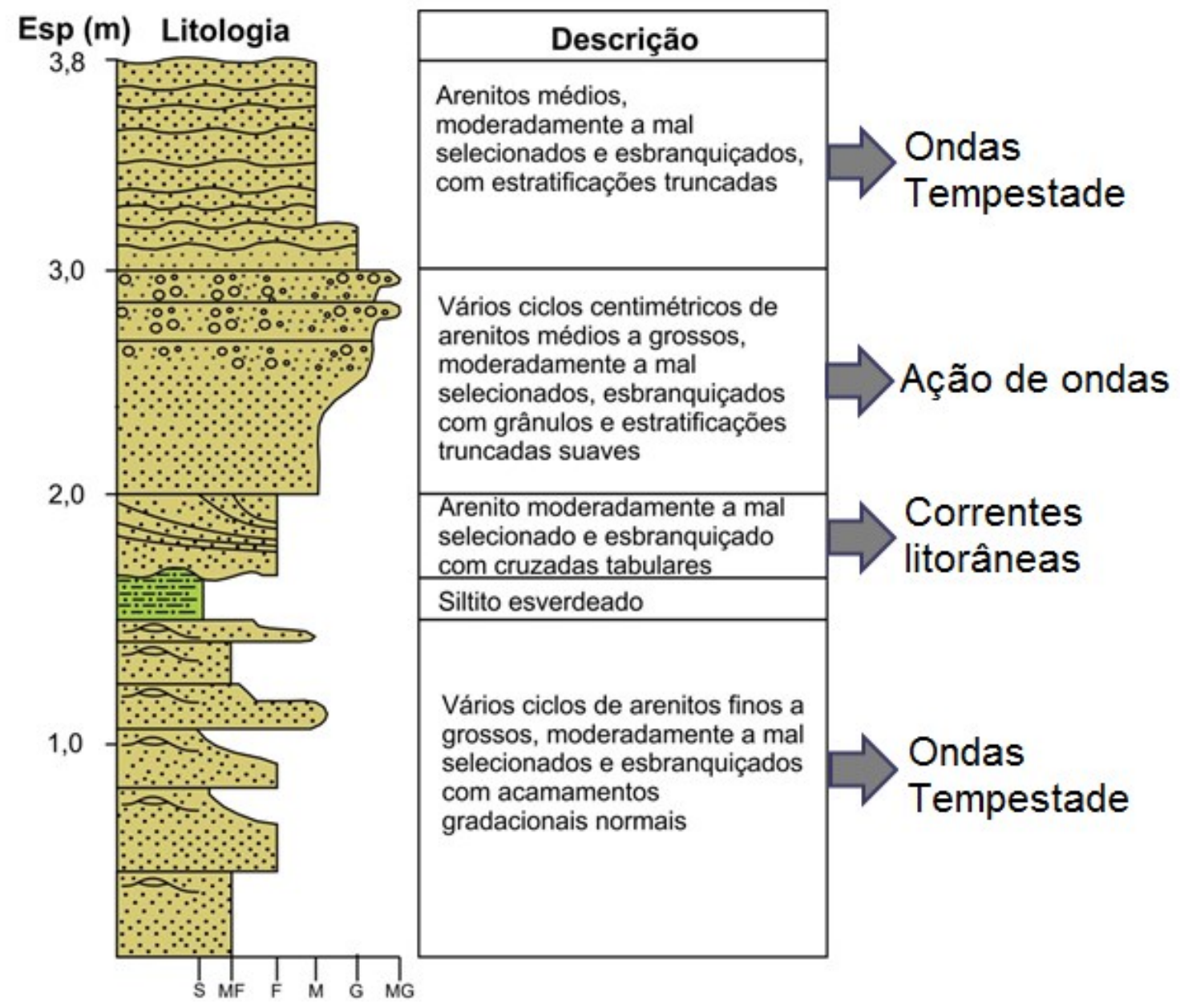

Figura 3.4 - Perfil litológico vertical da associação de facies B, com ciclos de acamamento gradacional na base e truncamentos de baixo ângulo no topo, interrompido por siltito, representado por fácies de menor energia do ambiente (ação de ondas); segue-se uma camada de arenito com cruzada tabular, possivelmente depositada por correntes litorâneas (paleocorrentes para NE); ainda nesta fase, depositam ciclos de arenitos grossos a muito grossos mal selecionados com acamamento gradacional inverso, representando barras progradantes de plataforma. Finalmente, no topo são depositadas arenitos médios mal selecionados, sob ação de ondas, ao retrabalhar sedimentos previamente depositados, provavelmente por deltas de granulação grossa ou leques aluviais. 


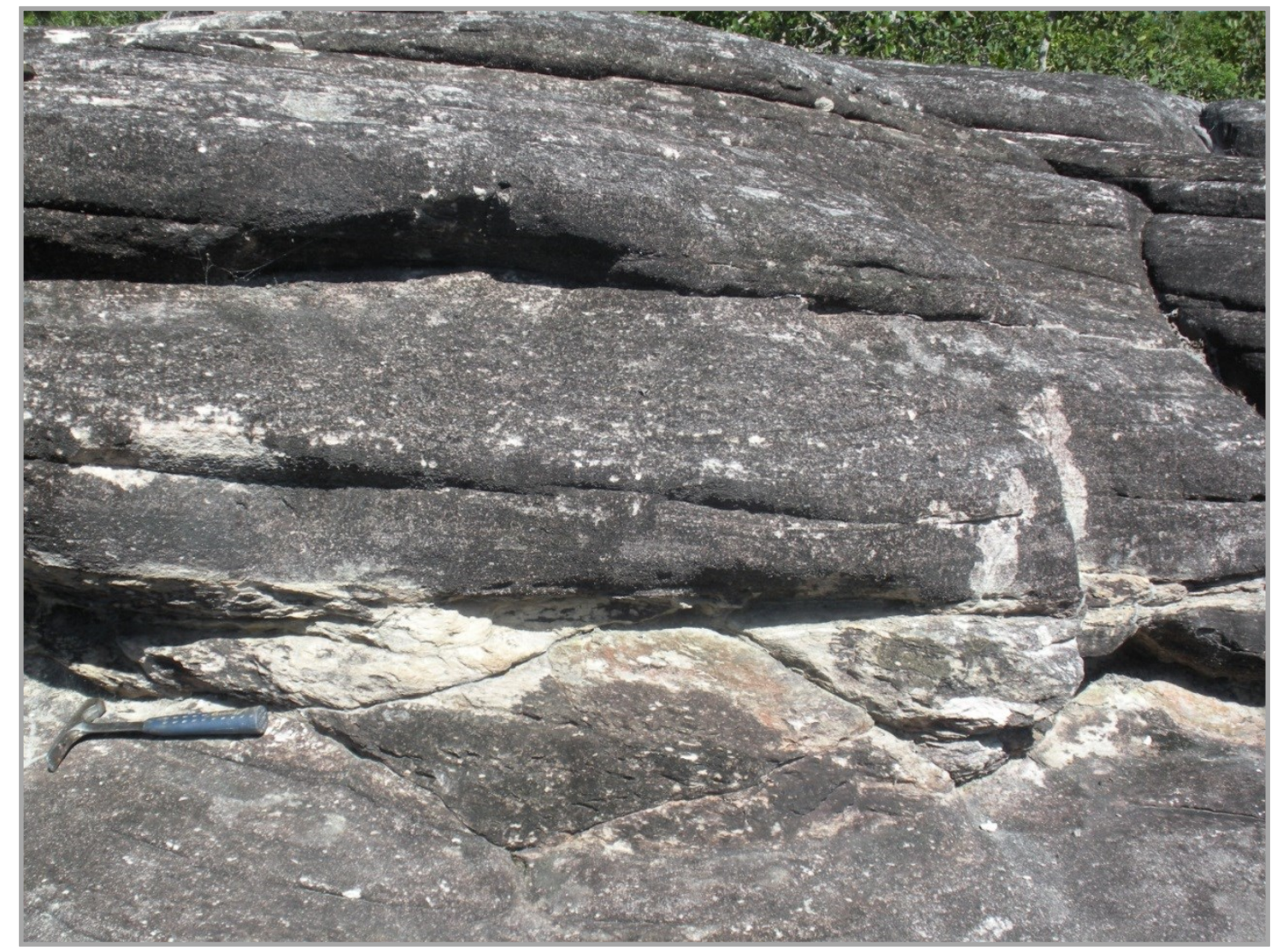

Figura 3.5 - Arenitos muito finos a médios, com estartificações onduladas truncadas de baixo ângulo (terço superior da foto) devido a ação de ondas de tempestades que retrabalharam depósitos arenosos de leques aluviais ou deltas de granulação grossa. Esta facies sobrepõe arenitos finos com estratificação cruzada tabular e base erosional (martelo), possivelmente depositados por correntes litorâneas dirigidas para NE.

Associação de Fácies C: É constituída por ciclos de arenitos esbranquiçados finos a médios, com grânulos e seixos de poucos centímetros de diâmetro em acamamento gradacional normal. O topo dos ciclos são truncados por superfícies erosionais suaves. A parte superior do afloramento é constituída por arenitos, também de coloração esbranquiçada de seleção regular e estratificações planoparalelas inclinadas com baixíssimo ângulo (figura 3.6). O afloramento encontra-se na rodovia Araguaçu-Alvorada. 
Interpretação: A parte basal, onde há o predomínio de estratificações cruzadas por ondas, o ambiente deposicional foi de plataforma rasa com ação de ondas de tempestades, à frente de ambiente de praia, interpretação para a seção superior do afloramento. Portanto, evidencia-se uma progradação deposicional.

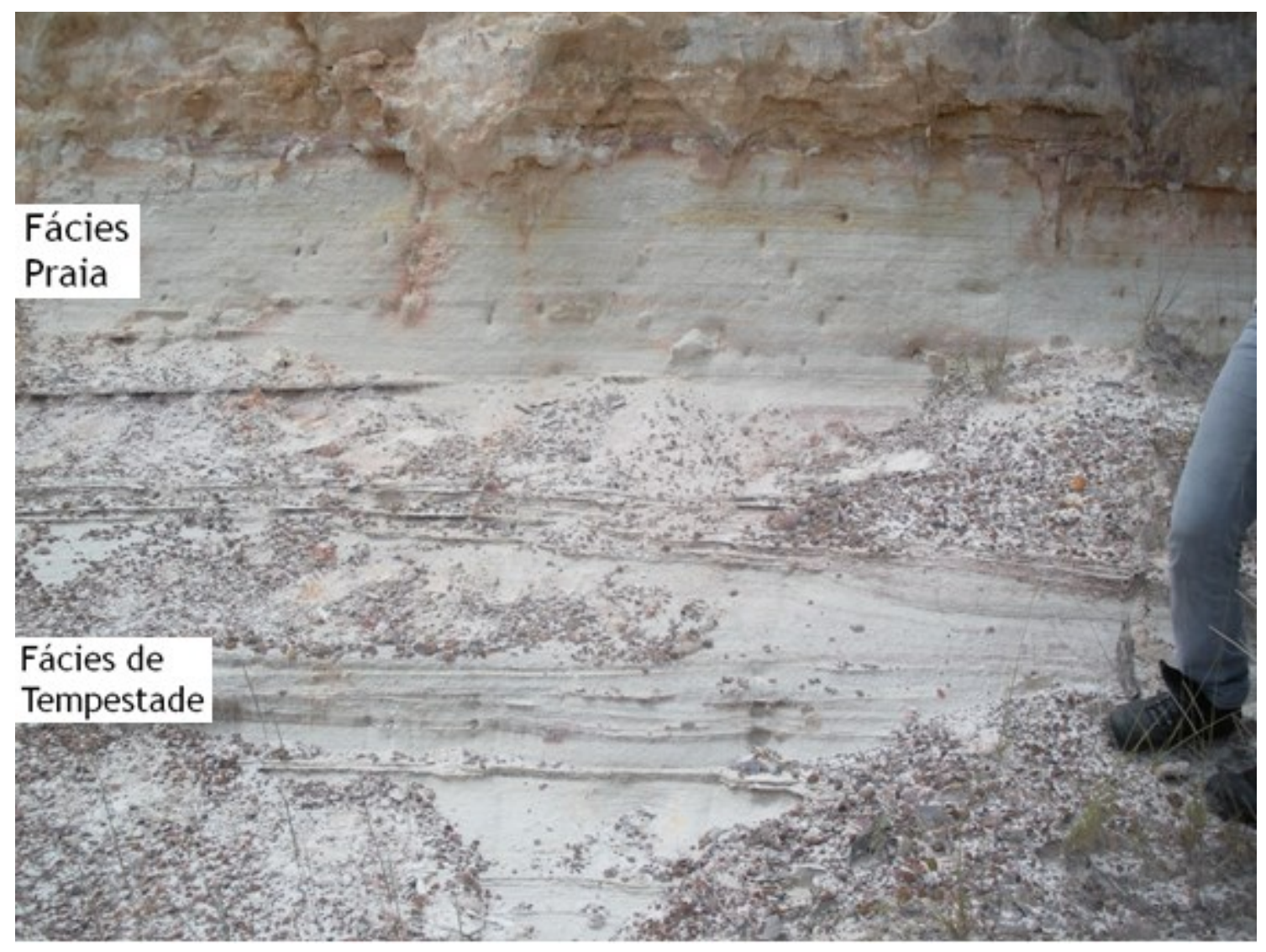

Figura 3.6 - Foto fácies $\mathrm{C}$, onde estão representadas no topo as fácies de praia e na base as fácies de tempestade. 


\subsection{Interpretação geológica com base em Landsat e SRTM}

Para a interpretação dos dados geológicos foram utilizadas a imagem de satélite (figura 3.7) e o relevo sombreado (figura 3.9a).

A composição Landsat 8 (figura $3.7 a$ ) foi realizada com as imagens das bandas 5, 6, 4 e apresentam intervalos espectrais variando de: 0,85 a $0,88 \mu \mathrm{m}$, 1,57 a $1,65 \mu \mathrm{m}$, e de 0,64 a $0,67 \mu \mathrm{m}$, respectivamente e resolução espacial de aproximadamente 30 metros. Nesta imagem com os limites do GAB de acordo com Lacerda Filho et al. (2004), nota-se que a vegetação é menos densa e a densidade de drenagem é menor na região do GAB que na região ao redor. $\mathrm{Na}$ figura $3.7 \mathrm{~b}$ observa-se que as principais drenagens foram traçadas sendo que do lado oeste foram bem delimitadas, pois as rochas deste lado são mais friáveis que a do leste; há ainda drenagens que demarcam bem a borda oeste do GAB e perpendicular a esta borda tem drenagens secundárias e retilíneas adentrando o GAB. Carvalho (2011) descreveu que na porção central do GAB predominam drenagens de primeira, segunda e terceiras ordens caracterizadas como sendo retilíneas ou levemente sinuosas compondo um padrão de drenagem reticulado. 


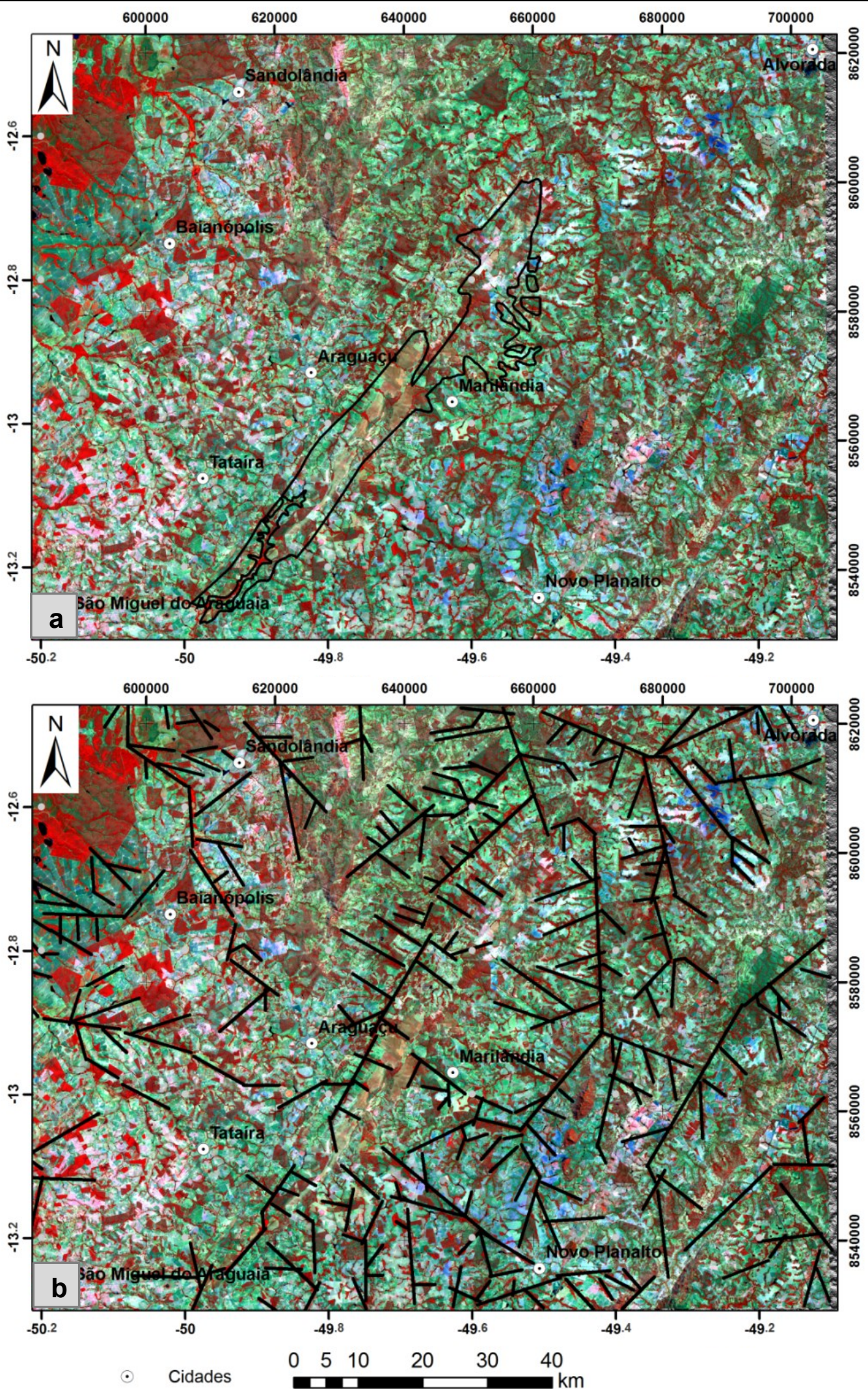

Figura 3.7 - a) Fusão das bandas 564 do satélite Landsat 8, composição R5-G6-B4 e limites do GAB de acordo Lacerda Filho et al. 2004; b)Interpretação das principais drenagens interpretadas a partir da imagem de satélite Landsat 8 composição 5,6,4. 
O mapa altimétrico (figura 3.8) foi adquirido por meio do software Oasis Montaj $^{\mathrm{TM}}$ da Geosoft, com resolução de 90 metros e foi utilizado para a correção de terreno da gravimetria descrita no capítulo 5. O relevo sombreado (figura 3.9a), com resolução de 30 metros, foi obtido através do projeto Topodata, que oferece o Modelo de Elevação do Terreno e produtos derivados a partir de dados do SRTM (Inpe, 2014). A interpretação do relevo sombreado foi feita com a marcação dos lineamentos primários e secundários (figura 3.9b). Como representado na roseta (figura 3.9c) a direção principal do lineamento primário foi de aproximadamente N35E, N55W, N70W e os secundários na direção E/W, além de lineamentos N65E que cortam o GAB.

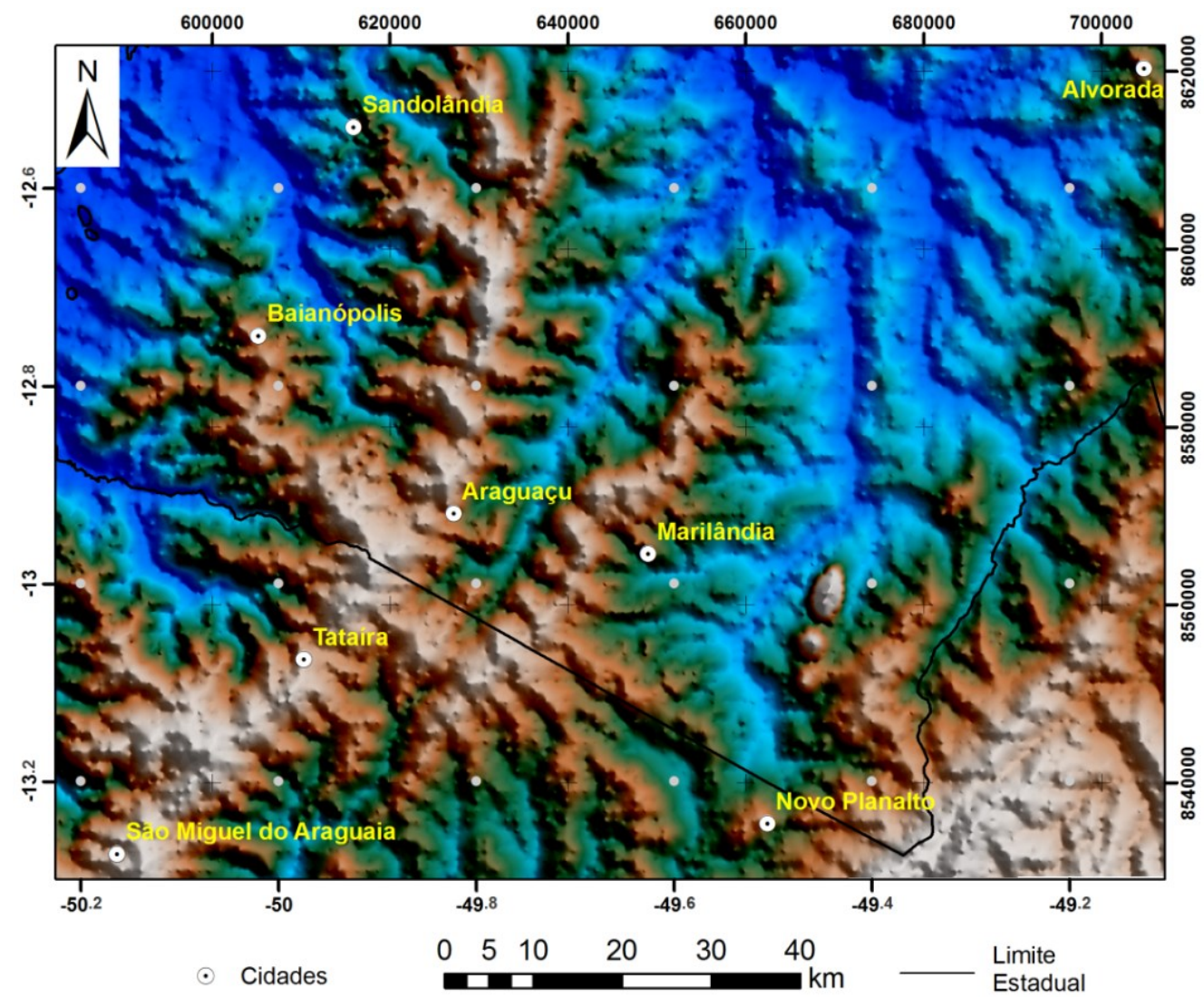

Figura 3.8 - Altimetria da área em estudo com 90 metros de resolução. A área de estudos apresenta pequena variação de elevação, aproximadamente, 130 metros. 
Universidade de Brasília

Programa de Pós-Graduação em Geociências Aplicadas
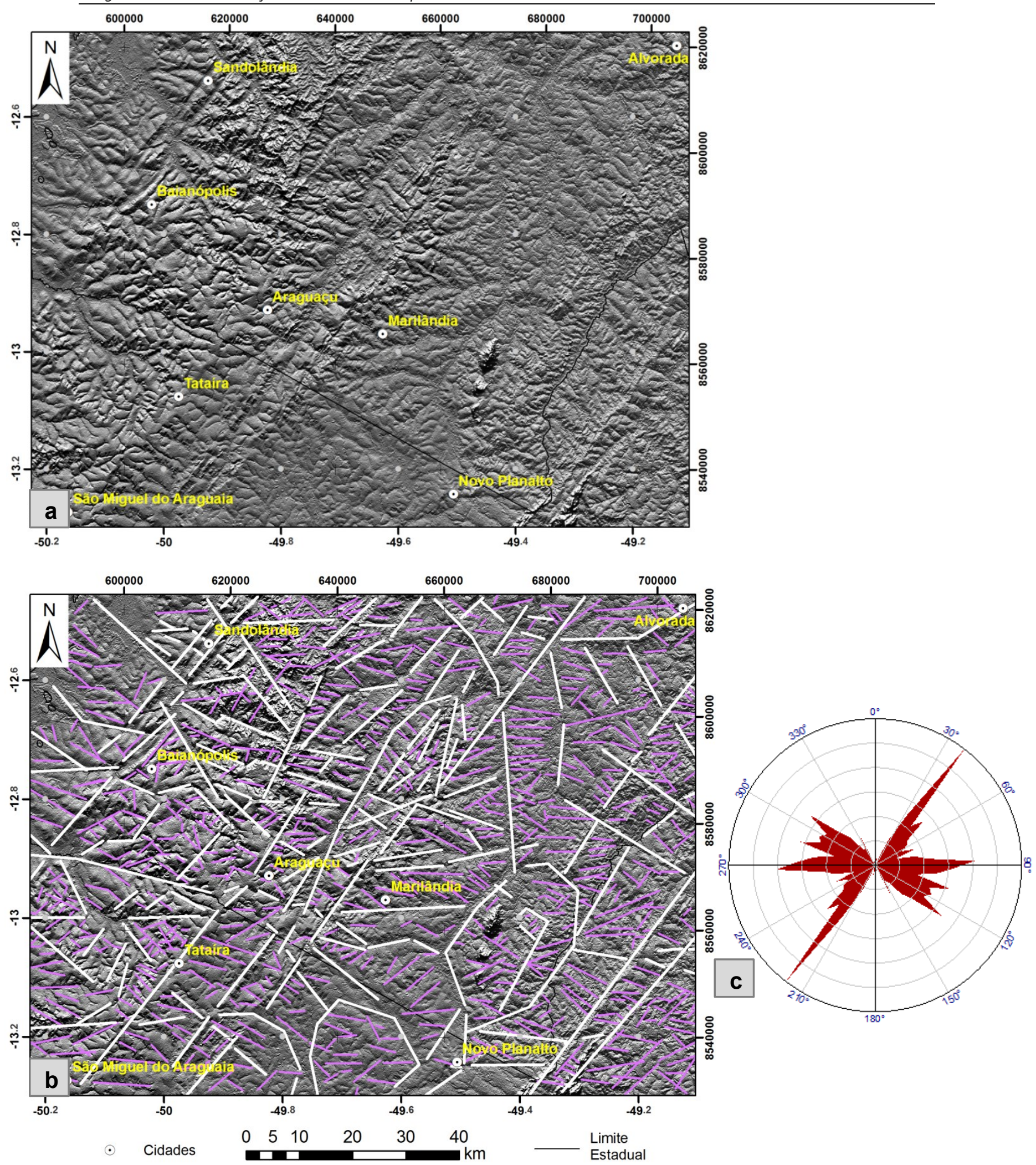

Figura 3.9 - a) Relevo sombreado; b) Principais lineamentos interpretados a partir do relevo sombreado. Em branco os lineamentos primários e os secundários em magenta. c) Roseta dos lineamentos traçados no relevo sombreado. Observam-se lineamentos de direção principal N35E, N55W, N70W e E/W. 


\section{Magnetometria Aérea}

\subsection{História e teoria do método}

O método magnético se baseia na medida de um campo total e análise de anomalias causadas pera variação lateral de magnetização de materiais em subsuperfície (Hinze et al. 2013). É talvez o mais antigo método geofísico, sendo o Sir William Gilbert, autor do de Magnete, quem realizou a primeira investigação do magnetismo terrestre, mostrando que o campo magnético podia ser aproximado por um campo magnético permanente não tendo uma relação com a direção norte e sul do eixo rotacional terrestre (Telford et al. 1990). No século 19 a atração entre a agulha das bússolas e as formações naturais de ferro, eventualmente foram utilizadas para prospecção no século 19. O auge deste método ocorreu após os levantamentos aéreos durante a Segunda Guerra Mundial com melhorias na instrumentação e navegação, como por exemplo, o desenvolvimento do primeiro magnetômetro fluxgate para uso em aviões, tornou possível o mapeamento toda a seção crustal em uma variedade de escalas, desde embasamentos fortemente magnetizados em escala regional a contatos em bacias sedimentares com baixa magnetização numa escala local (Nabighian et al., 2005; Telford et al. 1990).

O método magnético é a ferramenta primária na exploração mineral, mas com sua evolução passou a ser utilizado em outras áreas, a partir de seu uso exclusivo para o mapeamento de estruturas a incluir uma ampla variedade de novas aplicações, tais como localização de falhas em bacias sedimentares, definir contatos litológicos, o mapeamento de domos salinos em sedimentos fracamente 
magnéticos. Estas novas aplicações têm aumentado a utilidade do método em várias áreas de exploração e na busca de minerais, petróleo e gás, recursos geotermais, águas subterrâneas, e para uma variedade de outros fins, tais como a avaliação de riscos naturais, mapeamento de estruturas de impacto, engenharia e estudos do meio ambiente (Nabighian et al., 2005).

As primeiras medidas sistemáticas do campo magnético no Brasil são creditadas ao holândes Van Rickevorsehn, em 1880-1885, e consequentemente os levantamentos geofísicos resultaram na implantação de redes de referência do campo magnético terrestre com a criação do Observatório Magnético de Vassouras em 1915, pelo Observatório Nacional, com a estrutura para realizar registros contínuos e observações absolutas, passou a colaborar com o esforço internacional de estudo do tema, contribuindo com seus resultados para a primeira representação mundial do campo geomagnético realizado pelo Carnegien Institution of Washington, na década de 1940 (Rodrigues, 2012).

De acordo com Rodrigues (2012) o Observatório Magnético de Tatuoca foi criado em 1933, na oportunidade do Segundo Ano Polar Internacional. A estação foi fechada no mesmo ano e reaberta somente em 1957, por causa do acontecimento do Ano Geofísico Internacional que ocorreu neste observatório, e adquiriu um variógrafo de última geração que contribuiu com o estudo de variações diurnas do campo magnético. Uma rede de estações implantadas em território nacional complementavam os resultados dos observatórios de Tatuoca e Vassouras. A cada cinco anos, cada uma das estações é reocupada gerando novas medidas do campo magnético local e compõem a Carta Magnética 
Brasileira. Em 2012, a Rede Geomagnética possuía aproximadamente 300 estações espalhadas em várias regiões do país.

\subsubsection{Campo Magnético Terrestre}

A magnitude do campo magnético terrestre (figura 4.1) varia em cerca de 5 $\times 10^{-5} \mathrm{~T}$, por se tratar de um valor pequeno a medida mais conveniente para se usar na geofísica é o nano Tesla. O campo geomagnético pode ter um valor desde 22000 nT (Brasil) a 70000 nT (Sul Atlântico da Nova Zelandia) (Telford et al. 1990).

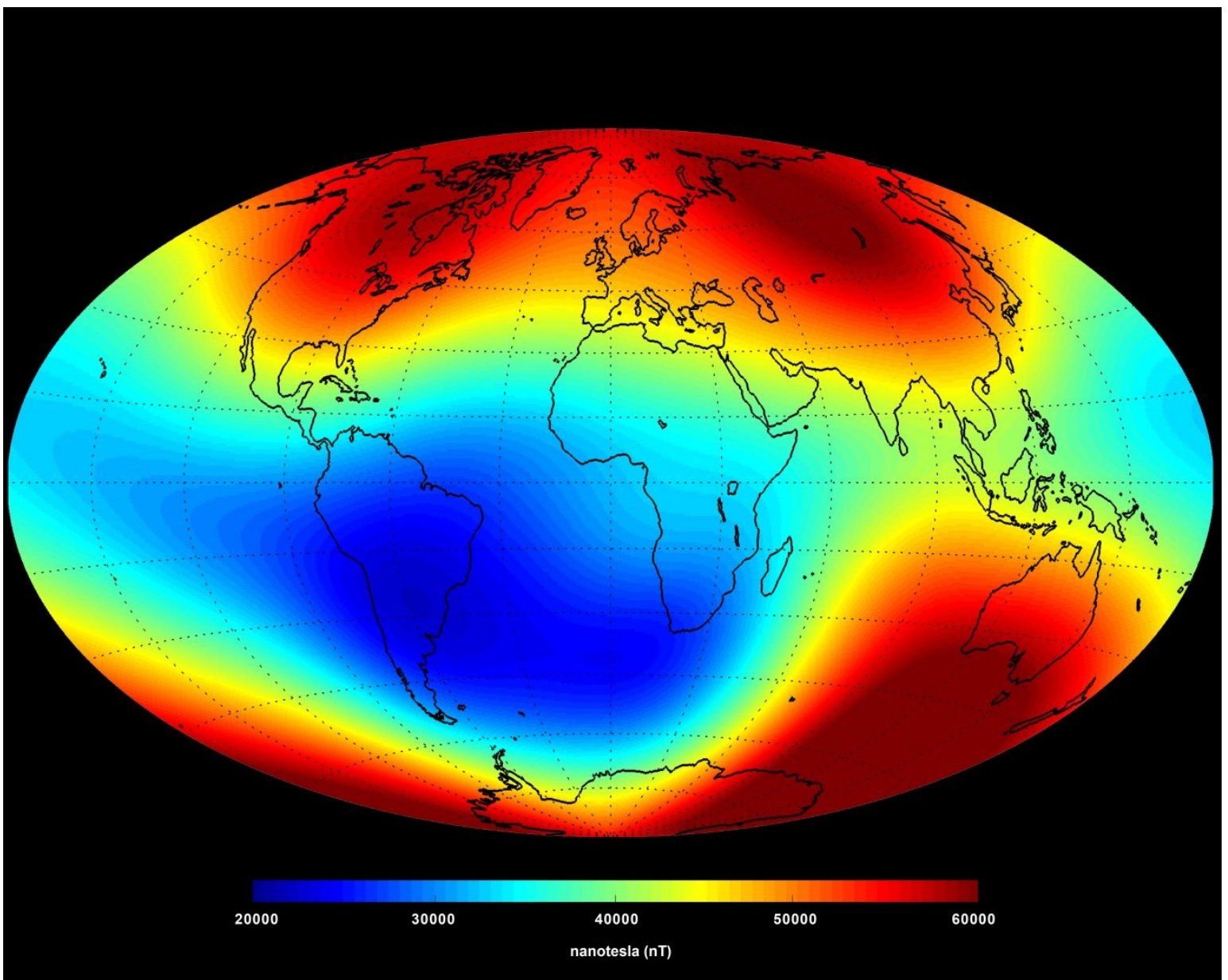

Figura 4.1- Campo magnético terrestre em junho de 2014 (European Space Agency, 2014). O Brasil encontrase numa região com uma baixa intensidade do campo magnético, denominada Anomalia Magnética do Atlântico Sul (AMAS). 
O campo magnético tem sua natureza vetorial, são necessários cuidados quanto à direção do campo que requer que seja expresso em três componentes ortogonais (figura 4.2a) ou em um escalar do campo total com sua orientação de inclinação e declinação (figura 4.2b; Reeves, 2005).

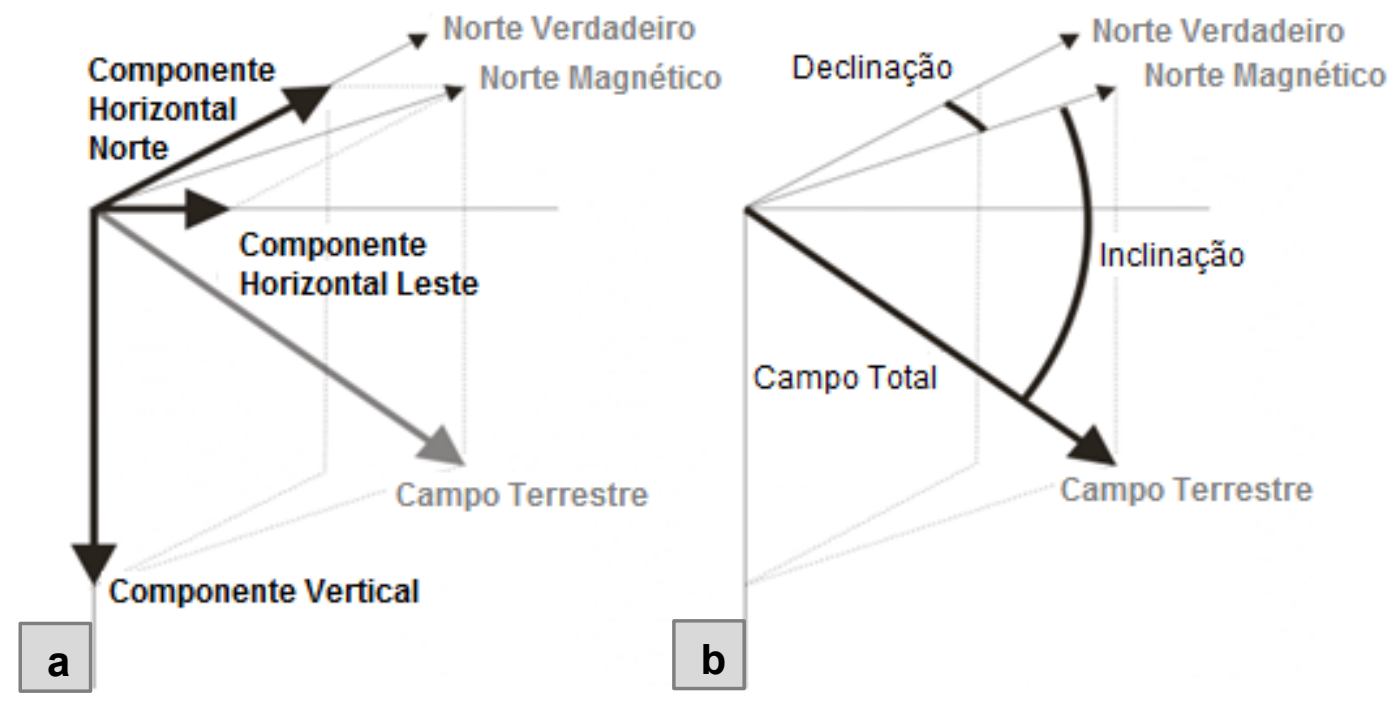

Figura 4.2 - Vetor do campo magnético total: a) Definido em três componentes ortogonais; b) definido como um escalar com o ângulo de inclinação e declinação (Reeves, 2005).

A partir do componente escalar do campo total, a inclinação (I) e a declinação (D) definem o campo magnético principal (Telford et al. 1990). O ângulo do vetor total com a componente horizontal do campo é conhecido como inclinação I e o ângulo entre norte magnético com o verdadeiro é conhecido como declinação (D). 


\subsubsection{Susceptibilidade magnética e magnetização}

A magnitude de uma magnetização $\left(\mathrm{J}_{1}\right)$ adquirida é proporcional à força do campo terrestre $(F)$ em sua vizinhança, onde a constante de proporcionalidade $k$, por definição é a susceptibilidade magnética. Para os geofísicos, k é o volume de susceptibilidade magnética, diferente da susceptibilidade da massa e molar que não são utilizadas (Reeves, 2005).

$$
\mathrm{J}_{\mathrm{l}}=\mathrm{kF}
$$

A susceptibilidade magnética em unidade SI é uma razão adimensional tendo uma magnitude muito menor que 1 para maioria das rochas. Porém, a magnetização é mais utilizada, tendo como unidade a mesma do campo magnético (nT), sendo um vetor soma da induzida com a remanente (Reeves, 2005). Rochas com uma maior quantidade de ferro e minerais ferrimagnéticos possuem uma maior susceptilibilidade, consequentemente, rochas básicas e ultrabásicas tem um valor de $\mathrm{k}$ maior, seguido pelas rochas ígneas ácidas $\mathrm{e}$ metamórficas com um valor intermediário e as rochas sedimentares são as que possuem valores menores, em geral (Reynolds, 1997). De acordo com Isles e Rankin (2013) a susceptibilidade magnética decresce com o aumento de oxidação, hidratação e a sulfetação de minerais.

As principais características de magnetização de uma rocha são determinadas por vários fatores como a geoquímica da rocha, espécies de minerais presentes que transportam o $\mathrm{Fe}$ (quanto de Fe reside dentro de minerais magnéticos) e o volume dessas espécies, os diferentes tipos de magnetização 
mostrada pelos minerais magnéticos, a intensidade e orientação do campo magnético externo, ou seja, inclinação e declinação (Isles e Rankin, 2013).

\subsubsection{Magnetização induzida e remanente}

Quando um material magnético é colocado sob um campo magnético, o material se torna magnetizado e a magnetização externa é somada ao campo magnético induzido no próprio material. Isso é conhecido como magnetização induzida. Quando o campo externo é retirado, a magnetização induzida desaparece, mas alguns materiais retém uma magnetização permanente ou remanente (Reynolds, 1997).

As rochas crustais, em geral, são fracamente magnéticas, mas podem exibir a magnetização induzida ou a remanente. Inevitavelmente estão sob a influência do campo magnético terrestre, e em alguns casos grava a sua orientação passada (Reeves, 2005; Telford et al. 1990). 


\subsection{Processamento dos dados}

Levantamentos magnéticos podem ser representados por um conjunto de perfis ou mapas magnéticos e em geral as anomalias magnéticas são numerosas e consequentemente a separação das anomalias regionais das residuais é complexa (Telford et al. 1990).

Os valores do campo magnético terrestre obtido são resultantes principalmente de campos magnéticos internos, externos e crustais, que podem ser definidos como, respectivamente: i) originado no núcleo a partir da convecção de corrente gerada pela movimentação de partículas; ii) o menor componente do campo total, caracterizado por grandes variações temporais e é causado pelas correntes elétricas que fluem na ionosfera gerada a partir da interação desta com a magnetosfera e os ventos solares (pulsações); iii) e a partir do menor campo entre os citados anteriormente, os minerais magnéticos da crosta, que ocorrem nos primeiros $5 \mathrm{~km}$, geram as anomalias do campo magnético que são utilizados em prospecção (Telford et al. 1990).

O mapeamento da variação do campo magnético total tem como propósito o estudo da geologia crustal. Para isso, as variações globais devem ser subtraídas das locais para que se obtenha a anomalia crustal (Blakely, 1995). Então, retira-se o IGRF e a variação diurna. A retirada do campo magnético terrestre principal é feita a partir do International Geomagnetic Reference Field (IGRF), que é uma série matemática temporal do modelo do campo, calculada a cada cinco anos. A variação diurna é causada pelas correntes elétricas localizadas na região mais condutiva da ionosfera (entre 90 e $120 \mathrm{~km}$ ), tendo seu pico ao meio dia e 
diminuindo com o entardecer e sua correção é feita a partir dos dados obtidos na estação base de magnetometria.

Os dados utilizados nesta pesquisa foram cedidos pelo Serviço Geológico do Brasil (CPRM), descritos no capítulo 1.4.1, sendo que já haviam sido realizadas as reduções do IGRF, variação diurna, e todas as compensações e correções referentes a levantamentos aéreos (e.g. Luyendik, 1997). Desta forma nosso trabalho se inicia com o campo magnético anômalo.

No processamento dos dados foi realizado o micronivelamento, além de filtragens, para a retirada de ruídos e realce do sinal de interesse, com o objetivo de gerar produtos que serão utilizados para a interpretação e integração dos dados juntamente a análise de profundidade e dados geológicos. Em todos os produtos (figura 4.3 até 4.10 ) pode-se observar anomalias magnéticas com continuidade e trend NE referente à zona de influência do Lineamento Transbrasiliano no qual está inserido o GAB.

\subsubsection{Micronivelamento}

O micronivelamento se refere à retirada de qualquer erro residual em um dado aéreo em função de ruídos na direção da linha de vôo. Para sua correção são utilizados métodos de filtragem para detectar os erros residuais que depois são subtraídos do dado (Luyendik, 1997). Neste trabalho foi utilizando o método proposto por Blum (1999) com base em Minty (1991). Esta rotina consiste em:

i) aplicar um filtro passa-alta (PA) nos dados interpolados (malha A), com direção perpendicular a linha de vôo gravando o resultado em uma malha B; 
ii) aplicar um filtro passa-baixa (PB) na malha B na direção da linha de vôo e gravando na malha C;

iii) a malha resultante, dados micronivelados, é obtida subtraindo-se a malha A da malha C.

O parâmetro para o filtro passa-alta e passa-baixa foram de 8 e 28 células, respectivamente. Esses números equivalem: i) para o filtro passa-alta, duas vezes espaçamento das linhas de vôo dividido pelo espaçamento do grid; e ii) para o filtro passa-baixa, uma vez espaçamento das linha de controle dividido pelo espaçamento do grid. Os dados utilizados tem espaçamento das linhas de vôo de $2 \mathrm{~km}$ e das linhas de controle de $14 \mathrm{~km}$. Na figura 4.3 pode se observar o CMA micronivelado.

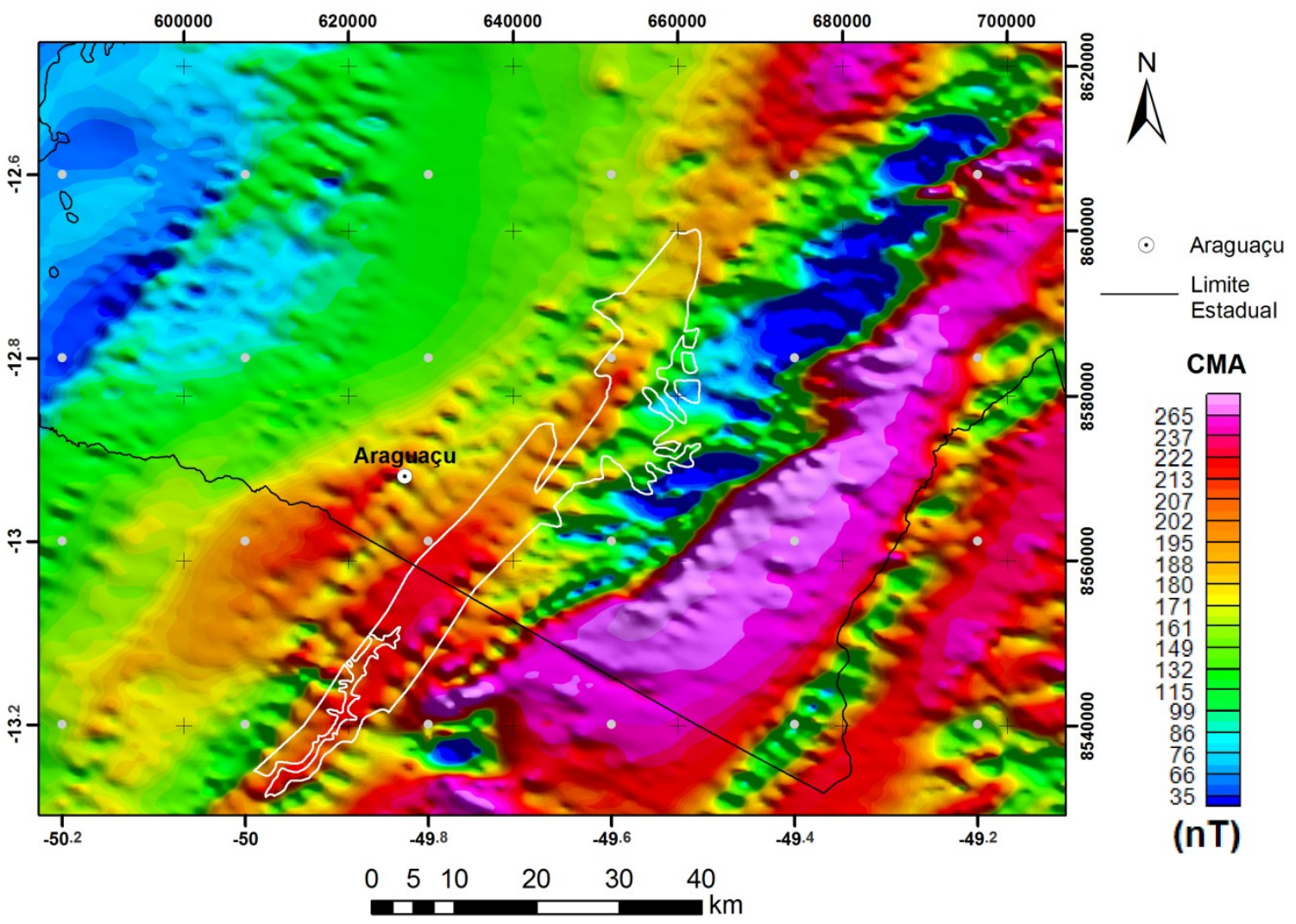

Figura 4.3 - Campo Magnético Anômalo onde se observa um trend NE referente à zona de influência do Lineamento Transbrasiliano e os limites do GAB que está inserido neste trend, em branco (de acordo Lacerda Filho et al. 2004). 


\subsubsection{Redução ao Polo}

A partir do Campo Magnético Anômalo (CMA) os dados foram reduzidos ao polo (RDP), para que se possa realizar uma melhor análise dos dados. O objetivo da RDP é representar as anomalias magnéticas como monopolos, simplificando a forma da anomalia e teoricamente fazendo com que a maior amplitude esteja relacionada ao centro do corpo. Vale ressaltar, que esta premissa só é verdadeira, se não houver magnetização remanente.

A RDP é necessária porque em latitudes intermediárias as anomalias magnéticas são dipolares. Porém, de acordo com Cooper e Cowan (2005) este método é instável em baixas latitudes, pois os ângulos de entrada são definidos como constantes para toda a área em estudo e causa resultados incoerentes se a fonte do corpo possui uma magnetização remanente desconhecida. Para reduzir este problema foi utilizada a redução ao polo diferencial (figura 4.4) que calcula as declinações e inclinações pra cada célula do grid e resolve o problema de instabilidade em baixas latitudes. Para esta correção foi utilizado o Geosoft versão 8.0 que disponibiliza esta ferramenta. 


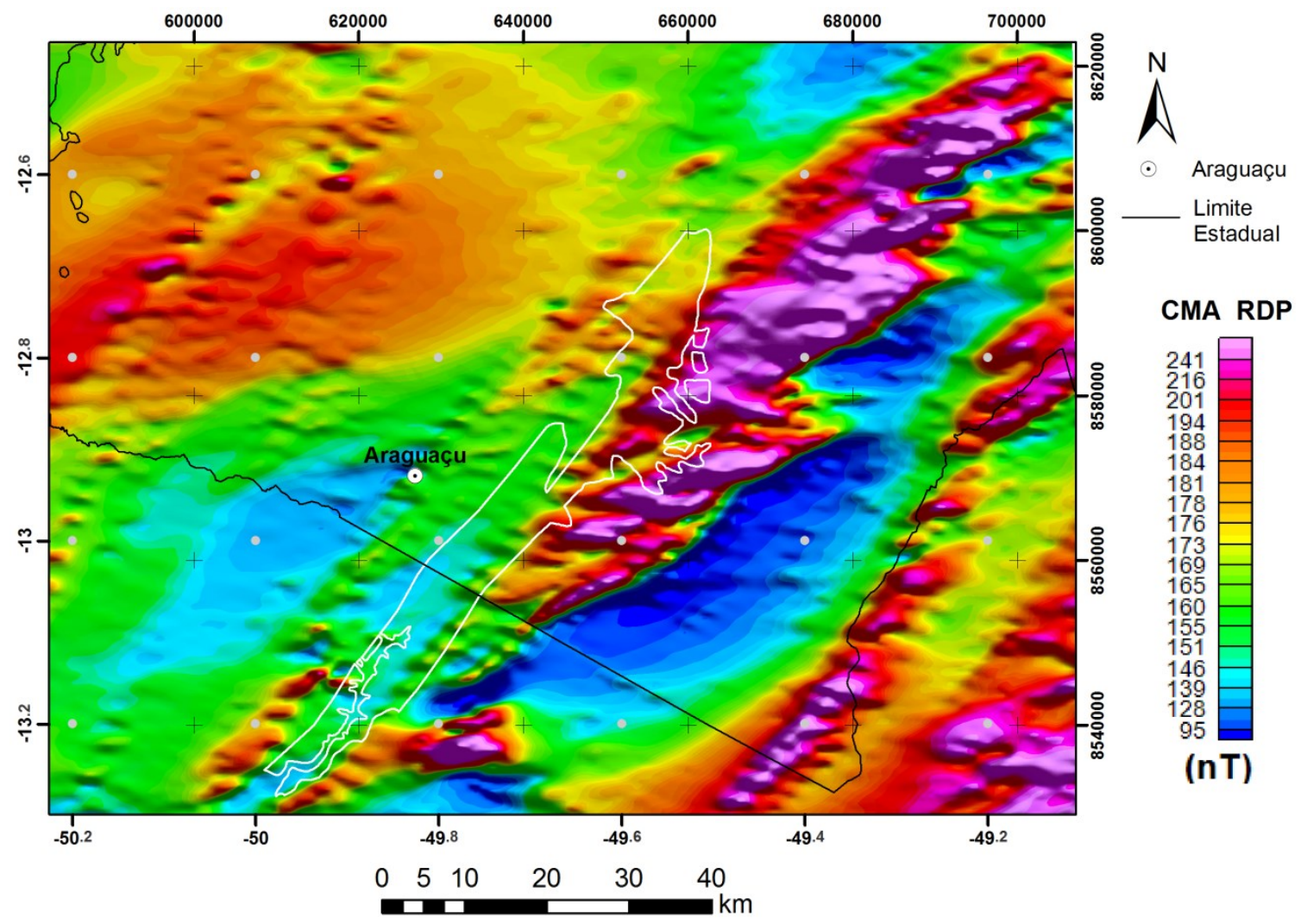

Figura 4.4 - Campo magnético anômalo com a Redução ao Polo Diferencial onde se observa um trend NE referente à zona de influência do Lineamento Transbrasiliano e os limites do GAB que está inserido neste trend, em branco (de acordo Lacerda Filho et al. 2004).

\subsubsection{Derivadas}

As derivadas nas três direções, x, y e z, são utilizadas para gerar os outros produtos e quando analisadas separadamente realçam os menores comprimentos de onda, que são relacionadas as anomalias rasas, estas funções demonstram a variação do sinal em relação à direção derivada, para exemplificar apresenta-se a erivada em z (figura 4.5). 


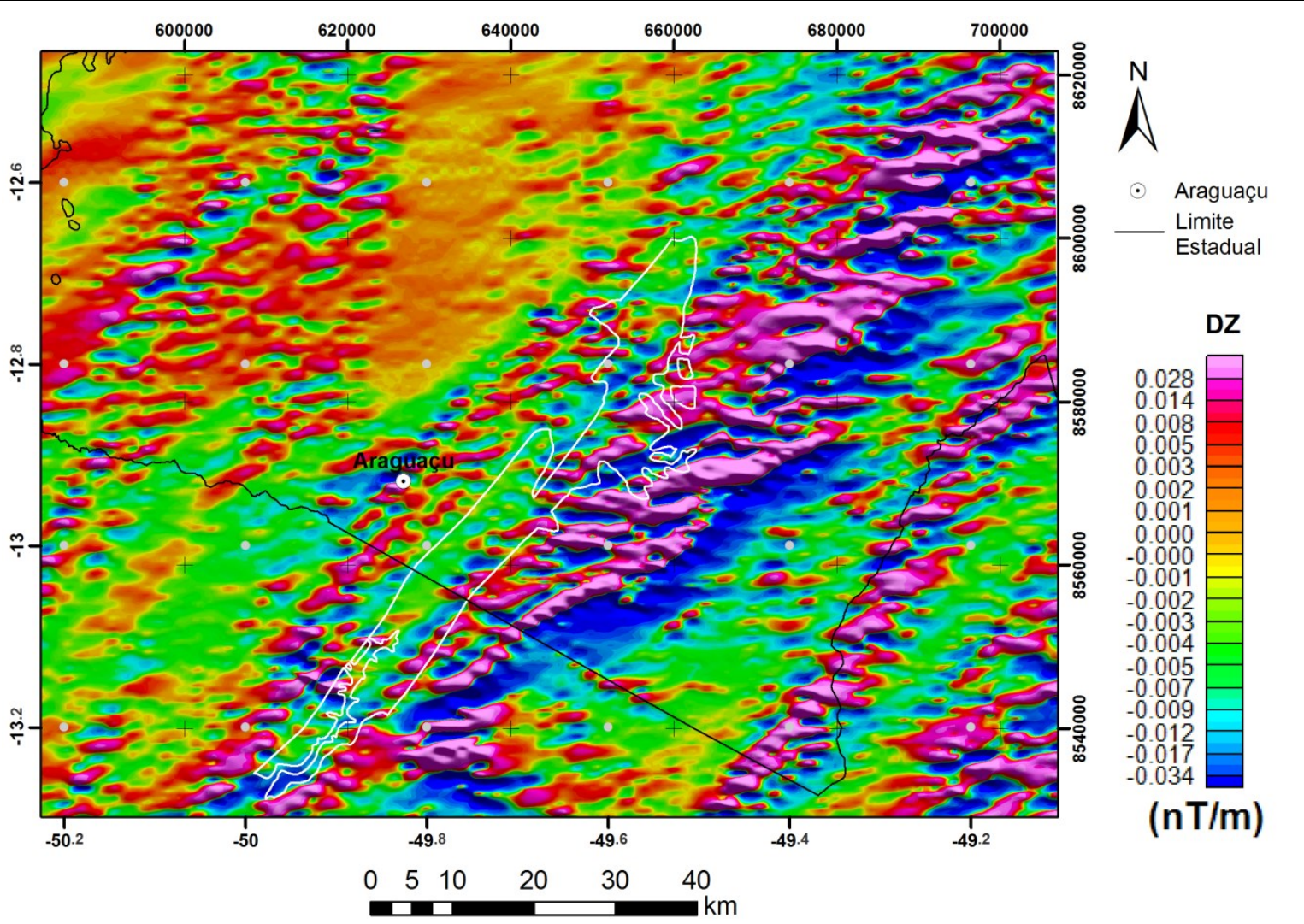

Figura 4.5 - Derivada em z onde se observa um trend NE referente à zona de influência do Lineamento Transbrasiliano e os limites do GAB que está inserido neste trend, em branco (de acordo Lacerda Filho et al. 2004).

O gradiente horizontal de uma anomalia de campo potencial (campo magnético) pode indicar mudanças laterais abruptas de propriedades físicas. Por esta razão utiliza-se a Amplitude do Gradiente Horizontal Total (eq.4.1; figura 4.6), introduzido por Cordell e Graunch (1985), representa na maior amplitude as bordas e no mínimo a parte central sendo que a força do sinal é atenuada com a profundidade (Ferreira et al. 2013; Cordell e Graunch, 1985). É calculado a partir das derivadas horizontais de primeira ordem.

$$
A G H T=\sqrt[2]{\left(\frac{d \vec{H}}{d x}\right)^{2}+\left(\frac{d \vec{H}}{d y}\right)^{2}}
$$




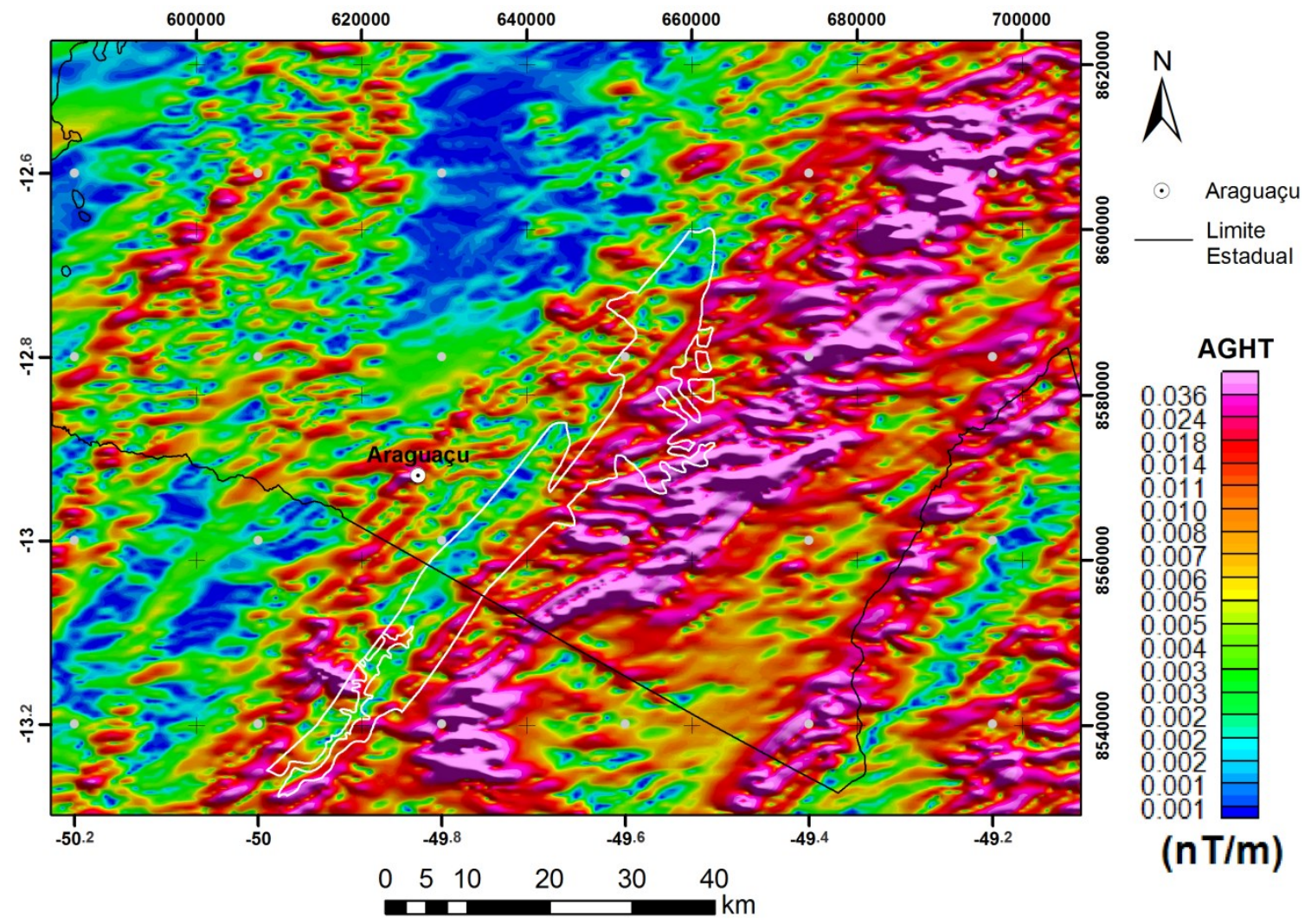

Figura 4.6 - Amplitude do Gradiente Horizontal Total onde se observa um trend NE referente à zona de influência do Lineamento Transbrasiliano e os limites do GAB que está inserido neste trend, em branco (de acordo Lacerda Filho et al. 2004).

Valores altos de variação do campo magnético ao longo das direções $x$ e $y$ podem ser indícios de contrastes nas propriedades físicas do meio, enquanto derivadas verticais representam variações com relação à profundidade. Este processo também pode ser utilizado como um método de separação regionalresidual. 
A partir dos dados de derivadas direcionais calcula-se a Amplitude do Sinal Analítico (ASA, eq. 4.2), introduzido por Nabighian (1972) tem por objetivo principal a centralização das anomalias e sua principal vantagem, quando utilizada em duas dimensões, é que seu resultado não depende dos parâmetros do campo magnético terrestre e da direção de magnetização da fonte, não sendo necessária a redução ao polo para que seja gerada. Li (2006) ressalta o uso inadequado do ASA em três dimensões sem a redução ao polo, pois muitos autores tem estendido as mesmas características do 2D para o 3D. Em 3D, o ASA é dependente da intensidade total do campo magnético e sua direção, da direção da magnetização remanente, do ângulo mergulho da fonte e da relação de profundidades do topo e da base ( $\mathrm{Li}, 2006)$.

$$
A S A=\sqrt[2]{\left(\frac{d \vec{H}}{d x}\right)^{2}+\left(\frac{d \vec{H}}{d y}\right)^{2}+\left(\frac{d \vec{H}}{d z}\right)^{2}}
$$

O ASA 3D (figura 4.7) pode ser utilizado para estimar profundidade de contatos verticais, e sua utilização deve ser feita com a premissa de que seu resultado não é independente de informações geológicas e outras restrições ( $\mathrm{Li}$, 2006). De acordo com Ferreira et al. (2013) o sinal do produto diminui com a profundidade da fonte. 


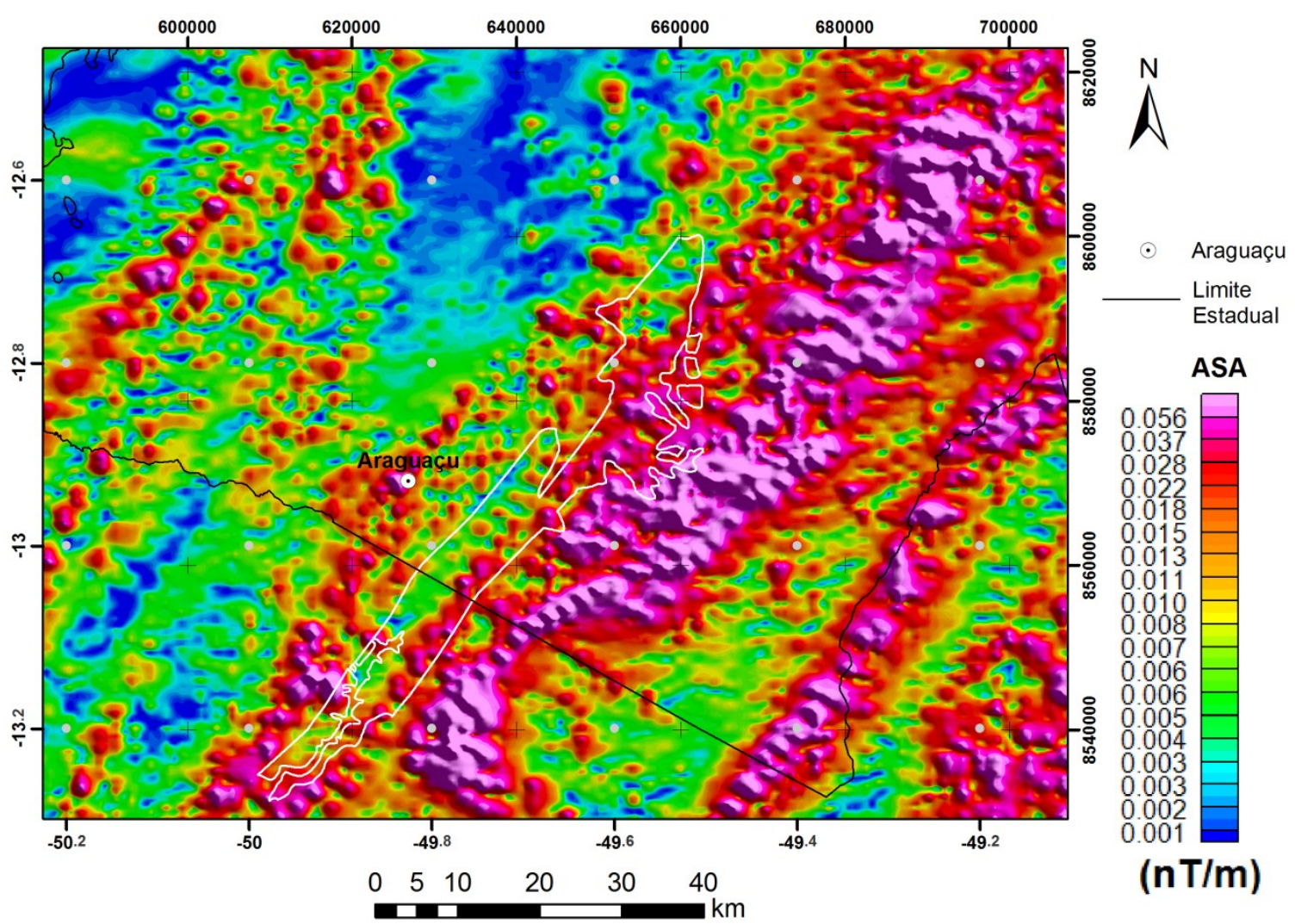

Figura 4.7 - Amplitude do Sinal Analítico 3D onde se observa um trend NE referente à zona de influência do Lineamento Transbrasiliano e os limites do GAB que está inserido neste trend, em branco (de acordo Lacerda Filho et al. 2004).

Outra ferramenta que utiliza uma propriedade do sinal analítico para o estabelecimento de feições é a Inclinação do Sinal Analítico (ISA, figura 4.8) definido por Miller e Singh (1994), sua principal função é o traçado de direções tais como lineamentos magnéticos e bordas de corpos, além de equalizar a amplitude do sinal de fontes mais rasas e profundas. A ISA com as curva de (figura 4.9) $0^{\circ}$ foi feito com o intuito de ajudar na interpretação de dados, considerando que no zero estão representadas as bordas (Verduzco et al. 2004).

$$
I S A=\tan ^{-1} \frac{\frac{d \vec{H}}{d z}}{\sqrt[2]{\left(\frac{d \vec{H}}{d x}\right)^{2}+\left(\frac{d \vec{H}}{d y}\right)^{2}}}
$$




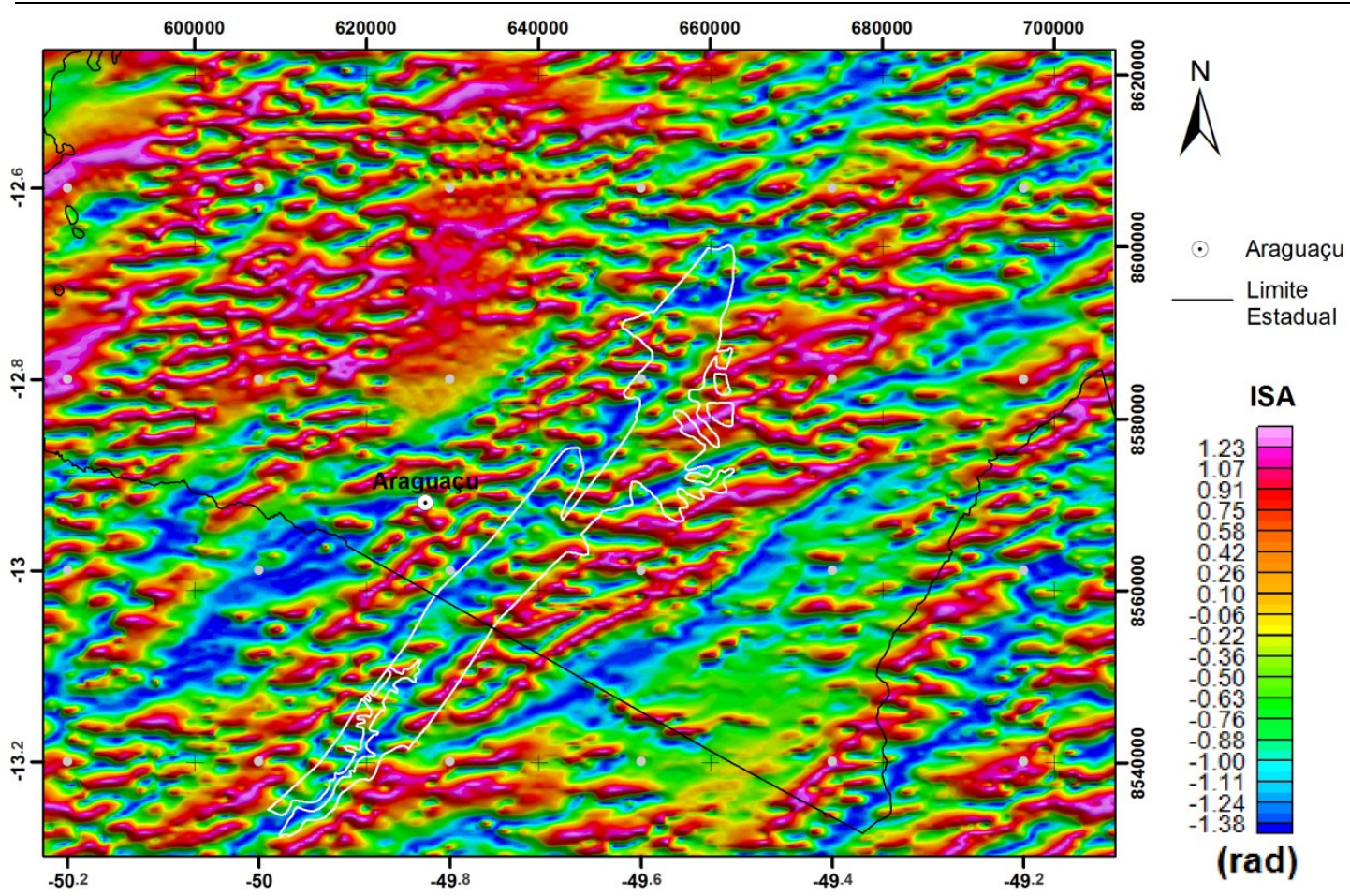

Figura 4.8 - Inclinação do Sinal Analítico onde se observa um trend NE referente à zona de influência do Lineamento Transbrasiliano e os limites do GAB que está inserido neste trend, em branco (de acordo Lacerda Filho et al. 2004).

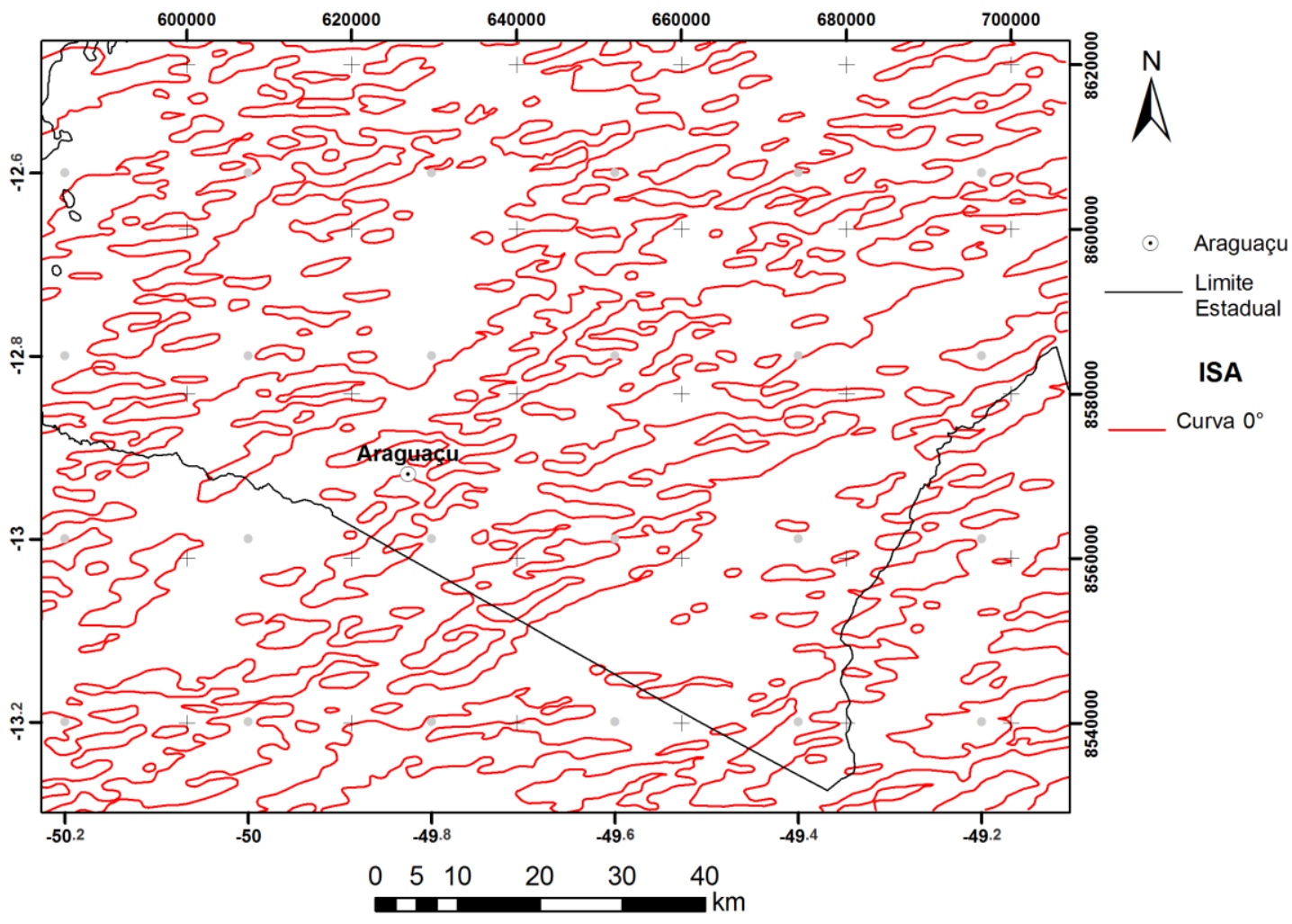

Figura 4.9 - Curvas de da Inclinação do Sinal Analítico referente a $0^{\circ}$ para ajudar na interpretação considerando que no zero podem estar representadas as bordas (Verduzco et al. 2004). 
A Inclinação do Sinal Analítico do Gradiente Horizontal (TAHG; fig. 4.10; eq. 4.4) foi definido por Ferreira et al. (2010) e demonstrou que o principal atributo deste método é mostrar a máxima amplitude das bordas das fontes, além de equalizar os sinais de fontes profundas e rasas, deixando os lineamentos mais contínuos.

$$
T A H G=\tan ^{-1} \frac{\frac{d \overrightarrow{A G H T}}{d z}}{\sqrt[2]{\left(\frac{d \overrightarrow{A G H T}}{d x}\right)^{2}+\left(\frac{d \overline{A G H T}}{d y}\right)^{2}}}
$$

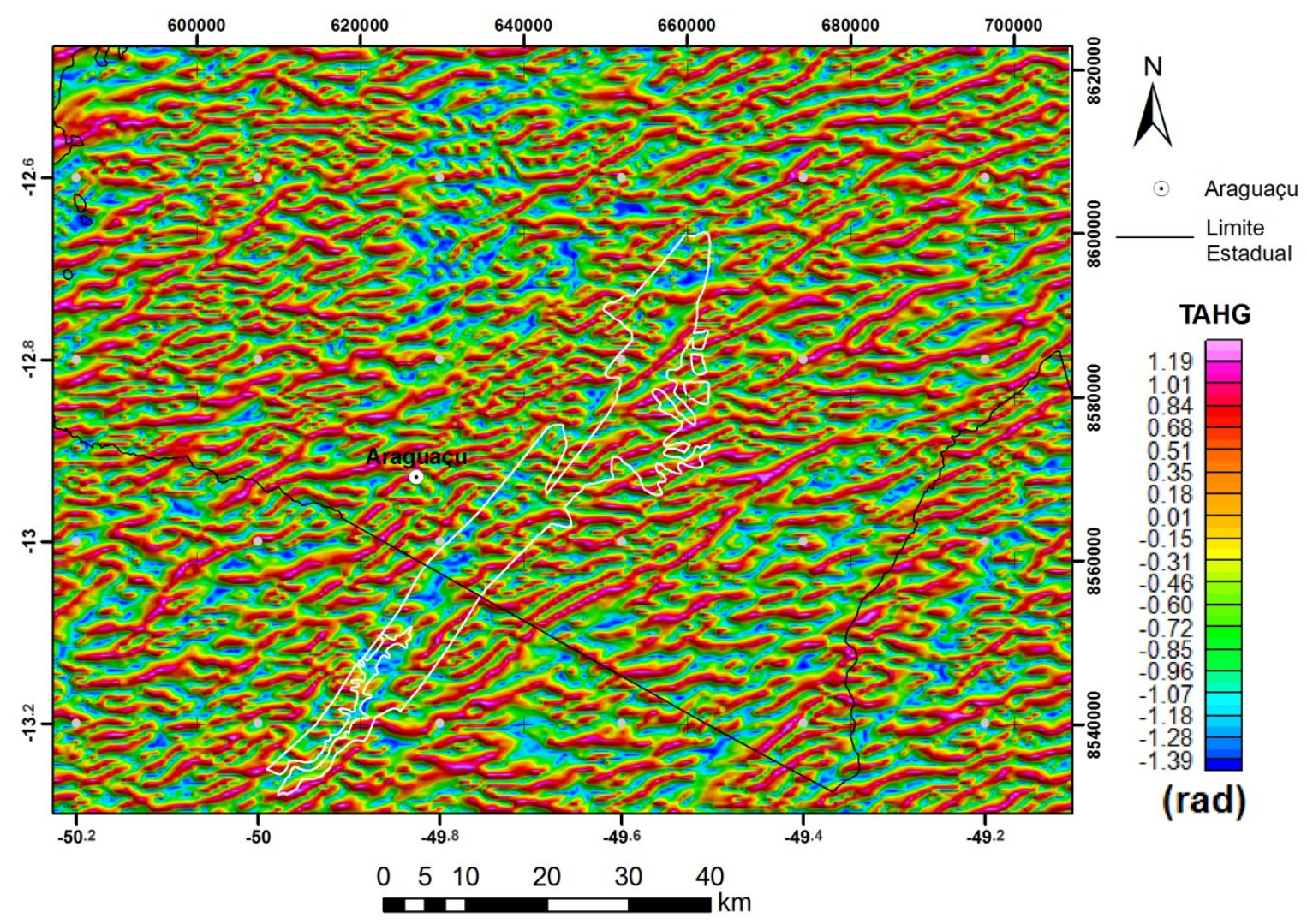

Figura 4.10 - Inclinação do Sinal Analítico do Gradiente Horizontal onde se observa um trend NE referente à zona de influência do Lineamento Transbrasiliano e os limites do GAB que está inserido neste trend, em branco (de acordo Lacerda Filho et al. 2004). 


\subsection{Interpretação e integração dos dados magnéticos}

Nesta etapa unidades de rochas magnéticas da área de estudo foram delineadas a partir da interpretação qualitativa dos produtos gerados conforme descrito anteriormente no item 4.2. O desafio para o interprete começa a partir do modelo do campo magnético ao traço de localização e forma da unidade de rocha magnética. A convenção adotada por vários autores é representar as unidades magnéticas como linhas que se aproximam do topo da superfície do corpo magnético (Isles e Rankim, 2013).

$\mathrm{Na}$ marcação dos lineamentos foram utilizados os passos descritos por Isles e Rankim (2013): i) traçar os lineamentos onde eles são observados; sem extrapolar ou interpolar; ii) marcar detalhes; conjuntos de pequenos segmentos e a geometria destes geralmente fornecem uma informação crítica sobre o estilo da estrutura geológica; iii) considerar varias orientações possíveis quando estiver marcando quebras que tem dimensões similares; iv) o mais subjetivo deve ser deixado para a etapa de integração das interpretações individuais dos produtos. A partir dos lineamentos traçados nos mapas magnéticos (figura 4.11) foi feita uma integração da interpretação individual dos produtos onde foi possível observar as direções preferencias de NE/SW e E/W, além de lineamentos que cortam o GAB numa direção N65E (figura 4.12). 
Universidade de Brasília

Programa de Pós-Graduação em Geociências Aplicadas
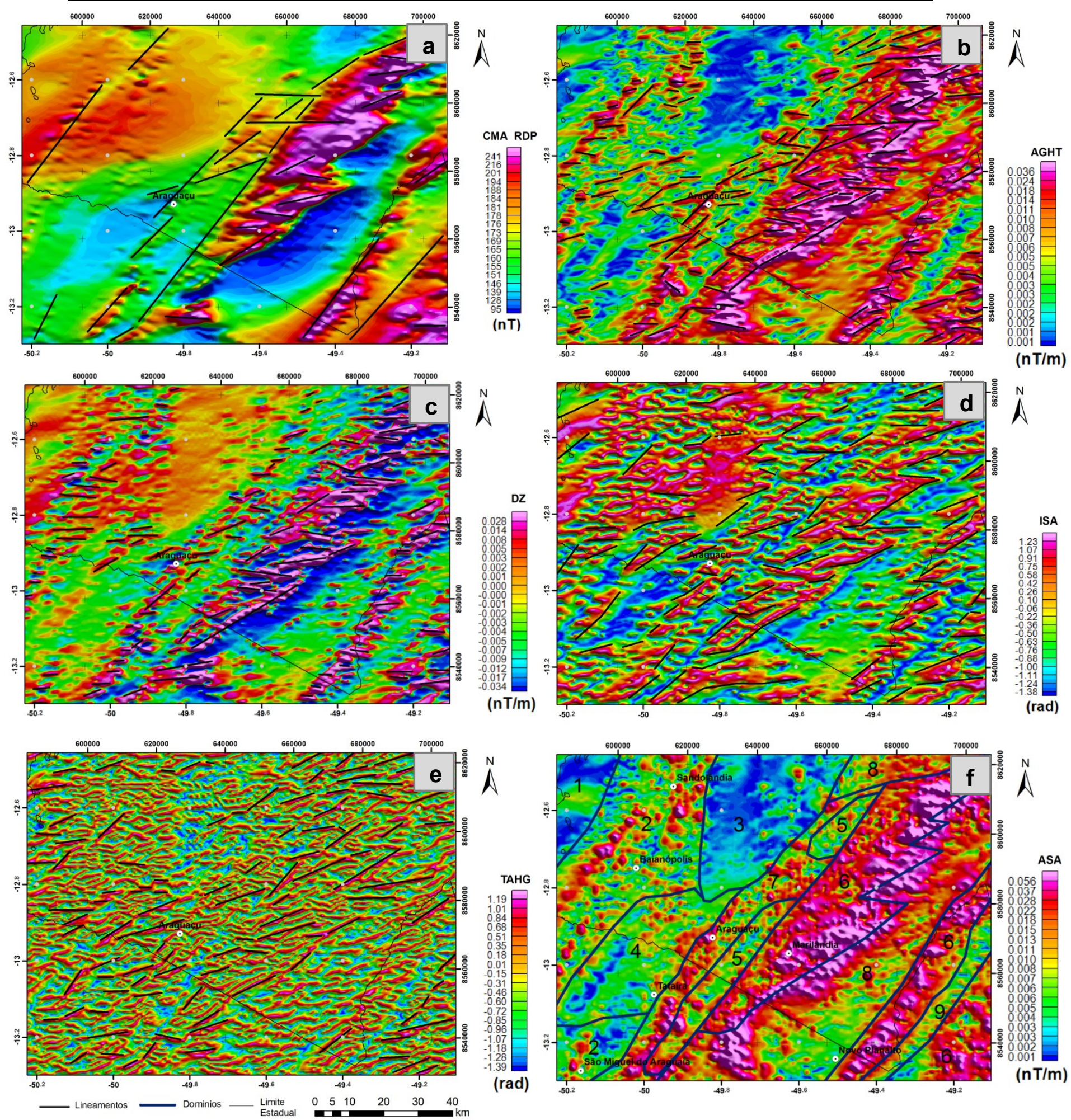

Figura 4.11 - Lineamentos (em preto) traçados nos mapas magnéticos: a) CMA reduzido ao polo; b) AGHT; c) Dz; d) ISA; e) TAHG e f) ASA com os domínios magnéticos (em azul). Lineamentos cortam o GAB numa direção N65E, além de outros em toda a região de direção preferencialmente E/W e $\mathrm{NE} / \mathrm{SW}$. Estes lineamentos de direção NE/SW podem estar relacionados à zona de influência do Lineamento Transbrasiliano. 
A direção N55W representada na interpretação dos dados geológicos não está representada nos dados magnéticos, o que pode ser explicado pela falta de contraste da magnetização, direção da linha de vôo em relação à direção da anomalia ou resolução dos dados.
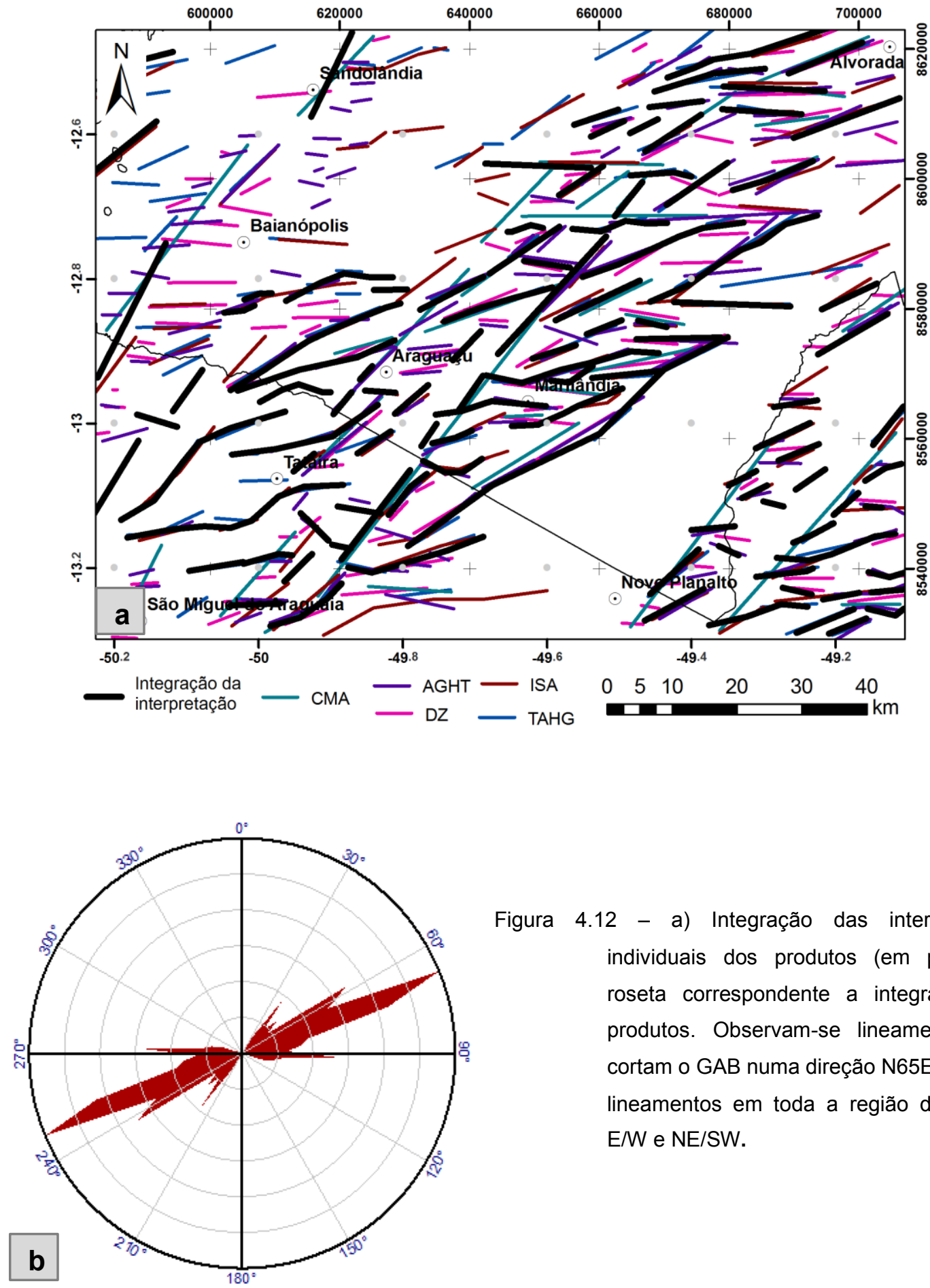

Figura 4.12 - a) Integração das interpretações individuais dos produtos (em preto); b) roseta correspondente a integração dos produtos. Observam-se lineamentos que cortam o GAB numa direção N65E. Além de lineamentos em toda a região de direção E/W e NE/SW. 
Ainda, de acordo com Isles e Rankim (2013), outra etapa é a observação de descontinuidade e padrão de tendência, tipicamente mais subjetiva e geralmente requer um julgamento pessoal. Porém, é tão importante quanto às unidades magnéticas interpretadas nos dados aeromagnéticos. Falhas, fraturas, zonas de cisalhamento, contatos discordantes são as fontes geológicas de descontinuidades mais comuns e espera-se que sejam frequentemente reconhecidas nos dados aeromagnéticos. Ressalta-se que existe uma variedade de características lineares perceptíveis na imagem aeromagnética, algumas das quais não estão relacionadas diretamente ou simplesmente a falhas e contatos afetando as unidades de rochas magnéticas delineadas.

A próxima etapa é a separação dos diferentes domínios magnéticos que resultou em nove domínios determinados de acordo com a densidade e magnitude dos lineamentos (figura 4.13). No domínio 1 há poucos lineamentos, sendo bem definido no ASA como um baixo magnético. O domínio 2 tem uma densidade média de lineamentos, como pode ser observado no ISA e TAHG, sendo que o domínio próximo a Sandolândia é cortado por uma descontinuidade de direção aproximada NE/SW. O domínio 3 é caracterizado por uma baixa densidade de lineamentos, sendo um baixo no AGHT e um alto no ISA. Esta diferença, provavelmente, deve-se ao fato de que o $A G H T$ é um produto na qual sua amplitude depende da profundidade da fonte, sendo o domínio 3 uma fonte profunda. O domínio 4 é marcado por uma zona com lineamentos sigmoidais e baixo magnético. O domínio 5 localiza-se na região do GAB e caracteriza-se com 
um baixo magnético com poucos lineamentos. O domínio 6 é caracterizado pelo maior alto magnético na área de estudo e por ser cortado por vários lineamentos de direção E/W e ENE/WSW. O domínio 7, borda oeste do GAB, com uma maior densidade de lineamentos segmenta o domínio 5, como pode ser observado no ISA e TAHG. O domínio 8 apresenta-se como uma baixo magnético e poucos lineamentos, porém no TAHG é possível observar uma continuidade com o domínio 3 na parte norte do mapa. O domínio 9 não possui lineamentos representativos. A correlação com a geologia será apresentada na integração do capítulo 6
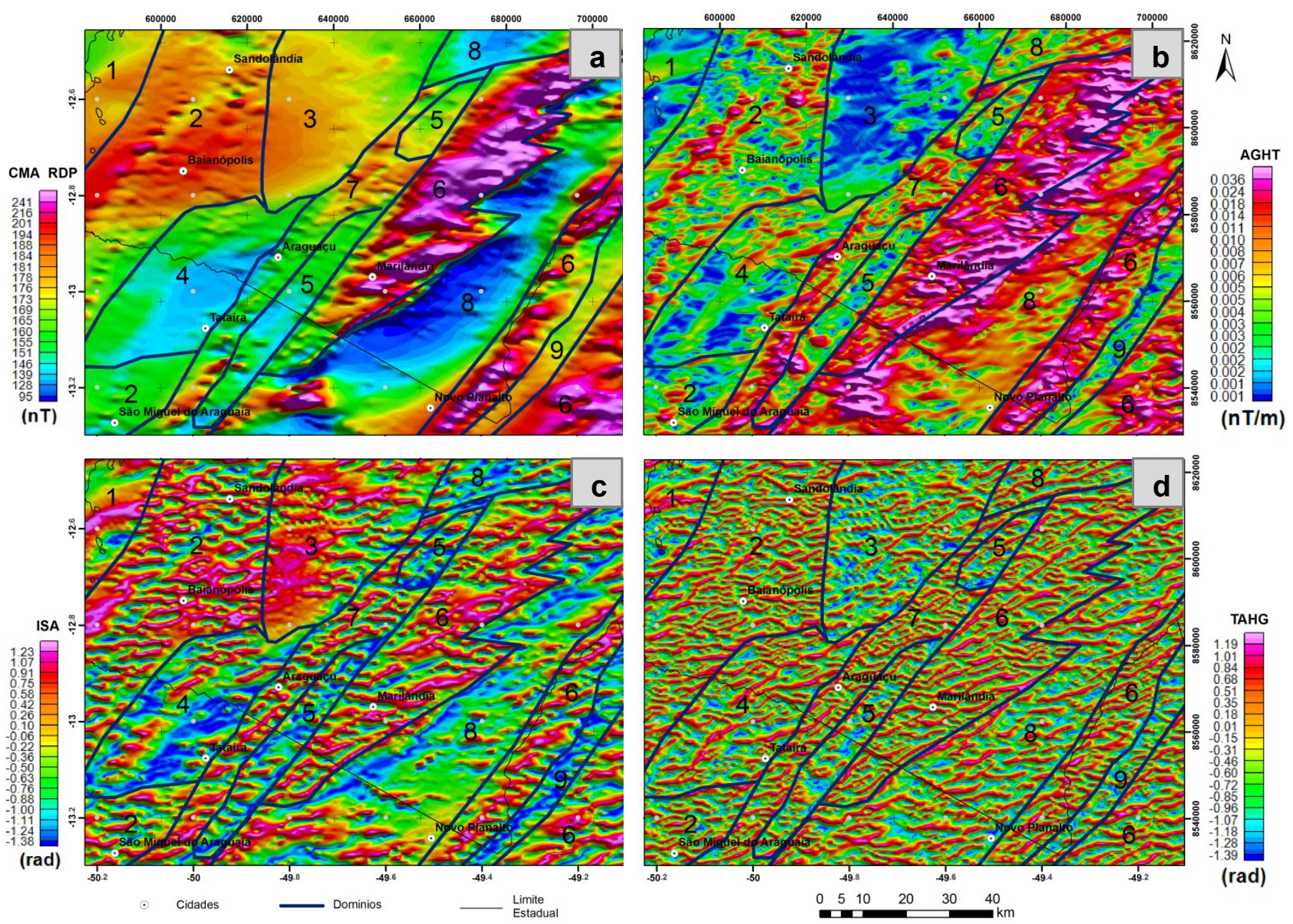

Figura 4.13 - Domínios interpretados com base na densidade e amplitude dos lineamentos. a) CMA reduzido ao polo; b) AGHT; c) ISA e d) TAHG. 


\section{Gravimetria}

\subsection{História e teoria do método}

O método gravimétrico mede o campo gravitacional terrestre para que a partir do processamento e redução dos dados se obtenha as diferentes densidades das rochas em subsuperfície. Tem como principio duas leis definidas pelo Sir Isaac Newton em Principia Mathematica (1687). A primeira é a Lei da gravitação de Newton (eq. 5.1), na qual define que entre duas partículas de massa $m$ existe uma força $(F)$ diretamente proporcional ao produto das massas e inversamente proporcional ao quadrado da distância $(R)$; a outra é a Segunda Lei de Newton (eq. 5.2) que ao ser relacionada com a eq. 5.1 demonstra a eq. 5.3, que a magnitude de aceleração devido à gravidade da Terra $(g)$ é diretamente proporcional a massa $(M)$ da Terra e inversamente proporcional ao quadrado de seu raio (Reynolds, 1997).

$$
\begin{aligned}
& F=\frac{G \cdot m \cdot M}{R^{2}} \\
& F=m \cdot g \\
& g=\frac{G \cdot M}{R^{2}}
\end{aligned}
$$

Onde $G=6.67 \times 10^{-11} \mathrm{~m}^{3} / \mathrm{kg} \cdot \mathrm{s}^{2}$;

A clássica história do uso da gravidade para o estudo da Terra começou no século XVII a partir das investigações geodésicas de tamanho, forma, massa e 
densidade do planeta utilizando um novo pêndulo para medir a gravidade (Hinze et al. 2013). Pierre Bouguer, em 1740, levou uma expedição ao Equador (antigo Peru) para determinar a curvatura do arco da Terra no Equador e poderia ter sido um dos primeiros a se atentar para a determinação da densidade média da Terra e consequentemente o valor de $\mathrm{G}$, através da necessidade indireta em seu trabalho geodésico. (LaFehr e Nabighian, 2012).

O geólogo John Michell com o objetivo de determinar a densidade da Terra criou um experimento utilizando a sensibilidade de atração entre duas pequenas quantidades de matéria, porém ele morreu antes que pudesse utilizar seu método. Então, o experimento foi passado para Francis John Hyde Wollaston que o entregou ao britânico Henry Cavendish, que após realizar pequenas alterações sem modificar o plano original, em 1798, utilizou o chamado Experimento de Cavendish para a obtenção da densidade da Terra (Cavendish, 1798). Seu experimento foi considerado o primeiro a ser utilizado para a determinação da constante gravitacional, porém de acordo com Clotfelter (1987) este não era o objetivo do experimento e a procura por esta constante começou somente há, aproximadamente, 100 anos depois.

No século XX houve uma grande expansão na ciência e na aplicação da exploração gravimétrica, principalmente para o mapeamento da subsuperfície para a indústria de óleo e gás, além do avanço computacional proporcionando metodologias de modelagem e processamento de dados, e desenvolvimento de levantamentos por satélites e aéreos (Hinze et al. 2013). Em 1900 existiam somente 2000 estações gravimétricas em todo mundo, todas com medidas de 
pêndulos. No começo de 1930, com o desenvolvimento da balança de torção e do gravímetro de mola, a coleta dos dados se tornou mais viável e com uma maior resolução, sendo utilizada na indústria petrolífera, engenharia civil, militar e setores acadêmicos.

Rodrigues (2012) em comemoração aos 185 anos do Observatório Nacional lançou um livro com mais informações sobre a história da gravimetria no Brasil. De acordo com a autora, a gravimetria no Brasil teve início quando Cândido Baptista de Oliveira construiu um pêndulo de Foucault em outubro de 1851 no Imperial Observatório Nacional (ON), porém o levantamento gravimétrico no Brasil, de forma sistemática, foi inaugurado em 1955, quando o ON adquiriu o gravímetro Worden número 178, da Houston Technical Laboratories (EUA), através do Conselho Nacional de Desenvolvimento Científico e Tecnológico (CNPq). Em 1978 o Observatório Nacional implantou a Rede Gravimétrica Brasileira. Em 2012, já reunia um conjunto de 631 estações de alta precisão referidas à estação do gravímetro absoluto instalado em Vassouras.

\subsubsection{Geóide}

O campo gravitacional é normal a uma superfície equipotencial denominada geóide (fig. 5.1) e coincide com o nível médio dos oceanos quando se considera que não há a presença de maré ou correntes oceânicas (Reynolds,1997).

Por causa dessas complexidades, o geóide é aproximado pela rotação de uma superfície esferoidal oblatada de densidade uniforme, na qual possui uma formula similar ao de um elipsoide de revolução, chamado de elipsoide de 
referência. A diferença de altura entre um e outro pode chegar a ser menor que 50 m, com algumas exceções (Telford et al. 1990).

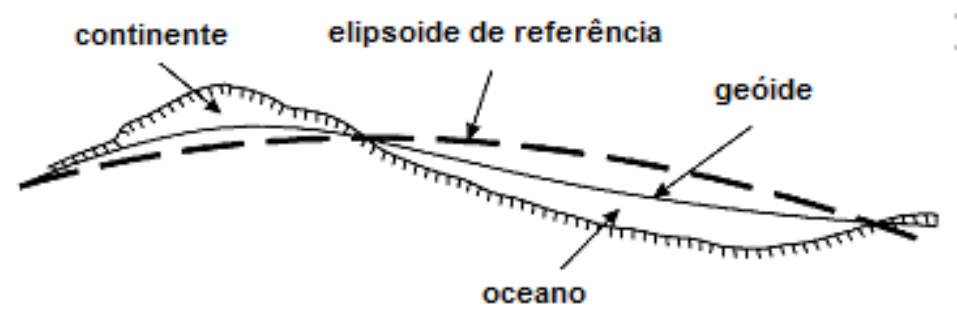

Figura 5.1 - Geóide e elipsoide de referência demonstrado em uma escala continental (Reynolds, 1997)

\subsubsection{Densidade}

A densidade de uma rocha depende principalmente de sua composição: rochas sedimentares $\left(1600\right.$ a $\left.2600 \mathrm{~kg} / \mathrm{m}^{3}\right)$, rochas ígneas $\left(2200\right.$ a $\left.3300 \mathrm{~kg} / \mathrm{m}^{3}\right)$ e metamórficas $\left(2400\right.$ a $\left.3500 \mathrm{~kg} / \mathrm{m}^{3}\right)$. Em rochas sedimentares a densidade dependeda porosidade, do grau de compactação, da cimentação, dos processos tectônicos e fluídos dos poros. Em geral, rochas máficas intrusivas (basaltos, gabros) são mais densas que as rochas félsicas (granitos, riolitos). Em rochas metamórficas é aumentada quanto maior for o grau metamorfismo e diminuição de acidez (Reynolds, 1997).

Observa-se que as variações de densidade em rochas de interesse em exploração, geralmente, não são grandes, mas anomalias são causadas pelo contraste lateral de densidade, não pela densidade absoluta (LaFehr e Nabighian, 2012). 


\subsection{Aplicações do método}

A partir da aquisição e processamento dos dados é possível realizar a análise de anomalias gravimétricas, que são indicações diretas da soma das variações de contrastes laterais de densidade em diferentes profundidades, podem estender da superfície terrestre ou marítima a profundidade que varia de 10 metros a mais de $100 \mathrm{~km}$ (LaFehr e Nabighian, 2012).

Este método tem sido largamente utilizado para a determinação da localização de bacias sedimentares e para interpretação de suas estruturas fornecendo informações importantes sobre os mecanismos de formação das bacias, além de estimativas de profundidade e geometria do embasamento e diferenciar camadas de sal, tendo sua importância histórica na indústria petrolífera. Também pode ser utilizado para identificar antigas zonas de sutura, estudos geológicos regionais, determinação de compensação isostática, exploração de depósitos minerais, detecção de cavidades em sub-superfície, determinação de espessura glacial, estudo das oscilações da maré, arqueologia (localização de tumbas com micro gravimetria), geodésia, monitoramento de vulcões e militar (Reynolds, 1997). 


\subsection{Aquisição dos Dados}

A aquisição dos dados terrestres utilizados neste trabalho durante 17 dias, quando foram adquiridos dados gravimétricos e geodésicos, simultaneamente, em estradas cobrindo toda a região do Gráben Água Bonita (GAB). As estações cortavam o GAB perpendicularmente e paralelamente com um espaçamento de quinhentos metros e um quilômetro, respectivamente. No total, adquiriram-se 498 estações (figura 5.2) com o gravímetro CG5 da Scintrex (SN 071140317) pertencente ao IG/UnB. Foram adicionados ao banco de dados 147 estações gravimétricas adquiridas na porção central do GAB que foram adquiridas por Carvalho (2011) utilizando o Lacoste e Romberg G613, em 2010, com um espaçamento de aproximadamente 800 metros na rodovia TO-181, e a cada 1500 metros em estradas não pavimentadas ou secundárias. 


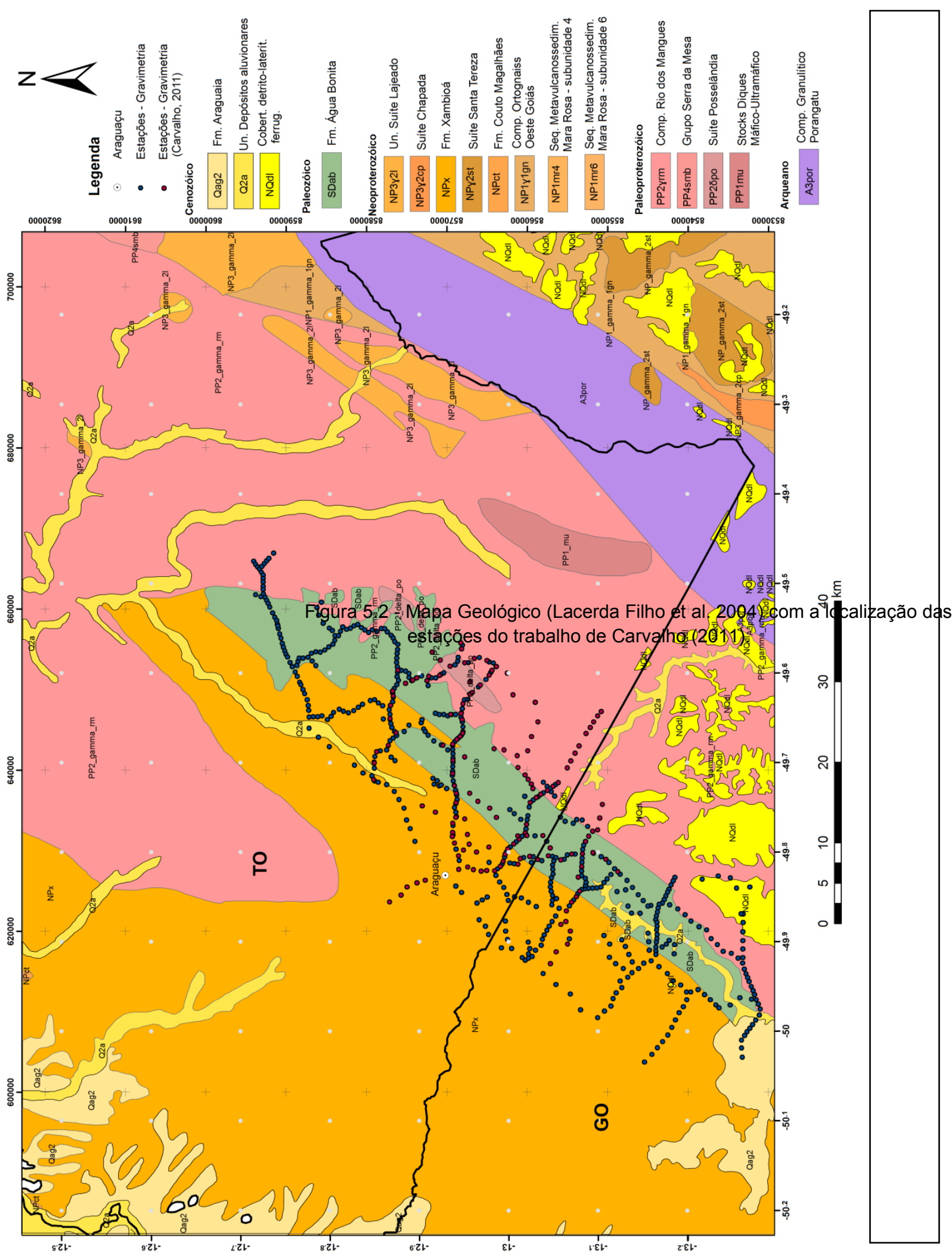


A base dos dados gravimétricos (figura 5.3) situada no pátio de entrada da Paroquia Imaculada Conceição de Araguaçu (TO) foi uma transferência da base localizada no Colégio Estadual de Porangatu (GO) realizada ao longo deste trabalho. O valor encontrado para a base de Araguaçu foi de 978173,908 mGal.

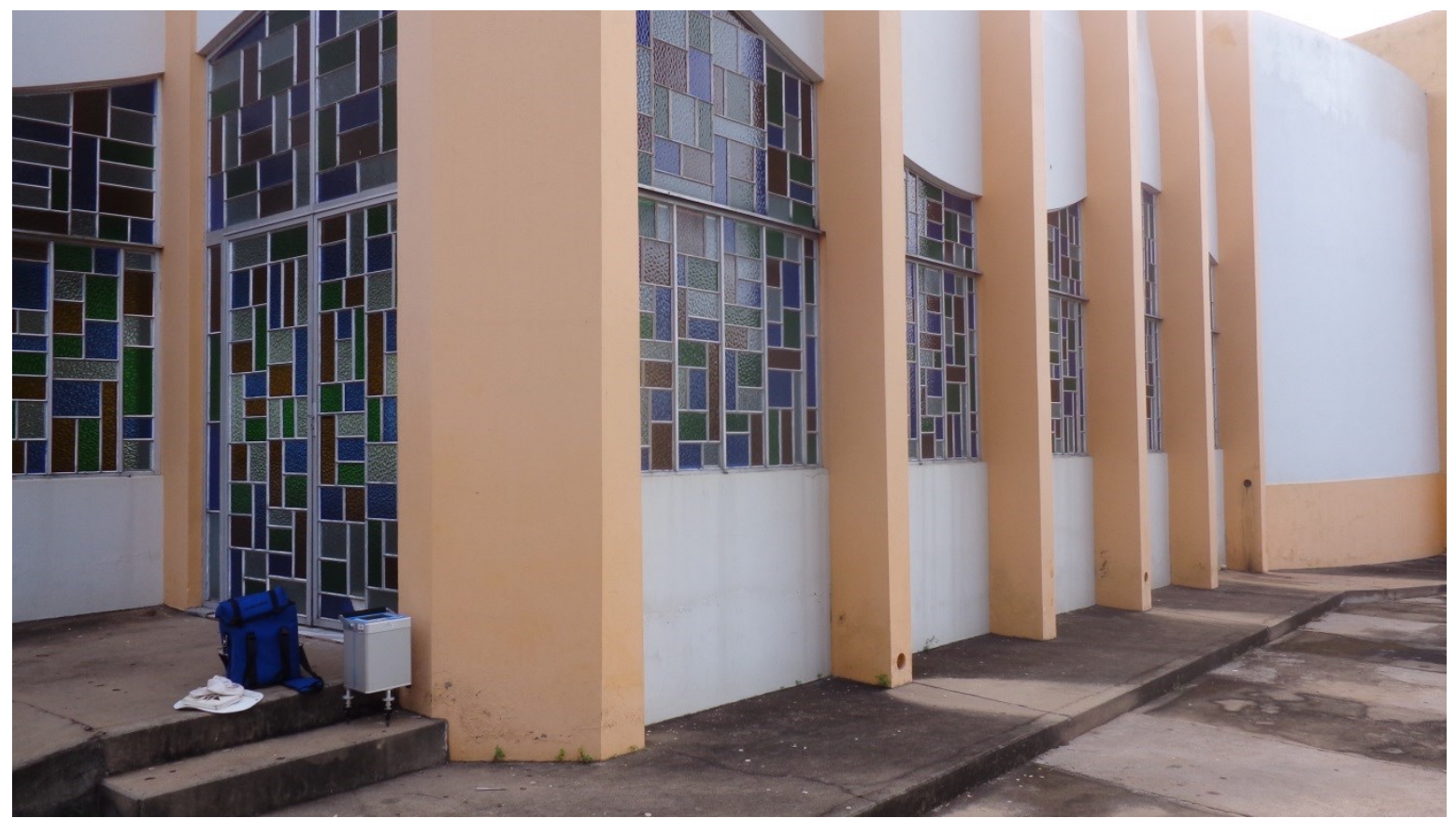

Figura 5.3 - Base gravimétrica localizada na Paroquia Imaculada Conceição de Araguaçu (TO).

Para a aquisição dos dados geodésicos foi utilizado o Receptor GNSS/RTK (Global Navigation Satellite System/Real Time Kinematic) Hiper Lite ${ }^{+}$da Topcon (figura 5.4) no modo semi-cinemático (stop and go). Neste método deve-se ficar na primeira estação no modo estático e esperar por pelo menos 30 minutos para que se possa resolver a ambiguidade e manter a configuração durante todo o levantamento, tomando o cuidando para não obstruir o recebimento do sinal durante toda a aquisição. Entre a passagem de um ponto de aquisição para o 
outro se coloca no modo cinemático e quando estiver na estação deve-se mudar para estático e esperar aproximadamente 5 minutos enquanto é feita a gravação.

As estações base utilizadas para o processamento dos dados geodésicos foram as estações de Gurupi-TO (TOGU) e São Félix do Araguaia - MT (MTSF) pertencentes à Rede Brasileira de Monitoramento Contínuo (RBMC).

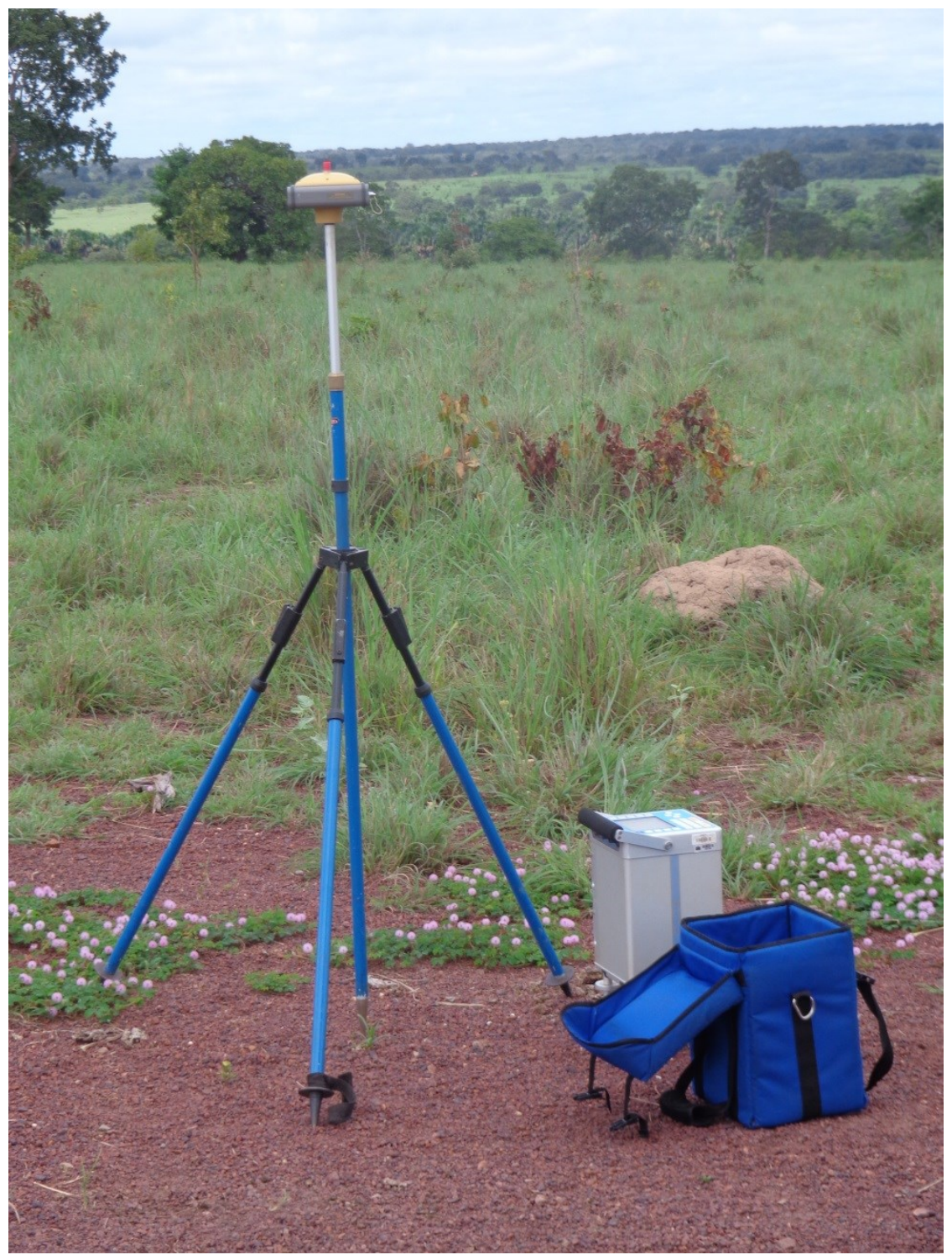

Figura 5.4 - Exemplo de uma estação com aquisição de dados com Receptor GNSS/RTK simultaneamente a aquisição dos dados gravimétricos com o gravímetro CG5. 


\subsection{Processamento dos Dados}

\subsubsection{Redução dos dados}

A magnitude do campo gravitacional depende da latitude, elevação, topografia ao redor do ponto de medida, maré e variação de densidade. Dessa forma, é necessário que sejam feitas as reduções gravimétricas para que todos os dados estejam ajustados a um mesmo referencial. As reduções gravimétricas realizadas são: de latitude, terreno, maré, Bouguer e Ar-Livre. No processamento dos dados foi utilizada a extensão gravity do Oasis Montaj da Geosoft.

\subsubsection{Altitude Elipsoidal e Ortométrica}

As alturas obtidas no levantamento geodésico são tipicamente alturas sobre o elipsoide de referência. Porém a altura que interessa, para exploração, é a ortométrica que é definida como sendo altura media do nível do mar e foi utilizada para este processamento. Por convenção o sinal é considerado positivo quando se move para acima do geóide. A variação global do geoide-elipsoide varia de +75 a -100m (LaFehr e Nabighian, 2012).

Para este trabalho utilizou-se o MAPGEO2010, concebido pelo Instituto Brasileiro de Geografia e Estatística (IBGE) que possui uma resolução de 5' de arco. A eq. 5.4 mostra como converter a altitude elipsoidal $(h)$ em altitude ortométrica $(H)$, onde $N$ é a altura ou ondulação geoidal que pode ser positivo ou negativo.

$$
H=h-N
$$




\subsubsection{Correção de Drift}

Os gravímetros possuem uma variação na leitura de acordo com o tempo. Esta variação é causada por causa da fadiga do material das molas e sua variação é aproximadamente linear. Para fazer simplificar e realizar esta correção ocupa-se a base no começo e no fim do dia para se observar a taxa de variação. Também é recomendada a aquisição de pelo menos uma medida repetida em cada estação base para maior acurácia.

\subsubsection{Correção de maré}

Medidas gravimétricas estão sujeitas a variações no tempo a partir da maré terrestre, da qual seus efeitos são função tanto do tempo como da localização (Telford et al. 1990). A maioria dos efeitos é causada pela posição do sol e da lua relativa a cada estação, mas mais efeitos secundários complexos (muito menor em amplitude) também são resultados da deformação da variação diurna, carga oceânica, e outras contribuições menores (Longman, 1959).

O efeito da maré pode ser de 0,3 mGal num período de seis horas, mas geralmente é menor e flutua como uma função com comportamento quase sinusoidal num período de 12 horas. Neste trabalho optou-se por corrigir após a aquisição utilizando o software de processamento. A partir da correção do drift e da maré obtém-se o valor de gravidade observada $\left(g_{o b s}\right)$. 


\subsubsection{Correção de Latitude}

Entre as varias razões do valor da gravidade variar na superfícieestá a forma da Terra. O raio do polo $(6357 \mathrm{~km})$ é, aproximadamente, $21 \mathrm{~km}$ a menos que o raio equatorial $(6378 \mathrm{~km})$, tornando a força gravitacional maior nos polos (cerca de $0,7 \%$ ). Além disso, por causa da rotação da Terra, existe uma força centrífuga (figura 5.5) atuando conforme o aumento da velocidade de rotação que é maior no equador $(1674 \mathrm{~km} / \mathrm{h})$ e decresce a zero nos polos. A resultante gravitacional nos polos (5186 mGal) é maior do que no equador e varia de acordo com a latitude, como deduzido por Clairaut em 1743. No século 20 , baseados na teoria de Clairaut, uma fórmula teórica foi desenvolvida para calcular o valor gravitacional resultante com base na latitude geográfica e nível do mar relativo (Reynolds, 1997).

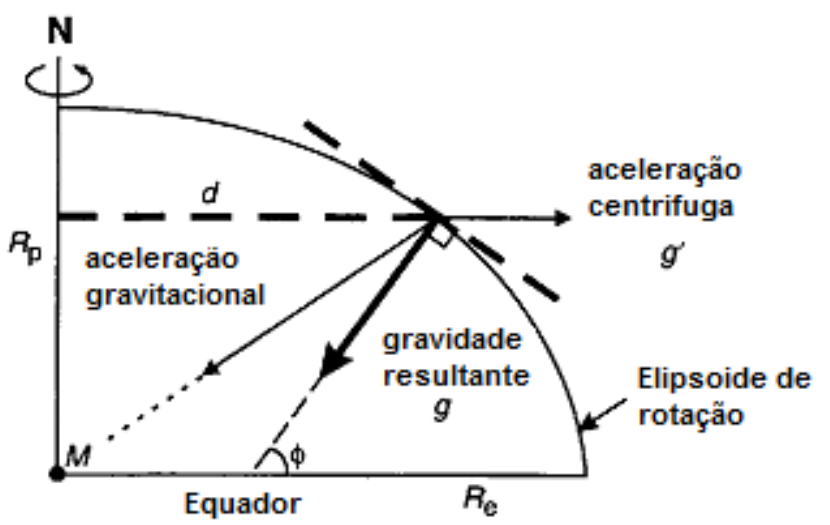

Figura 5.5 - Resultante da aceleração centrífuga e da aceleração devido à gravidade (Reynolds, 1997). 
Durante o século $\mathrm{XIX}$ e $\mathrm{XX}$, o aumento do número de medidas e cooperação internacional levaram ao padrão de fórmulas desenvolvido pelos geodesistas, mas também utilizada em exploração, relacionada à gravidade teórica ( $g$ ) (LaFehr e Nabighian, 2012). Em 1930 a International Union of Geodesy and Geophysics adotaram a Fórmula Internacional da Gravidade, depois utilizando cálculos refinados e um melhor ajuste dos parâmetros terrestres, foi definida a Geodetic Reference System 1967 (GRS67).

A fórmula de 1930 tem como base medidas de pêndulos realizadas em 1906 em Potsdam, a qual se acreditava ter um erro aproximado de 14 mGal. As diferenças entre as fórmulas não são importantes em exploração desde que se use a mesma para todo o levantamento (LaFehr e Nabighian, 2012). Com o avanço computacional e instrumental outras fórmulas foram calculadas como a de 1984 (eq. 5.5) utilizada neste processamento, de acordo com Blakely (1995).

$$
g_{t}=\frac{978032.67714 *\left(1+0.00193185138639 *\left(\sin ^{2}(\varphi)\right)\right.}{\sqrt{\left(1-0.00669437999013 *\left(\sin ^{2}(\varphi)\right)\right.}}
$$

A gravidade teórica é subtraída da gravidade observada na estação, processo conhecido como correção de latitude. Se não corrigido, um gradiente norte-sul poderá ser observado nos dados. 


\subsubsection{Correção Ar-livre}

A correção Ar Livre (eq. 5.6) é empregada para compensar os efeitos da diferença de altitude entre as estações em relação ao geóide ou a um nível de referência arbitrário, pois a força gravitacional diminui com a distância. A correção ar-livre é a diferença entre o valor gravitacional medido ao nível do mar e a elevação $h$ sem considerar a densidade das rochas entre estes níveis (Reynolds, 1997). É definida como:

$$
\delta g_{A L}=0,03086 h \quad m G a l
$$

\subsubsection{Correção Bouguer}

Esta correção parte do princípio de que com a mudança da elevação as medidas realizadas sofrem influências de excessos ou déficits de massa entre a estação e o nível de referência. Com um aumento da massa a força gravitacional também aumenta. Para corrigir este efeito utiliza-se a correção Bouguer (eq. 5.7) (Reynolds, 1997).

Esta correção assume que a medida foi realizada sobre uma placa de área infinita e espessura constante $h$, na qual a constante de densidade é $\rho$, então a atração gravitacional vertical resultante é igual a (Telford et al. 1990):

$$
\delta g_{B}=0.04196 \rho h \quad m G a l
$$

A densidade utilizada no processamento foi de $2,67 \mathrm{~g} / \mathrm{cm}^{3}$, densidade média da crosta. 


\subsection{Anomalias Ar-Livre e Bouguer}

\subsubsection{Anomalia Ar-Livre}

Anomalia Ar-Livre (eq. 5.8) leva em consideração a variação da latitude e da altura em relação ao datum de referência. Nesta anomalia, assume-se que não há o efeito de massa entre a altura do ponto de medida e o datum de referência, sendo utilizada principalmente em dados marinhos (Hinze et al. 2013). É calculada utilizando o $g_{o b s}$ e com as correções de latitude $\left(g_{t}\right)$ e Ar Livre $\left(\delta g_{A L}\right)$ com a equação 5.8. A figura 5.6 é o resultado da anomalia ar livre para a área de estudo. Pode se observar um baixo gravimétrico segmentado na região onde se encontra o GAB.

$$
\Delta g_{\text {Ar Livre }}=g_{o b s}-g_{t}+\delta g_{A L}
$$

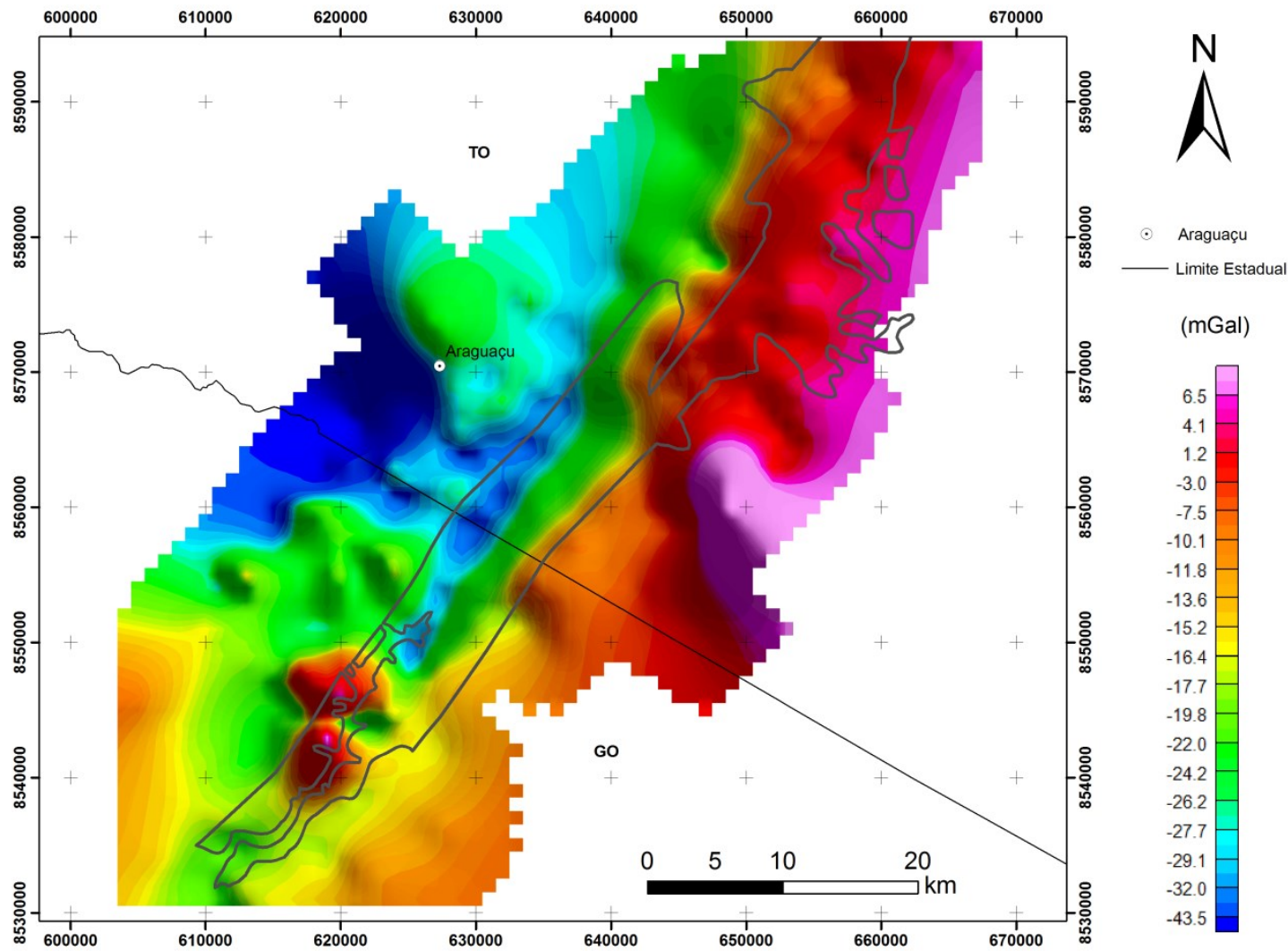

Figura 5.6 - Mapa de Anomalias Ar Livre e limites do GAB de acordo Lacerda Filho et al. (2004). 


\subsubsection{Anomalia Bouguer}

Se não existissem variações laterais na densidade da crosta, após todas as correções, a anomalia Bouguer e Ar Livre iriam ser iguais. Porém onde existe variação lateral, resulta na chamada anomalia Bouguer (eq. 5.9). De maneira geral, as anomalias Bouguer são positiva em regiões oceânicas, enquanto em áreas montanhosas, as anomalias são negativas. Isto indica que as rochas dos oceanos são mais densas que o normal, enquanto as das montanhas são menos densas (Telford et al. 1990). É calculada com o $g_{o b s}$ e com as correções de latitude $\left(g_{t}\right)$, Ar Livre $\left(\delta g_{A L}\right)$, Bouguer $\left(\delta g_{B}\right)$ e Terreno $\left(\delta g_{T}\right)$.

$$
\Delta g_{\text {Bouguer }}=g_{o b s}-g_{t}+\left(\delta g_{A L}-\delta g_{B}+\delta g_{T}\right)
$$

A correção de terreno $\left(\delta g_{T}\right)$ é realizada para eliminar a interferência causada pela massa resultante da topografia que se encontra ao redor do ponto de medição. Existem diversos métodos para o cálculo desta correção. Neste trabalho, o software utilizou a combinação dos métodos descritos por Nagy (1966) e Kane (1962). Primeiro é criado um grid com a correção de terreno regional a partir de um modelo digital de terreno regional sobre um modelo de terreno local com uma amostragem melhor e depois este grid é usado para corrigir os efeitos do terreno. Quando esta correção é realizada tem-se a anomalia Bouguer completa (figura 5.7). 


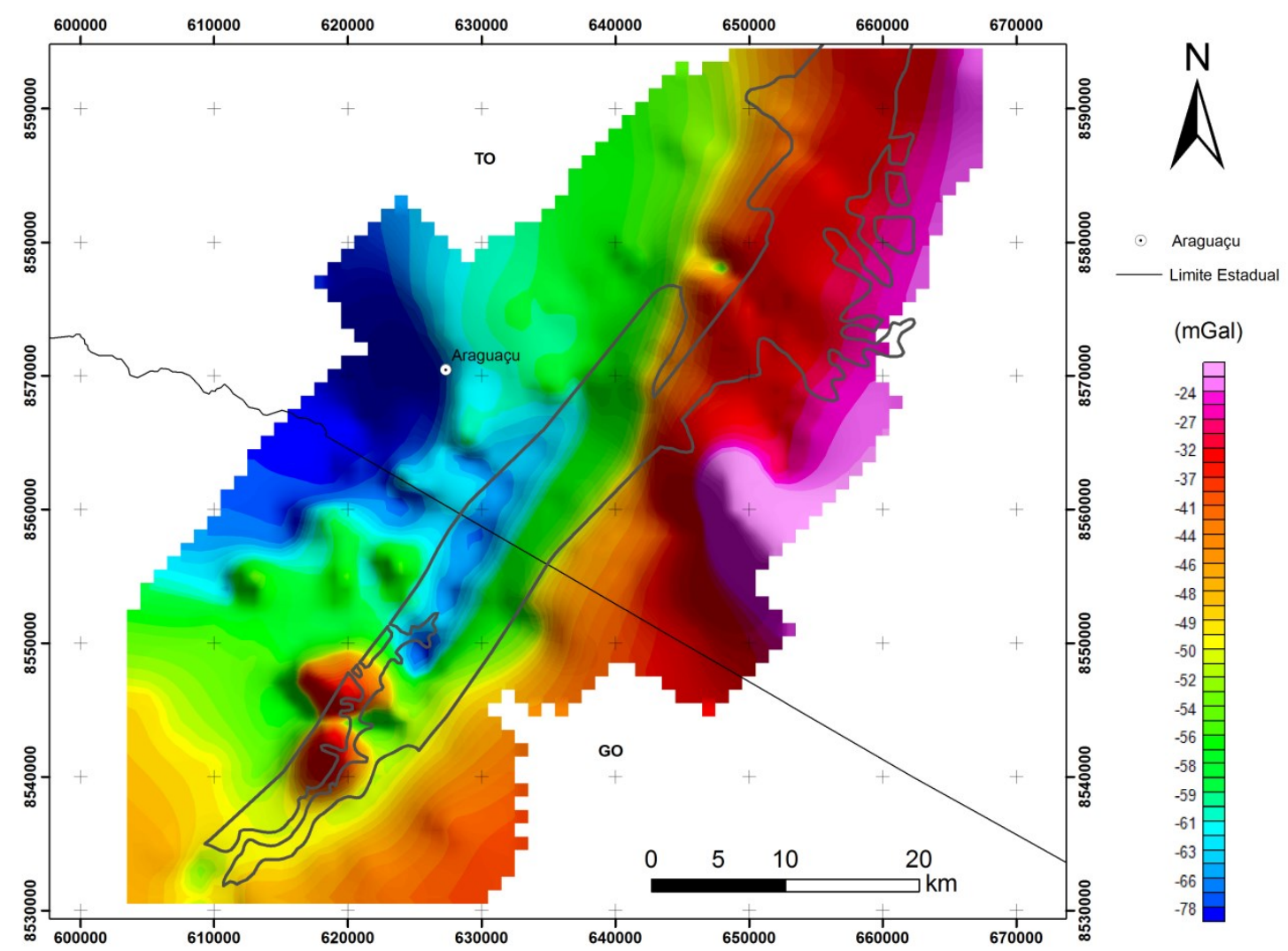

Figura 5.7 - Anomalia Bouguer Completa e limites do GAB de acordo Lacerda Filho et al. (2004).

O mapa de anomalia Bouguer Completa (figura 5.7) possui efeitos regionais que resultam em valores mais baixos a oeste, representado pela Faixa Araguaia, e outros mais altos a leste, no Complexo Rio dos Mangues. Para retirar este efeito foram testados vários filtros e optou-se por utilizar um Butterworth com um grau polinominal 2 que resultou no efeito que pode ser observado na figura 5.8a.

Com a retirada dos efeitos regionais (figura $5.8 \mathrm{~b}$ ) observaram-se baixos gravimétricos mais definidos na região do gráben cujo baixo com maior amplitude dentro de seus limites está localizado na porção centro sul. Como a anomalia possui uma variação mais brusca a leste, esta borda deve ser mais verticalizada que a da borda oeste, que varia mais suavemente, além disso, lineamentos N65E cortam o GAB e o segmentam em um alto gravimétrico. 

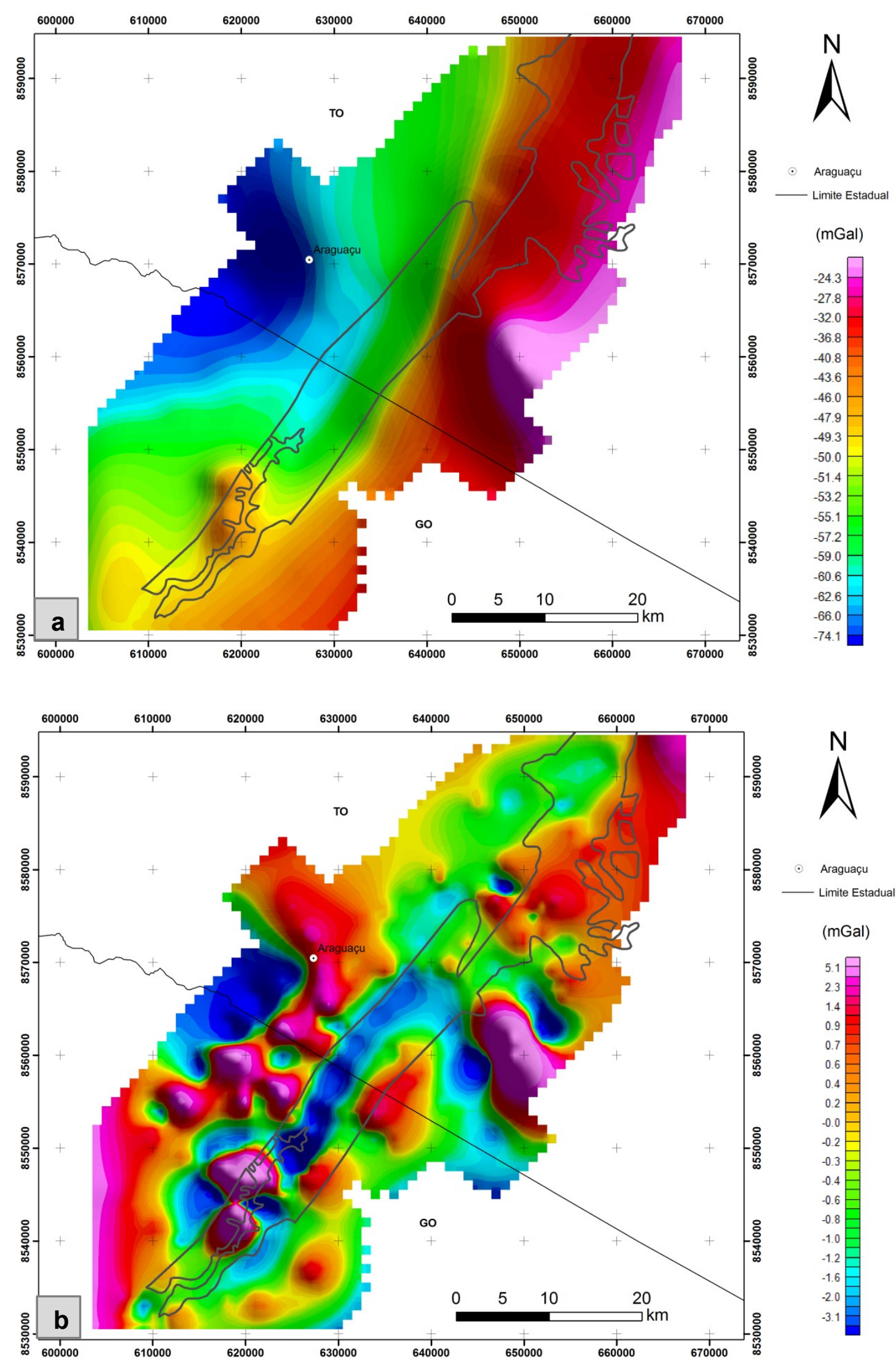

Figura 5.8 - a) Efeito regional retirado da Anomalia Bouguer; b) Anomalia Bouguer Completa sem os efeitos regionais. Limites do GAB de acordo Lacerda Filho et al. (2004). 


\section{Análise de Profundidade e integração dos dados}

A interpretação dos dados geofísicos e geológicos já realizados nos capítulos anteriores juntamente com a análise de profundidade foi utilizada para a criação de um mapa integrado com as principais informações.

\subsection{Análise de Profundidade}

A análise de profundidade dos dados magnéticos e gravimétricos foi feita utilizando os métodos do espectro de potência, matched filter e Deconvolução de Euler para que a partir destes resultados seja feita a modelagem gravimétrica e o modelo geológico do GAB.

\subsubsection{Análise do Espectro de Potência}

O método desenvolvido por Spector e Grant (1970) para a análise do espectro de potência de dados magnéticos e gravimétricos é um passo essencial no processamento dos dados. Com a utilização da Transformada de Fourier é realizada a análise do espectro de potência. Em geral, o campo potencial de anomalias é analisado em um gráfico com uma escala logarítmica no eixo y e número de onda no eixo x. Considerando um grid onde com varias fontes, o espectro em log pode ser interpretado e determinar estatisticamente a profundidade ao topo de fontes que podem ser relacionadas com a eq. 6.1:

$$
\log E(r)=\frac{-s}{4 \pi}
$$


A profundidade de um conjunto de fontes é determinado pela medida da declividade do espectro de energia $(s)$, dividido por $4 \pi$. O espectro (figura 6.1) pode ser interpretado por retas que representam as fontes. Quando a fonte é profunda caracteriza-se com um baixo numero de onda e vai aumentando conforme for mais rasa. O ruído caracteriza-se como uma reta horizontalizada no final do espectro antes da frequência de Nyquist, que define até quando é possível representar um sinal de forma que não ocorra o falseamento do sinal e acima dessa frequência o sinal deve ser desconsiderado.

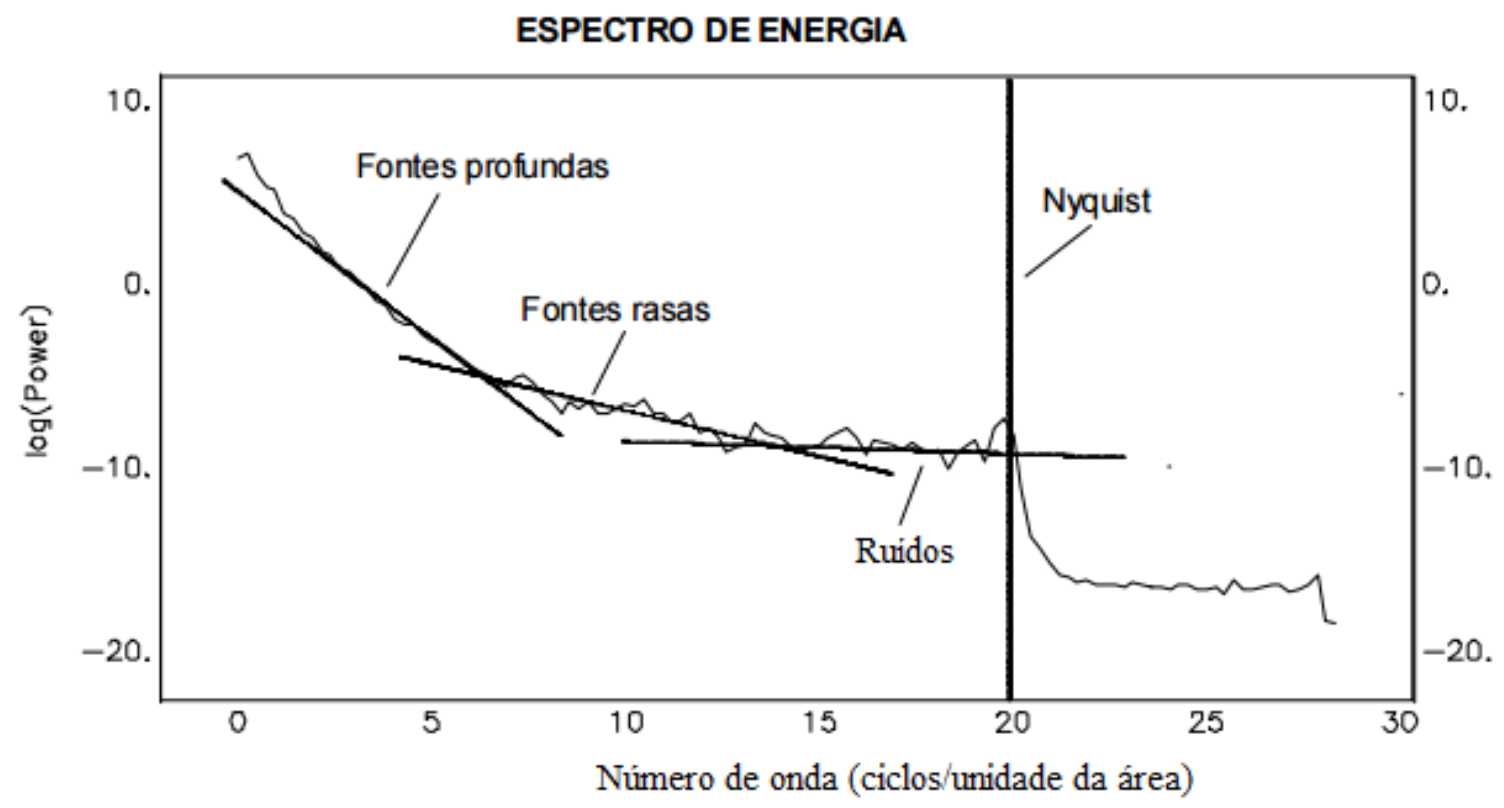

Figura 6.1 - Espectro de Potência e a representação das fontes mais profundas, rasas e ruído (Whitehead, 2009).

O campo magnético anômalo sem ser reduzido ao polo foi utilizado para a magnetometria e na gravimetria a anomalia Bouguer Completa. Como o resultado depende de uma boa determinação de retas e da equação obtida pela regressão linear, para a separação foi utilizado o coeficiente de determinação $R^{2}: \mathrm{Na}$ magnetometria (figura 6.2) e gravimetria (figura 6.3) observou-se uma boa 
correlação em todas as retas (valor próximo a 1) exceto para o ruído e para a reta que representa os dados a partir da frequência de Nyquist, porém este resultado é esperado pois os dados apresentam-se com distribuição aleatórios a partir desta frequência.

Os resultados encontrados para magnetometria foram: a) fontes mais profundas: a $18,187 \mathrm{~km}$; b) fontes intermediárias a $8,059 \mathrm{~km}$; c) fontes rasas a 2,391 km, 1,652 km e 1,012 km; d) ruído a 421 metros e e) Nyquist aproximadamente a partir de 0,95 ciclos $/ \mathrm{km}$. Para a gravimetria: a) fonte mais profunda a $9,083 \mathrm{~km}$; b) fontes intermediária a 3,335 e 2,456 km e c) fonte mais rasa $1,397 \mathrm{~km}$ d) ruído a 333 metros.

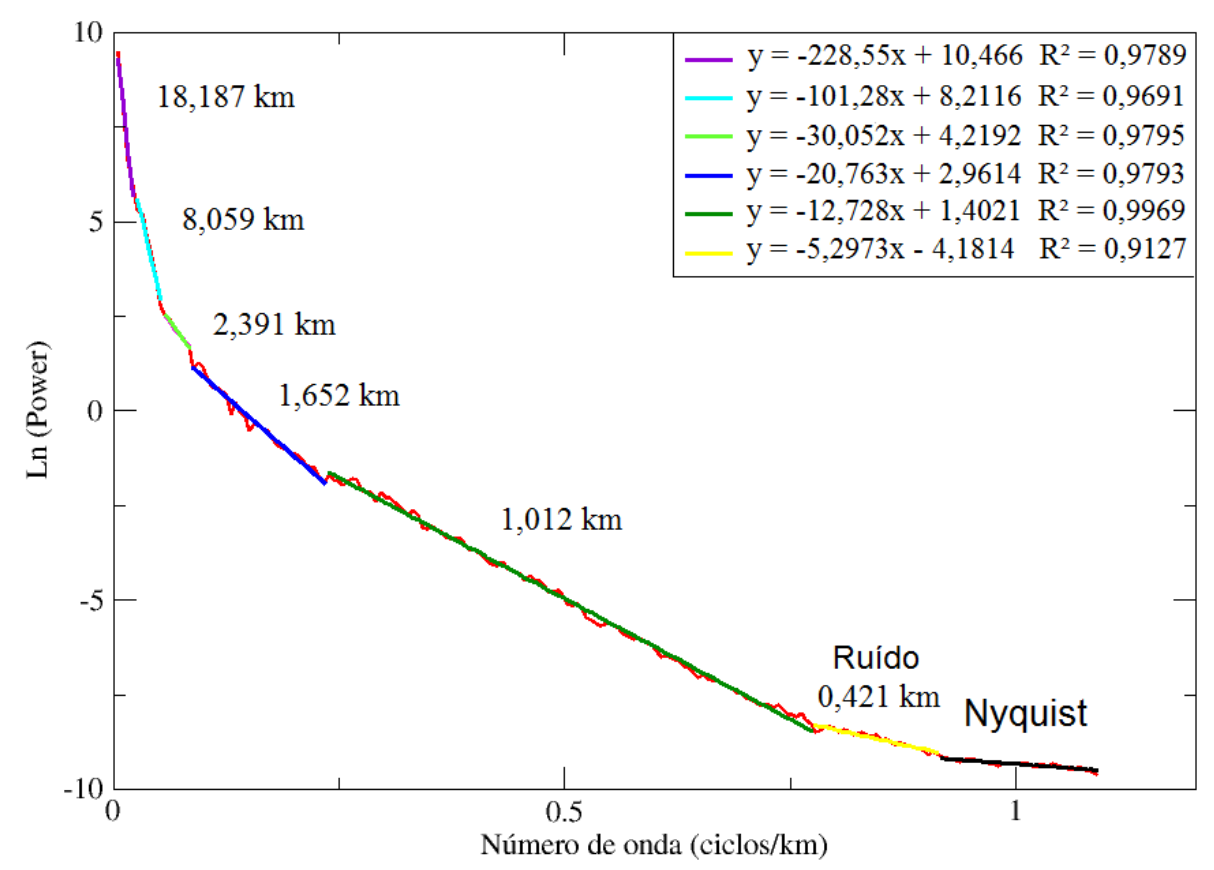

Figura 6.2 - Espectro de Potência para os dados magnéticos e representação das fontes mais profundas, rasas, ruído e Nyquist. 


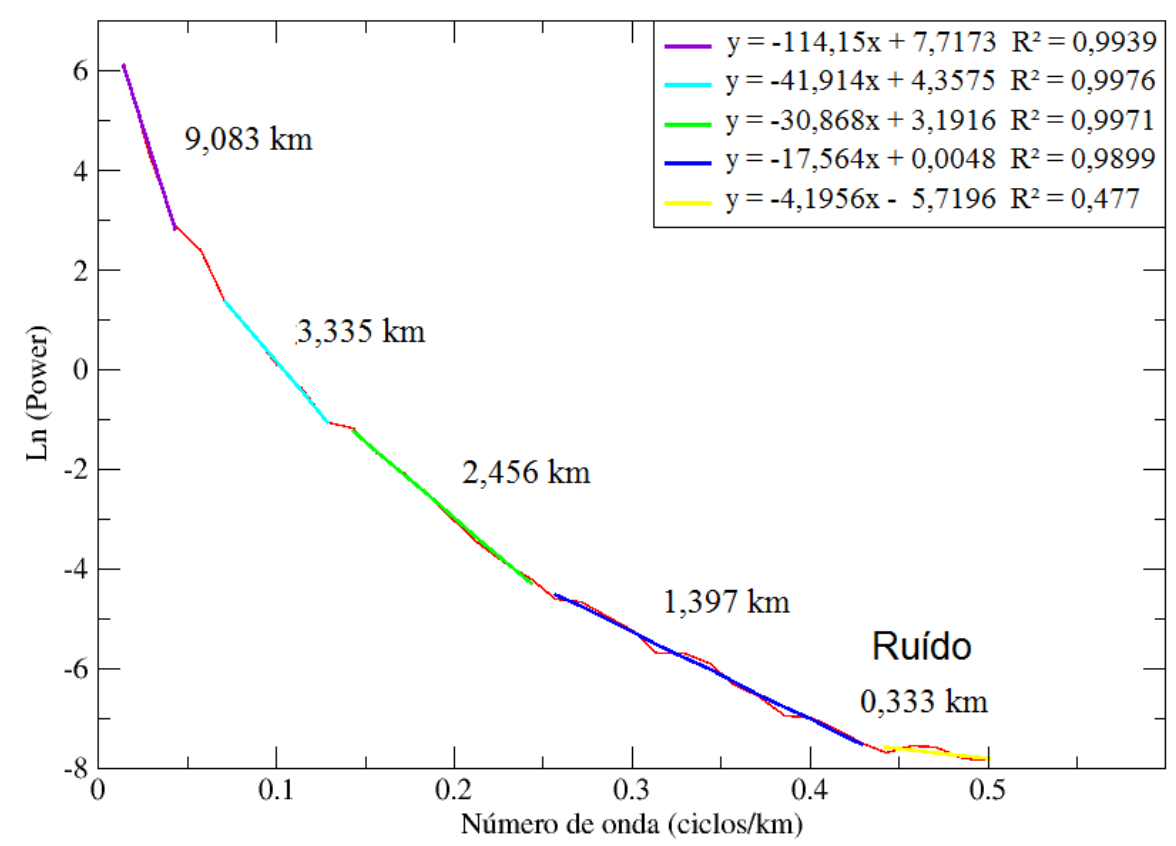

Figura 6.3 - Espectro de Potência para os dados gravimétricos e representação das fontes mais profundas, rasas, ruído e Nyquist.

\subsubsection{Matched Filter}

Numerosos métodos de campo potencial existem para atenuar os sinais de interesse de dado magnético, sendo que muitos destes métodos fazem uso da frequência espacial (ou número de onda) utilizando a Transformada de Fourier (Sheriff, 2010). O matched filter pode ser utilizado para separar os pequenos comprimentos de onda da anomalia, originadas a profundidades rasas, daquelas com um maior comprimento de onda que geralmente se originam em maiores profundidades (Philips, 2001; Blakely, 2005). Sua utilização tem uma longa historia na aplicação de dados aeromagnéticos a estudos tectônicos, estrutural e pesquisa de exploração (Nabighian et al. 2005) 
O método se baseia em fontes equivalentes que são camadas fictícias abaixo da superfície de observação onde a distribuição de magnetização produz o campo magnético residual. Como Spector e Grant (1970) mostraram que as camadas fontes a diferentes profundidades podem ser observadas com a análise do espectro de potência; Syberg (1972) propôs o matched filter, no domínio da frequência, que caracteriza partes do espectro de potência para diferentes características (figura 6.4). A filtragem do campo magnético total extrai as frequências correspondentes a variação de profundidade (Phillips, 2001). A separação é mais bem sucedida quando o sinal de interesse domina uma banda do espectro de potência do campo.

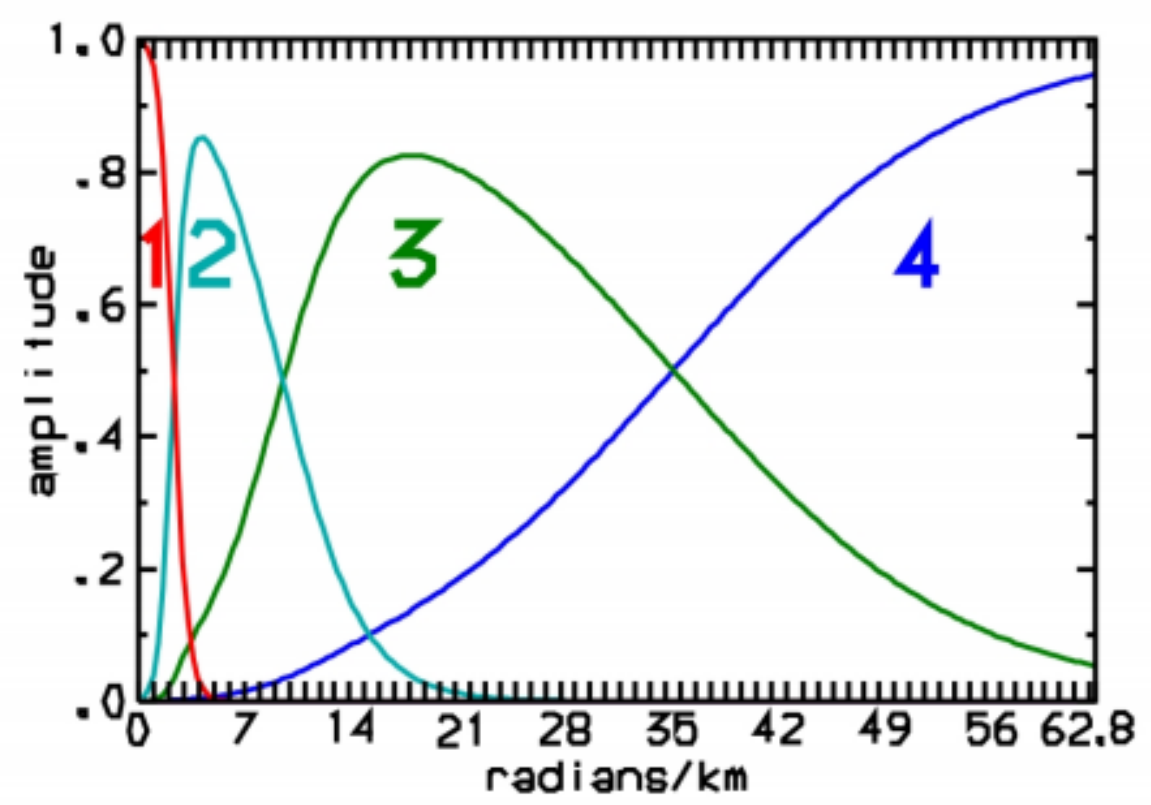

Figura 6.4 - Exemplo de um resultado do matched filter (Phillips, 2001). Diferentes comprimentos de onda para 4 camadas a diferentes profundidades. 
Na magnetometria o espectro de potência (figura 6.5) foi gerado através do CMA, as retas foram marcadas para a separação do comprimento de onda e obteve-se resultado nas seguintes profundidades (figura 6.6): a) 28,206 km; b) $8,642 \mathrm{~km}$; c) 1,620 km e d) 326 metros, equivalente ao ruído.

Ao comparar este resultado das profundidades da magnetometria com o do espectro de potência do item 6.1.1, observa-se que a fonte mais profunda do espectro de potência está mais rasa que a do Matched Filter, isto pode ocorrer porque ao realizar a Transformada de Fourier utilizando o Magmap é retirada a superfície de tendência causada pelos grandes comprimentos de onda.
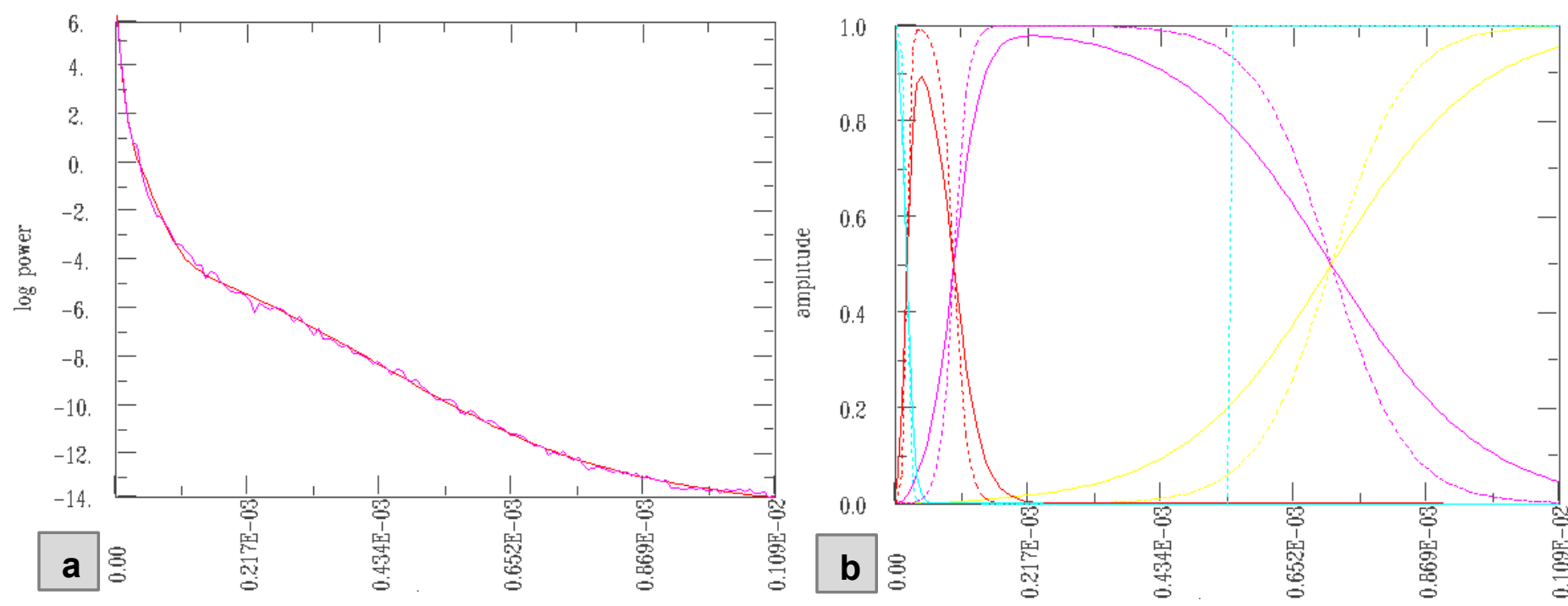

Figura 6.5 - a) Espectro de potência para a magnetometria; b) Diferentes comprimentos de onda para 4 camadas a diferentes profundidades. 

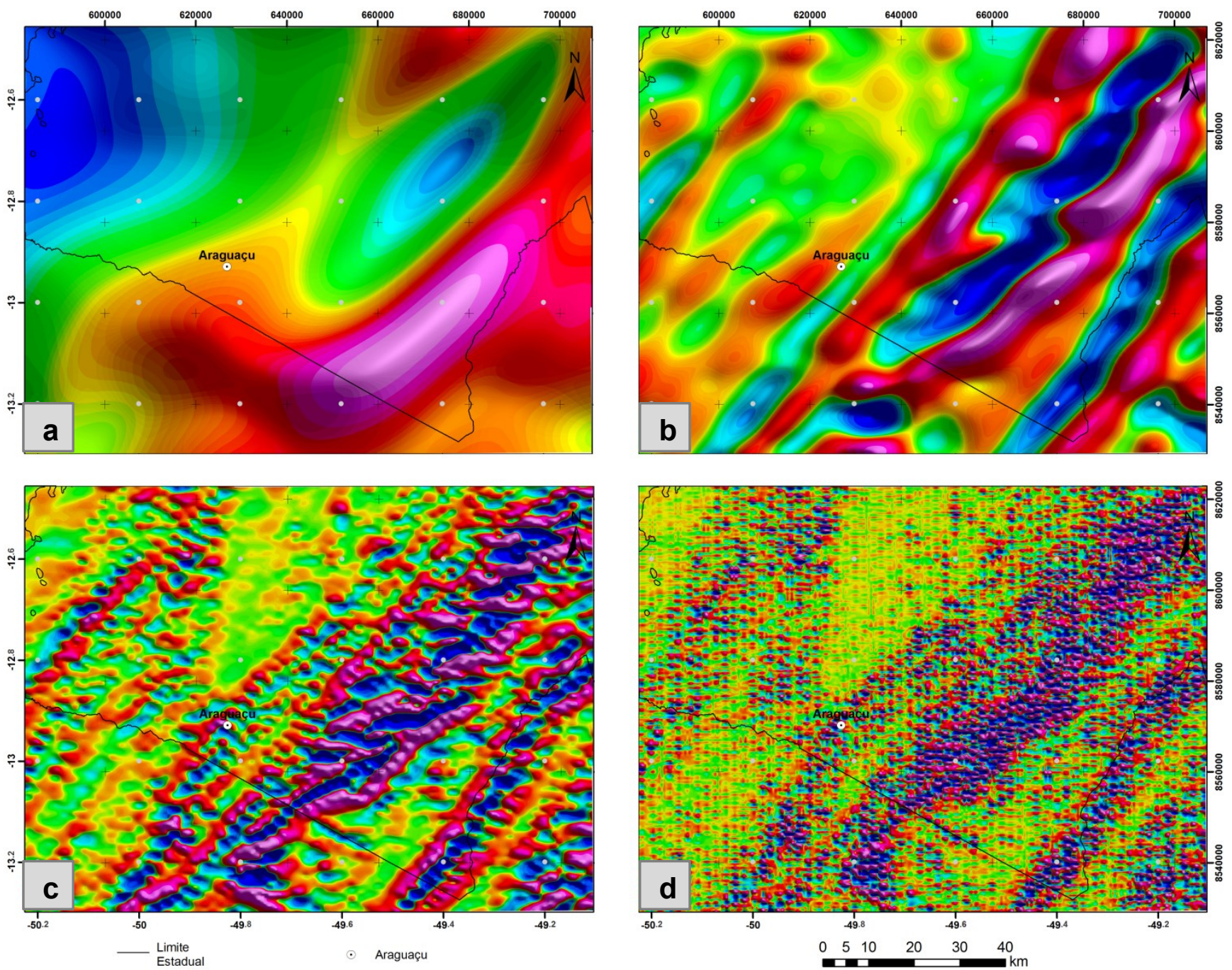

Figura 6.6 - Resultado do matched filter para a magnetometria: a) $28,206 \mathrm{~km}$; b) $8,642 \mathrm{~km}$; c) 1,620 km e d) 326 metros, equivalente ao ruído.

Com o intuito de se obter mais informações sobre o Lineamento Transbrasiliano, o resultado do matched filter a, aproximadamente, $8 \mathrm{~km}$ foi utilizado para se fazer um AGHT e um TAHG (figura 6.7). Desta forma foi possível observar lineamentos na região do Graben Água Bonita e um de grande expressão que se localiza no meio dessa região de influência do LTB. A utilização do TAHG em grids resultantes do matched filter aparenta ser uma boa ferramenta para o estudo de fontes mais profundas, considerando sua função de separar comprimentos de onda. 

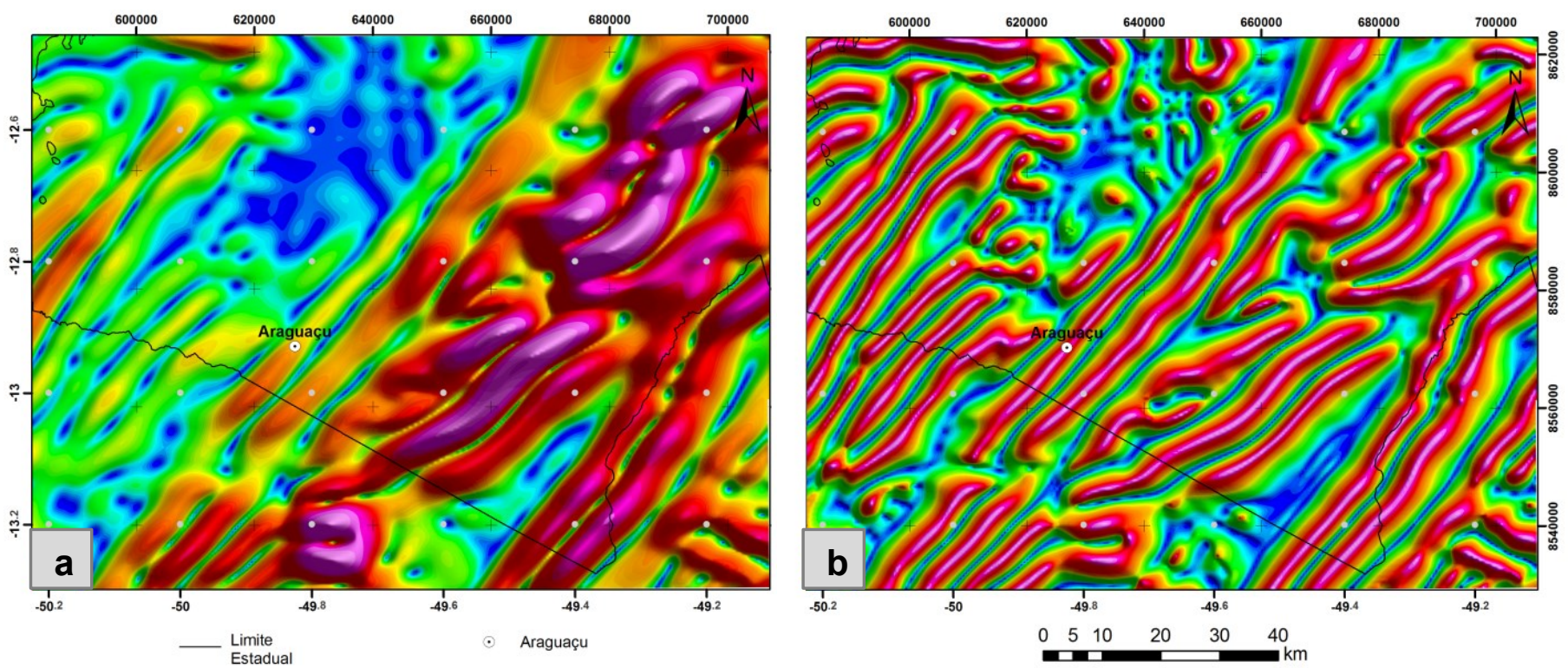

Figura 6.7 - Grid do Matched Filter a aproximadamente $8 \mathrm{~km}$ com a aplicação do: a) AGHT e b) TAHG Observa-se em ambos os mapas anomalias contínuas relacionadas à zona de influência do Lineamento Transbrasiliano.

Na gravimetria o espectro foi gerado para a anomalia Bouguer Completa

(figura 6.8) as profundidades obtidas para os diferentes comprimentos de onda

foram de: a) 2,608 km; b) 1,884 km e c) 427 metros (figura 6.9). Sendo que a profundidade mais rasa está relacionada a ruídos.
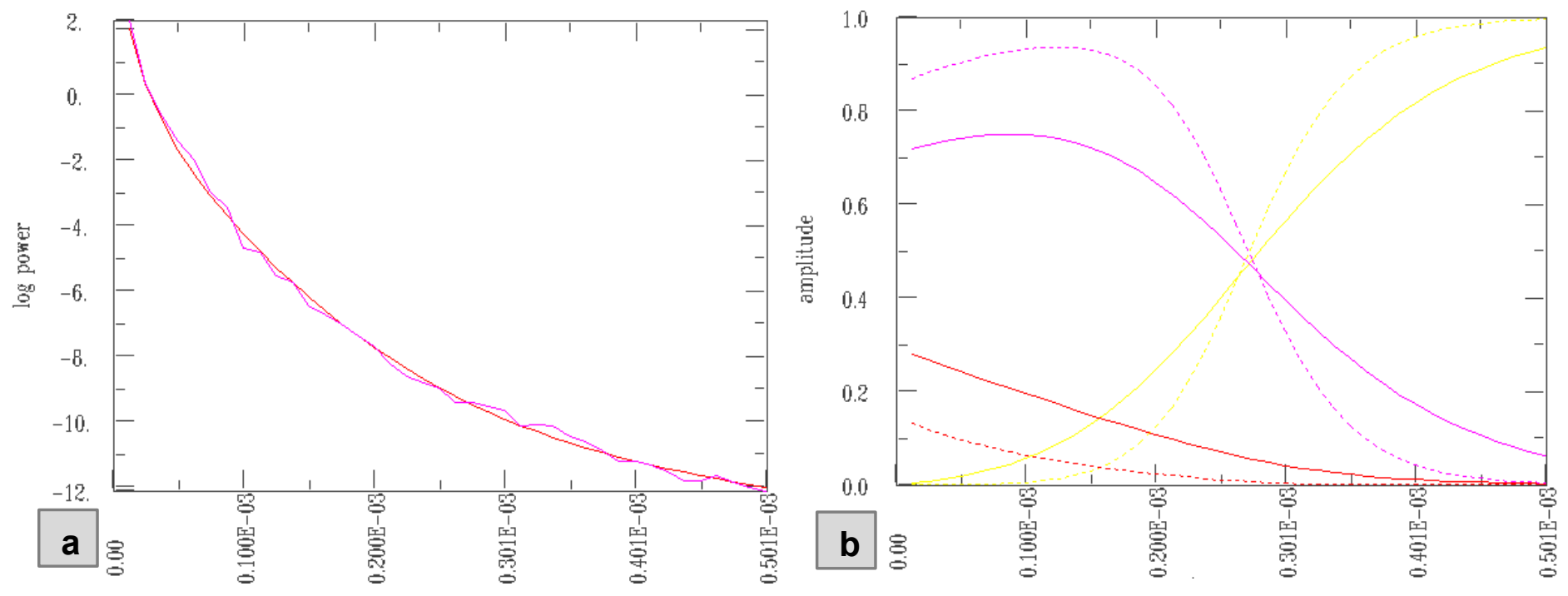

Figura 6.8 - a) Espectro de potência para a gravimetria; b) Diferentes comprimentos de onda para 3 camadas a diferentes profundidades. 

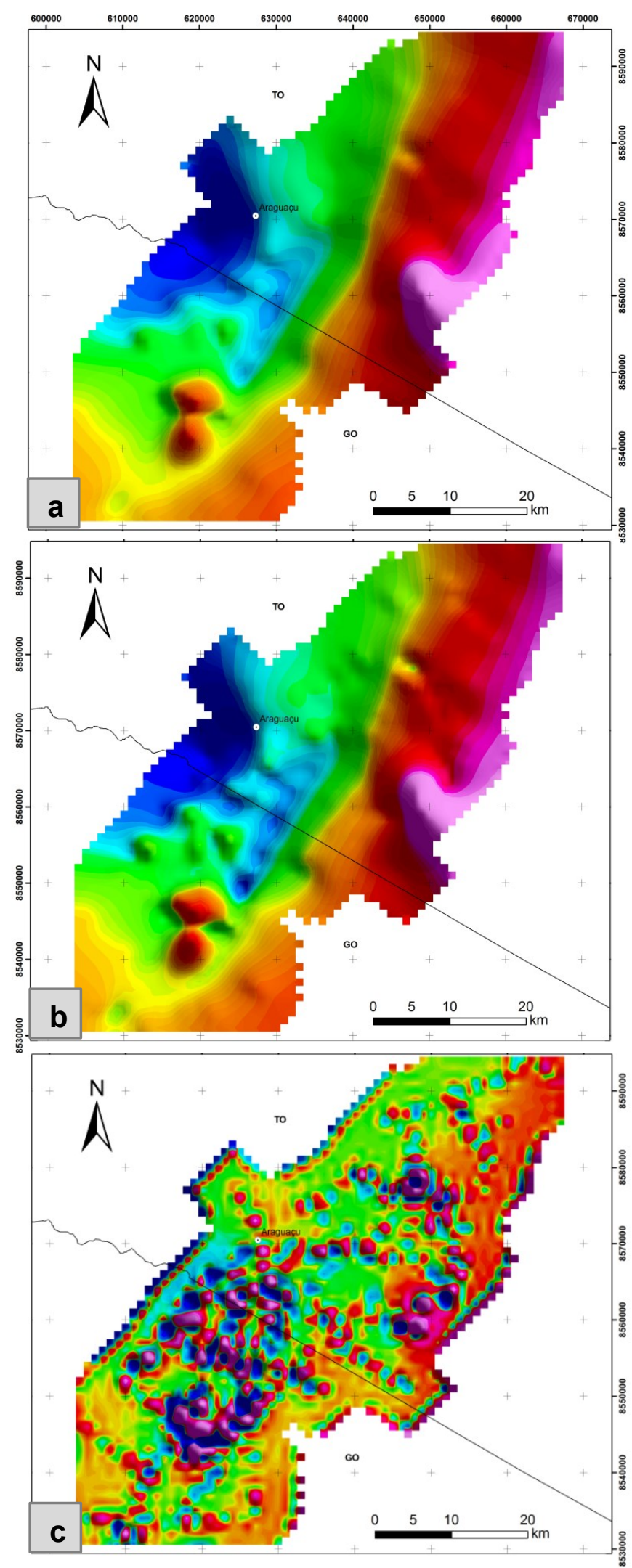

Figura 6.9 - Resultado do matched filter para a gravimetria: a) 2,608 km; b) 1,884 km e c) 427 metros. Nas figuras $a$ e $b$ observa-se um baixo gravimétrico na região do GAB. 


\subsubsection{Deconvolução de Euler}

A Deconvolução de Euler (Reid et al. 1990) é um método que fornece uma rápida estimativa de localização e da geometria das fontes anômalas sem presumir a direção do vetor de magnetização. É realizada a partir da estimação de índice estrutural e seleção de critérios de solução para uma aplicação bem sucedida deste método. $O$ índice estrutural que produz a menor dispersão das soluções é o mais indicado. A anomalia magnética de campo total $T(x, y, z)$ produzida por uma fonte tridimensional e não corrigida de um campo regional aditivo constante, satisfaz a equação de Euler 3D (eq. 6.7; Reid et al. 1990, onde $\left(x_{0}, y_{0}, z_{0}\right)$ é a posição da fonte magnética na qual o campo total $T$ é detectado no $(x, y, z)$ definida como:

$$
\left(x-x_{0}\right) \frac{\partial}{\partial x} T+\left(y-y_{0}\right) \frac{\partial}{\partial y} T+\left(z-z_{0}\right) \frac{\partial}{\partial z} T=-n T
$$

Onde, $n$ é o parâmetro estrutural definido como uma medida da taxa de decaimento da anomalia com a distância entre a fonte e o ponto de medida, ou seja, é um indicador da forma geométrica da fonte.

Tabela 6.1- Índices estruturais para as diferentes geometrias de fontes do método magnético e gravimétrico (Reid et al. 1990; Withehead, 2010).

\begin{tabular}{|cll|}
\hline Índice Estrutural & Magnético & Gravimétrico \\
\hline $\mathbf{0}$ & Contatos e falhas & Soleiras e diques \\
\hline $\mathbf{1}$ & Soleiras e diques & Cilindros \\
\hline $\mathbf{2}$ & Corpos 2D, cilindros e pipes verticais & Esfera \\
\hline $\mathbf{3}$ & Corpos 3D e esferas & \\
\hline
\end{tabular}


Neste trabalho foi utilizado o método da deconvolução de Euler 3D padrão para os dados gravimétrico e o da deconvolução de Euler 3D localizada nos dados magnéticos.

O Euler 3D padrão movimenta uma janela de tamanho fixa sobre o grid calculando as soluções para cada janela. Tipicamente muitas soluções são geradas então é feito um refinamento baseado em critérios como limite da porcentagem máxima de tolerância do erro e da máxima distância do tamanho da janela que pode ser aceito. $O$ tamanho da janela deve ser grande o bastante para incluir a anomalia em estudo e não tão larga que resulte na contaminação de anomalias adjacentes (Withehead, 2010).

O Euler 3D localizado utiliza o cálculo do sinal analítico e localizar a coordenada de máxima amplitude deste sinal e depois gera as soluções de Euler com as profundidades das fontes anômalas. Após a localização da maior amplitude são utilizados algoritmos que estimam os diferentes tamanhos de janelas que serão usadas depois na Deconvolução de Euler, com o mesmo algoritmo do método padrão. Este método possui menos soluções que o padrão, por selecionar somente as máximas amplitudes (Withehead, 2010). 
$\mathrm{Na}$ magnetometria a deconvolução de Euler foi feita com um índice estrutural de 0,5 , erro de $10 \%$ e uma janela de 3 vezes o tamanho do grid, ou seja $1500 \mathrm{~m}$. Foram feitos vários testes até que se encontrasse o maior agrupamento dos resultados e ao ser comparado aos produtos dos dados geofísicos representou bem todos os lineamentos (figura 6.10). As profundidades máximas encontradas foram, aproximadamente, $9 \mathrm{~km}$. Para representação em mapa as soluções foram separadas em 3 intervalos principais: a) 200 a 480 metros; b) 480 a 1040 metros e c) 1040 a 9000 metros (figura 6.11).

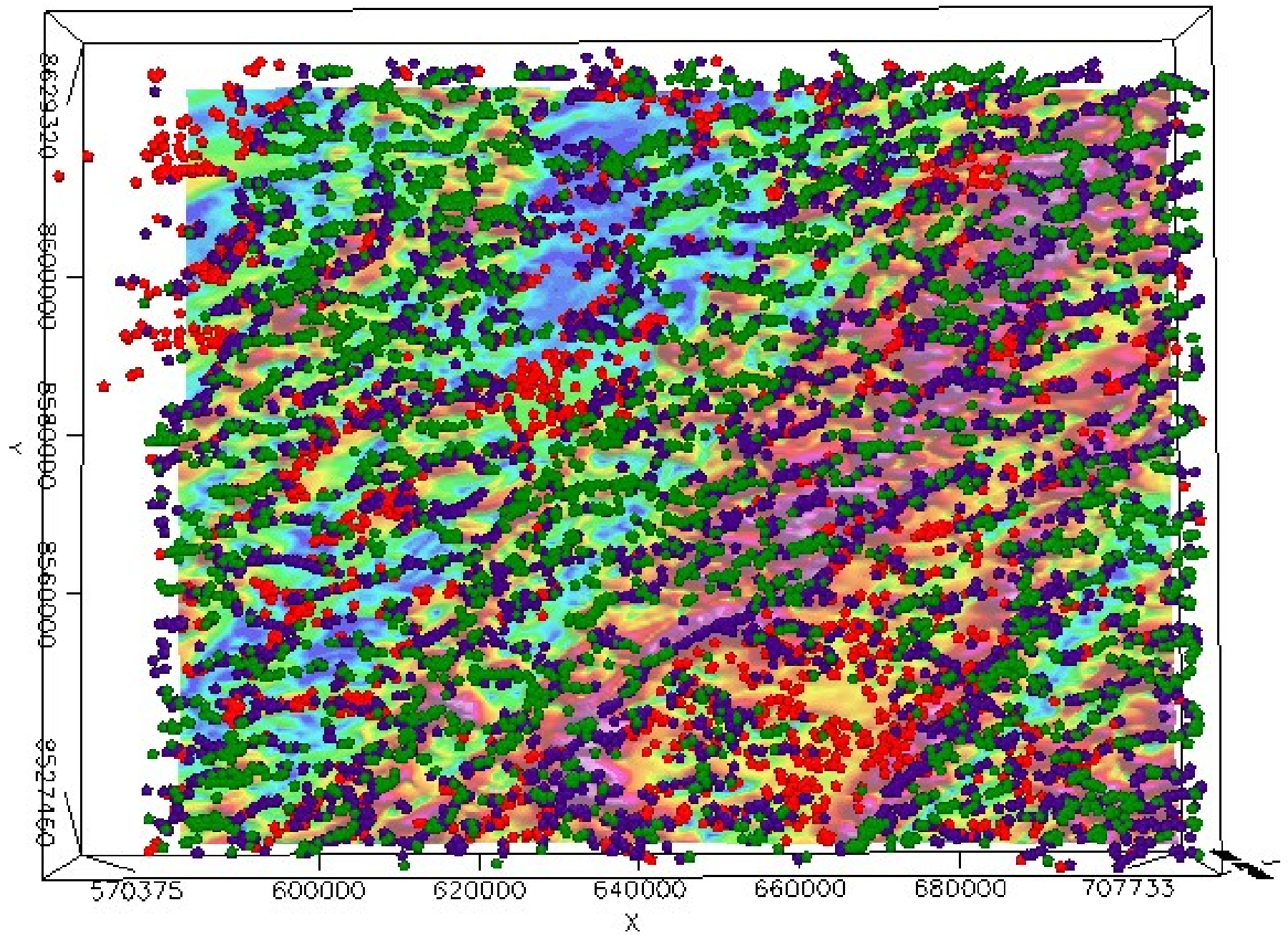

Figura 6.10 - Mapa ao fundo é o AGHT com as soluções de Euler representadas por cículos coloridos : a) 200 a 480 metros, em verde; b) 480 a 1040 metros, em roxo e; c) 1040 a 9000 metros, em vermelho. 

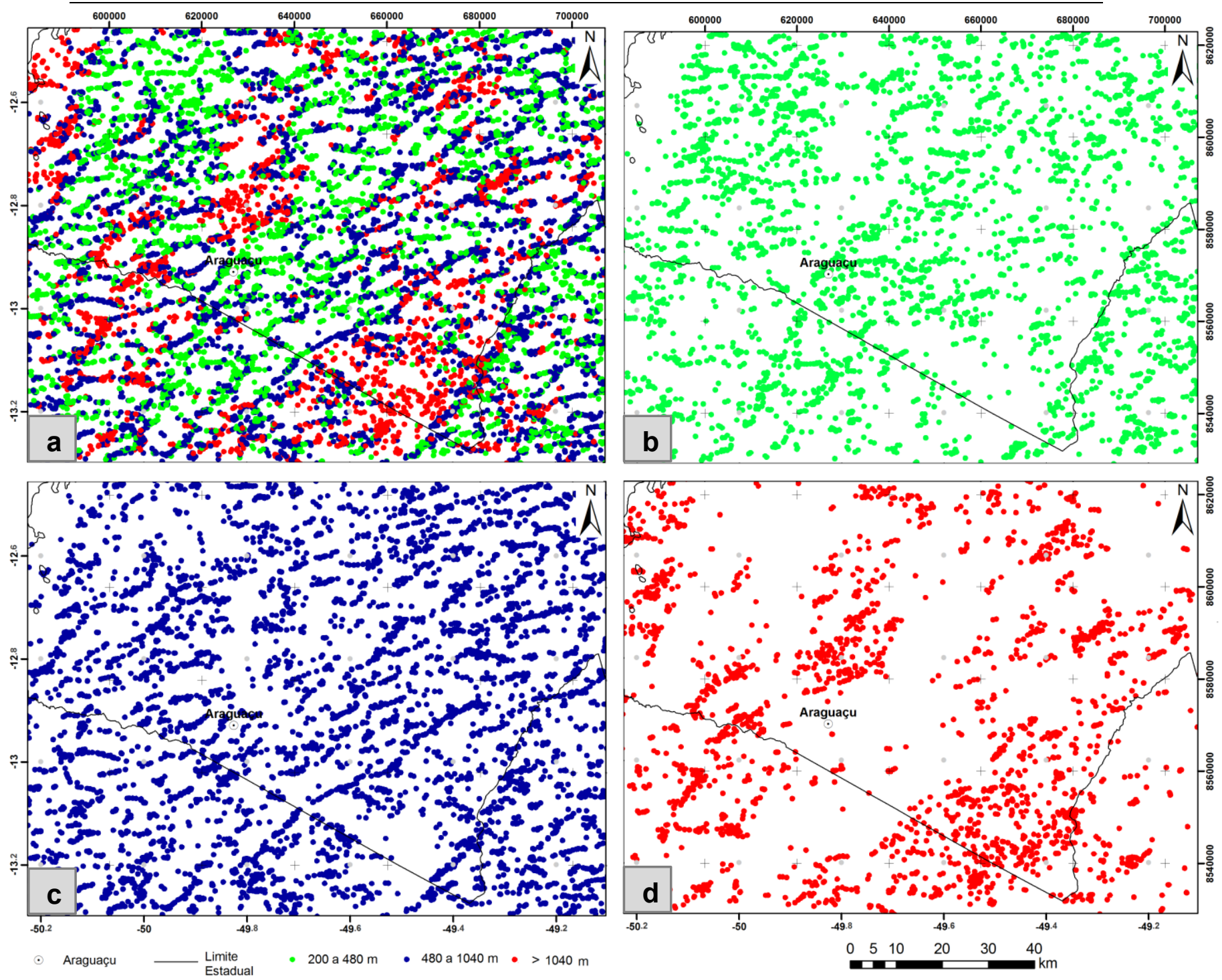

Figura 6.11 - a) Todas as soluções de Euler: b) 200 a 480 metros, em verde; c) 480 a 1040 metros, em azul e; d) 1040 a 9000 metros, em vermelho.

A partir da figura 6.12 observa-se uma boa correlação entre a interpretação dos lineamentos e o resultado do Euler em profundidades mais rasas (figura 6.12a) e mais profundas (figura 6.12b). Os lineamentos descritos no domínio 4 da magnetometria como zona com lineamentos sigmoidais que cortam o GAB possuem profundidades até $3 \mathrm{~km}$ e próximo a Novo Planalto localizam-se fontes profundas bem aglomeradas que alcançam $9 \mathrm{~km}$. 

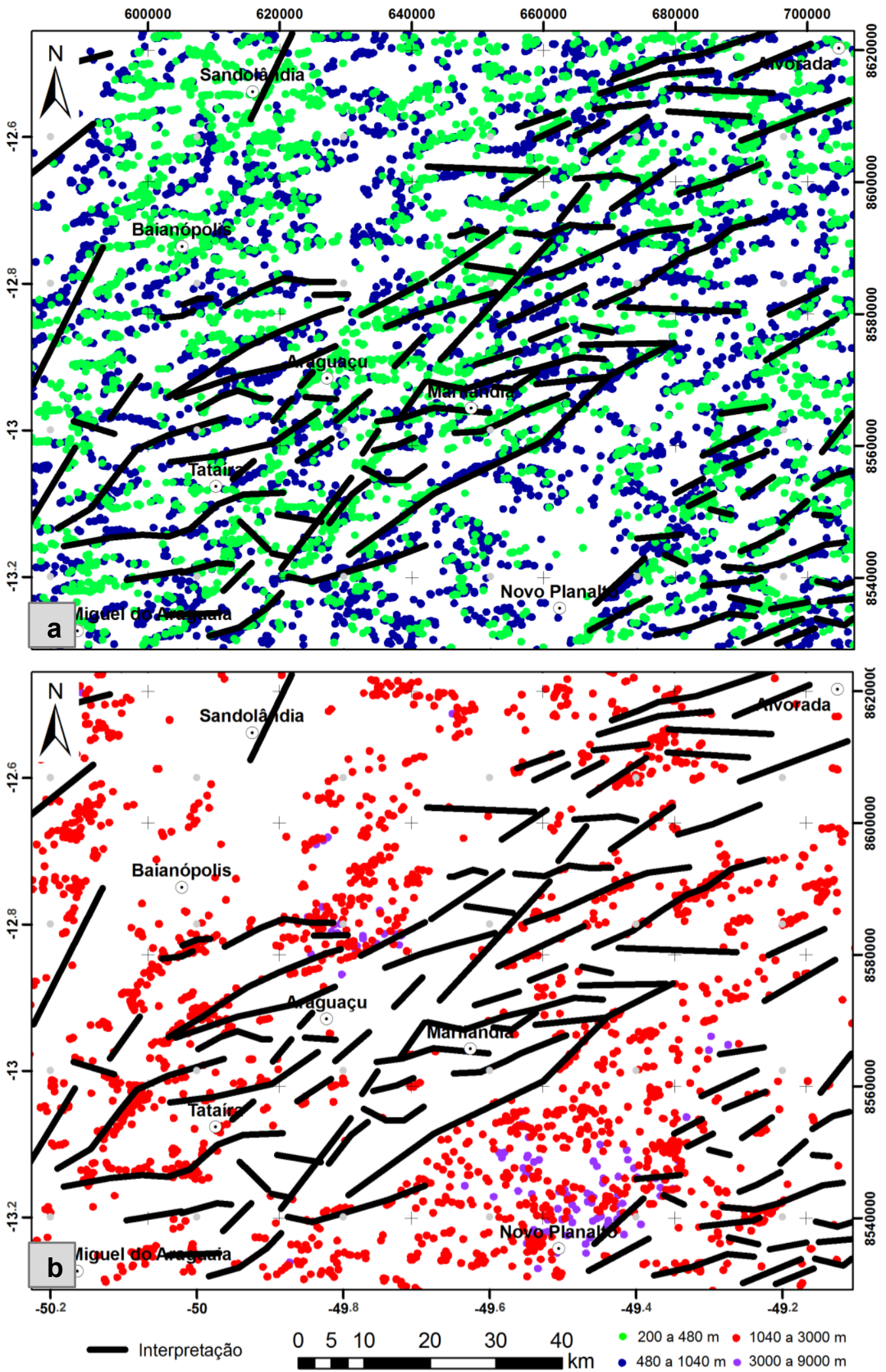

Figura 6.12 - Integração da interpretação dos dados magnéticos (linhas pretas) com o resultado da deconvolução de Euler: a) fontes mais rasas e b) fontes mais profundas. 
De acordo com Isles e Rankim (2013), deve se ressaltar que o dado aeromagnético reflete a variação de magnetização em varias profundidades, aumentando a possibilidade de que os lineamentos mais rasos e mais profundos estejam superimpostos e, portanto não se espera que todas as descontinuidades observadas sejam interpretadas como falhas ou contatos.

Na deconvolução de Euler da gravimetria (figura 6.13) foi utilizado o índice estrutural 2 para definir os locais de maior profundidade da bacia. O tamanho da janela foi de 6 vezes o tamanho da célula do grid $(1 \mathrm{~km})$, o erro foi de $15 \%$ e máxima distância aceita foi de 3000. Foram obtidos diferentes valores de profundidade que variam entre $1000 \mathrm{~m}$ e $2800 \mathrm{~m}$.

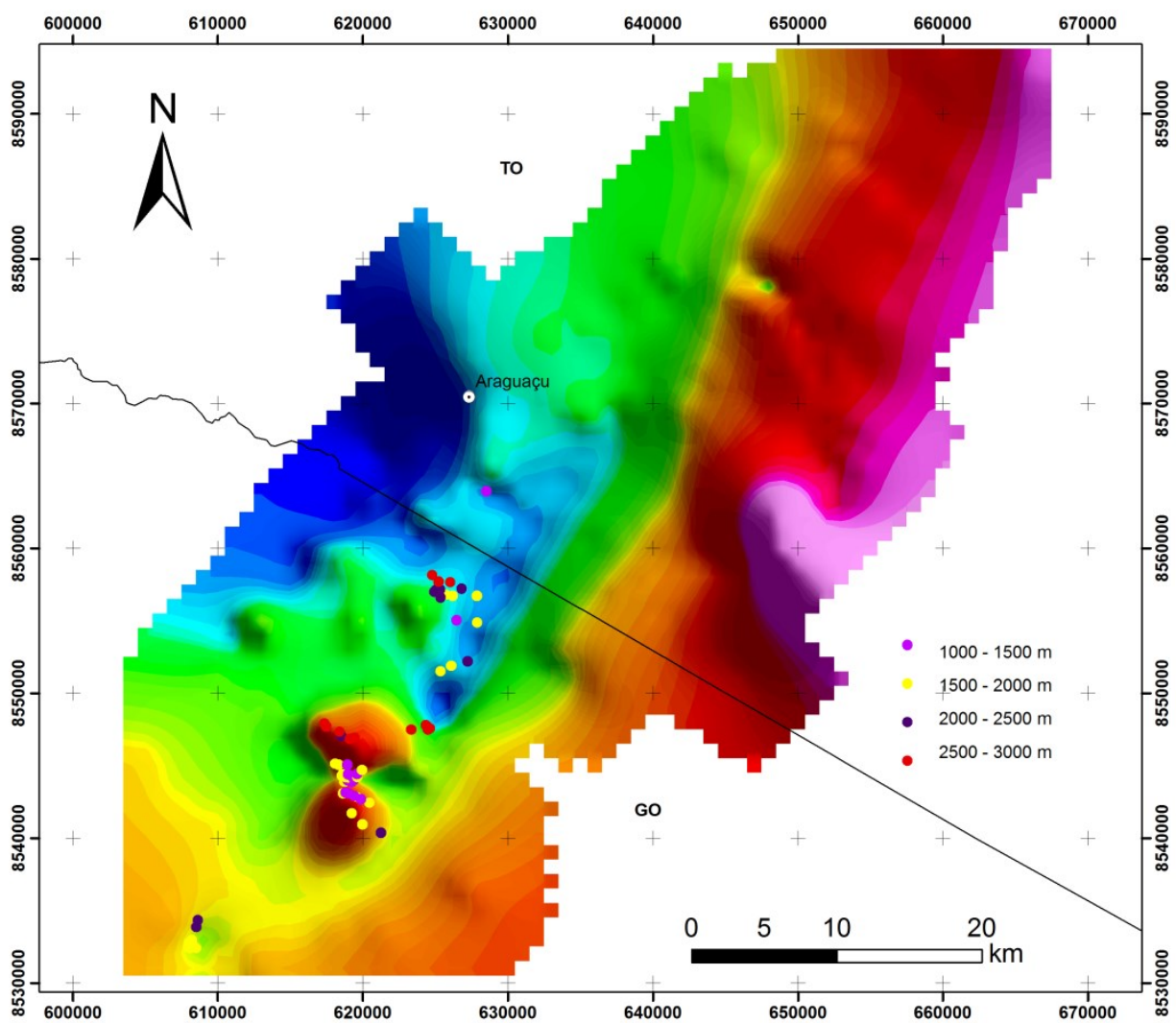

Figura 6.13 - Soluções de Euler para a gravimetria. Foram obtidos diferentes valores de profundidade que variam entre $1000 \mathrm{~m}$ e $2800 \mathrm{~m}$. 


\subsection{Integração dos dados}

As informações adquiridas a partir da interpretação dos dados magnéticos, gravimétricos e geológicos foram integrados e um novo mapa geofísico-geológico foi criado (figura 6.14). A Formação Xambioá e o Complexo Rio dos Mangues foram separados em unidades menores não mapeadas no mapa geológico de Goiás com escala de 1:500.000 (Moreira et al. 2008) e na folha SD-22 da Carta Geológica do Brasil ao Milionésimo (Lacerda Filho et al. 2004), desta forma não foi possível fazer uma associação à litologia conhecida.

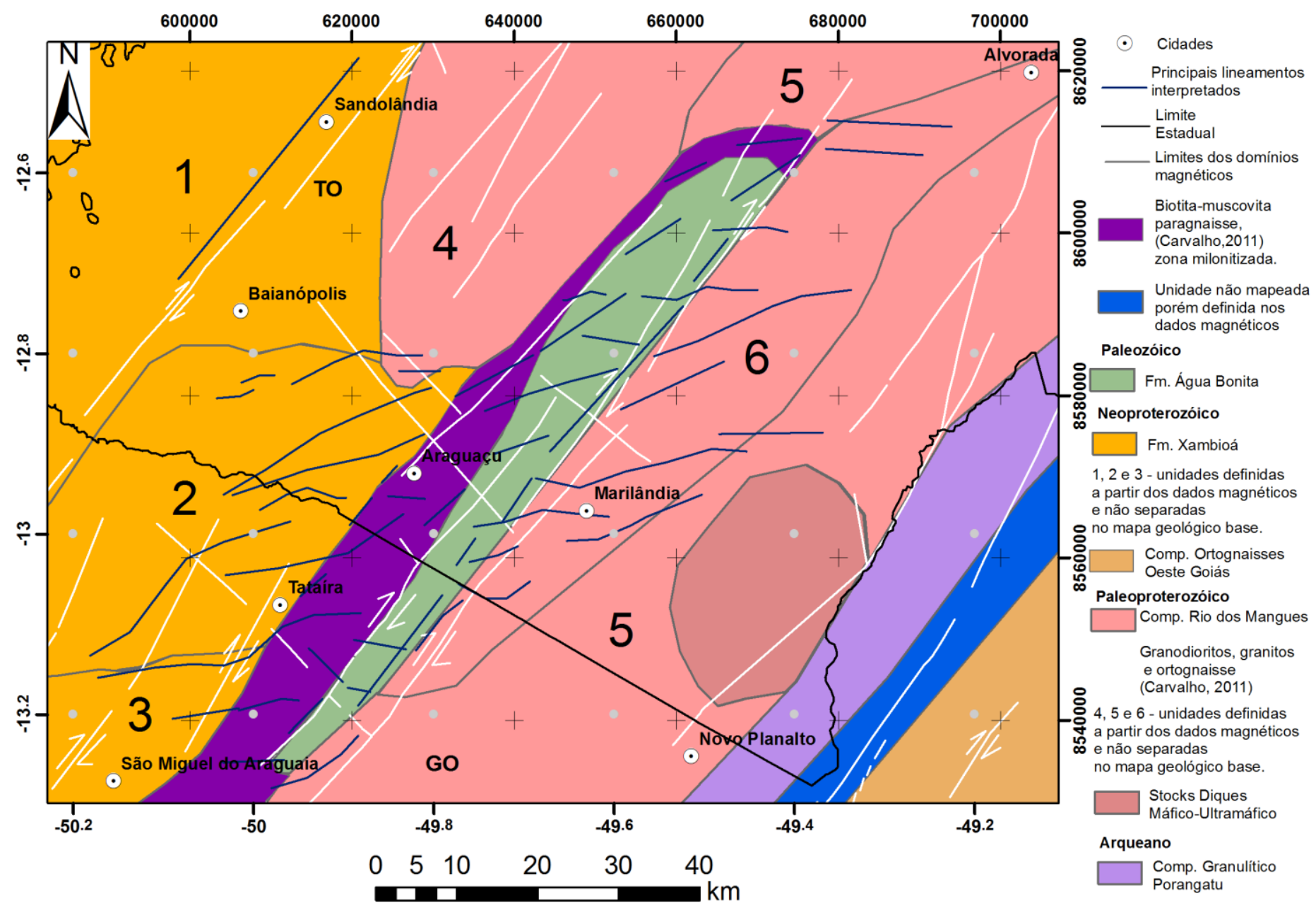

Figura 6.14 - Integração da interpretação dos dados geofísicos e geológicos com os mapa geológico e estruturas geológicas (em branco) de acordo o Lacerda Filho et al. (2004) e novos limites litogeofísicos. 
O domínio 6 encontra-se próximo a cidade de Marilândia onde Carvalho (2011) encontrou um afloramento de ortognaisse próximo a entrada sul da vila de Marilândia (figura 6.15), podendo corresponder ao alto magnético característico deste domínio. Foi separada uma faixa milonítica que já foi definida por Carvalho (2011) na borda oeste do gráben (figura 6.16) que em função das características nos dados geofísicos e dados de campo adquiridos neste trabalho permitiu que esta fosse estendida até a borda norte do GAB.

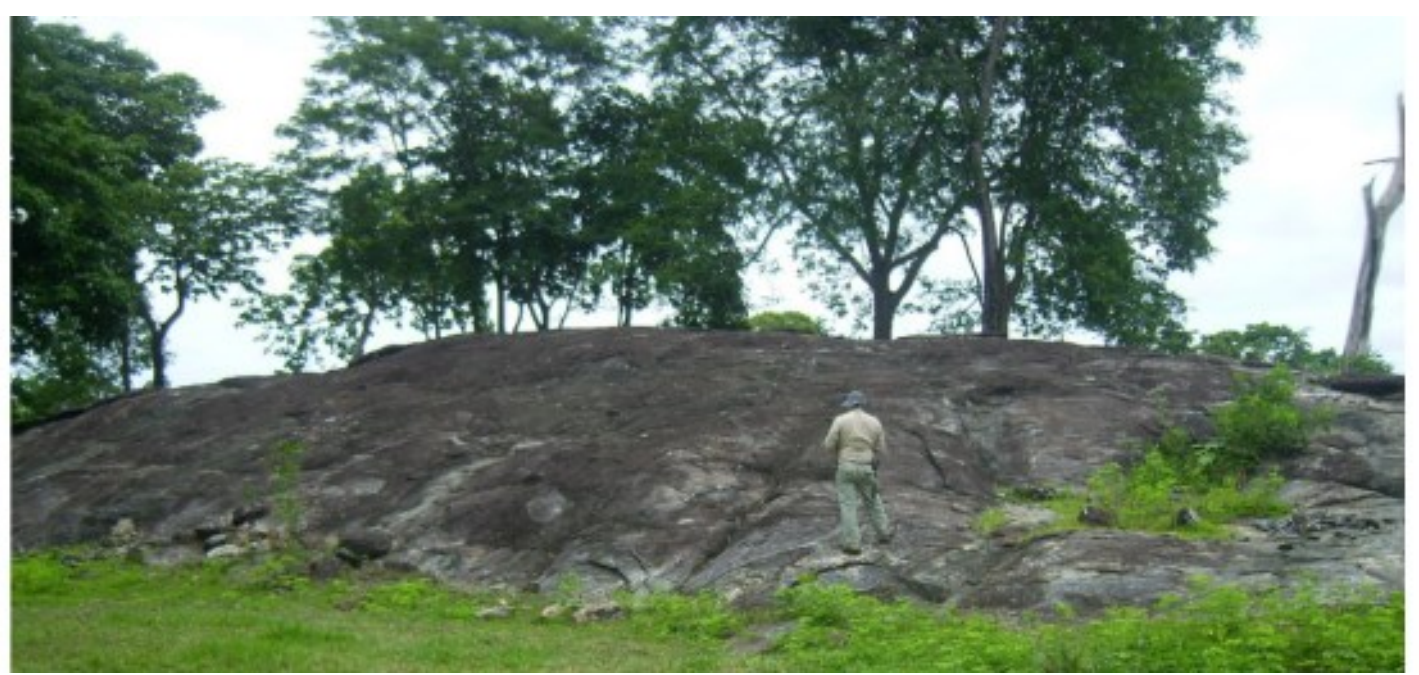

Figura 6.15 - Afloramento de ortognaisse próximo a entrada sul da vila de Marilândia (Carvalho, 2011), onde se encontra o domínio 6 da integração.

A partir da interpretação dos dados geológicos o Complexo Granulítico de Porangatu pode ser bem definido assim como a estrutura circular classificada como "stocks de diques máficos ultramáficos" (Lacerda Filho et al. 2004), que também foi bem determinada nas soluções de Euler (figura 6.12) alcançando $9 \mathrm{~km}$ de profundidade e estão próximas à cidade Novo Planalto. O domínio 5 foi bem determinado nas soluções de Euler da magnetometria (figura 6.12) onde foram as soluções observadas mais profundas com até $3 \mathrm{~km}$. 


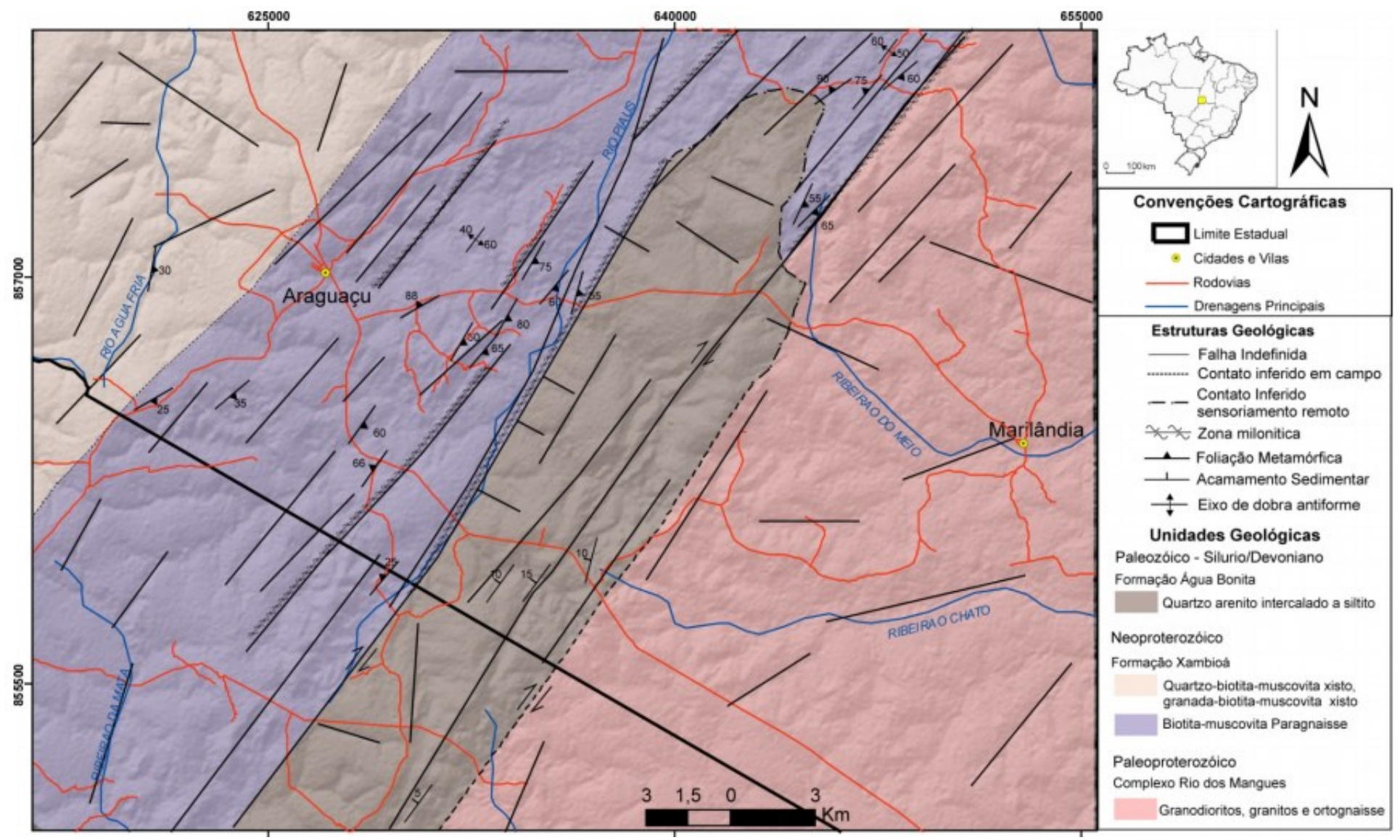

Figura 6.16 - Mapa geológico da porção central do Graben de Água Bonita de acordo com Carvalho (2011).

Não foi possível observar a localização e limite da Suíte Posselândia, que se localiza a leste do GAB de acordo com o mapa geológico. A unidade em azul (figura 6.14) entre o Complexo Granulítico de Porangatu e os Ortognaisses do Oeste do Goiás não se encontrava no mapa geológico, mas foi bem determinada a partir dos dados magnéticos. Os principais lineamentos interpretados foram adicionados no mapa, mas não foi possível defini-los como falhas ou fraturas e cinemática por causa da falta de dados estruturais. 


\section{Modelagem Gravimétrica e Modelo Geológico}

\subsection{Modelagem Gravimétrica}

Para a modelagem gravimétrica foi utilizado o GM-SYS, um programa que permite a criação de um modelo geológico de forma interativa e cálculo em tempo real do sinal gerado pelo modelo (Popowsky et al. 2009). Foi feito um modelo bidimensional, ou seja, que varia em profundidade e na direção do perfil (X) e não varia em Y. Para o cálculo da resposta do modelo o programa utilizada os métodos de Talwani et al. (1959), Talwani e Heirtzler (1964) e faz uso dos algoritmos descritos em Won e Bevis (1987).

Todos os perfis gravimétricos adquiridos foram analisados e aquele com o baixo gravimétrico mais acentuado foi escolhido para a modelagem. Neste perfil da anomalia Bouguer completa com direção perpendicular ao gráben (figura 7.1), foi aplicado um filtro polinominal de grau 1 para se retirar o efeito regional. Foram utilizadas as densidades de acordo Castro et al. (2014) onde o Arco Magmático de Goiás tem 2,710 $\mathrm{g} / \mathrm{cm}^{3}$ (ortognaisses a leste do GAB) $2,450 \mathrm{~g} / \mathrm{cm}^{3}$ para a FAB (relacionada à densidade da sequência sedimentar da Bacia do Parnaíba); 2,700 $\mathrm{g} / \mathrm{cm}^{3}$ para as sequência metassedimentares do Araguaia (paragnaisses a oeste do $\mathrm{GAB}$ ); exceto para a densidade da sessão rifte onde o valor de densidade utilizado foi atribuído neste trabalho como $2,640 \mathrm{~g} / \mathrm{cm}^{3}$. O modelo (figura $7.2 \mathrm{~b}$ ) foi obtido com um erro de modelagem foi de 1,182 mGal (figura 7.2a). A modelagem foi feita até a profundidade de $8 \mathrm{~km}$ (figura 7.2c). A profundidade máxima para a 
FAB foi de 1,6 km e um rifte que vai até $2,4 \mathrm{~km}$. O lineamento expressivo do LTB que está na borda leste do GAB foi modelado com um mergulho subvertical para oeste.

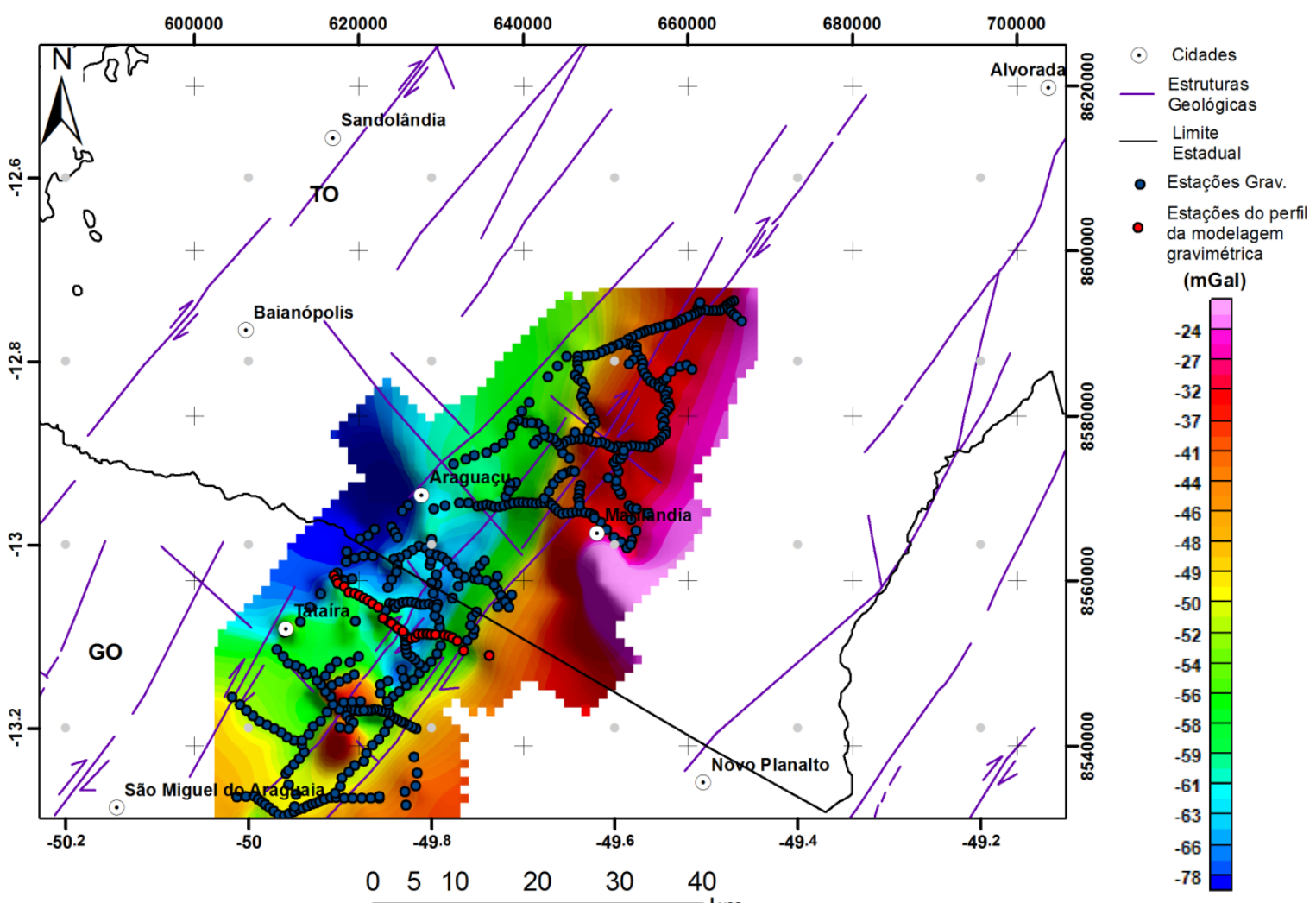

Figura 7.1 - Anomalia Bouguer Completa com as estações gravimétricas, o perfil da modelagem gravimétrica (em vermelho) e as estruturas da folha SD22 em roxo (de acordo Lacerda Filho et al. 2004).

A partir da tabela 7.1 observa-se que as principais fontes encontradas na análise do espectro de potência e matched filter, estão a aproximadamente $8 \mathrm{~km}$, a 2,4 km e 1,6 km. O resultado da Deconvolução de Euler na gravimetria resultou em até 2,8 km e no matched filter da gravimetria observou-se um baixo na mesma região com profundidade de 1,8 km e também a 2,6 km. Então, o modelo deve resolver esta relação entre as diferentes profundidades encontradas e das informações adquiridas na interpretação, integração e modelagem gravimétrica. A 
partir disto foi criado um modelo geológico com um rifteamento precursor, que pode ser relacionado ao Grupo Jaibaras, e que está associado ao baixo gravimétrico a aproximadamente $2,4 \mathrm{~km}$ e um duplex extensional num sistema strike slip com profundidade de até $1,6 \mathrm{~km}$ onde foram acomodados os sedimentos pré-existentes da FAB e do rifte.

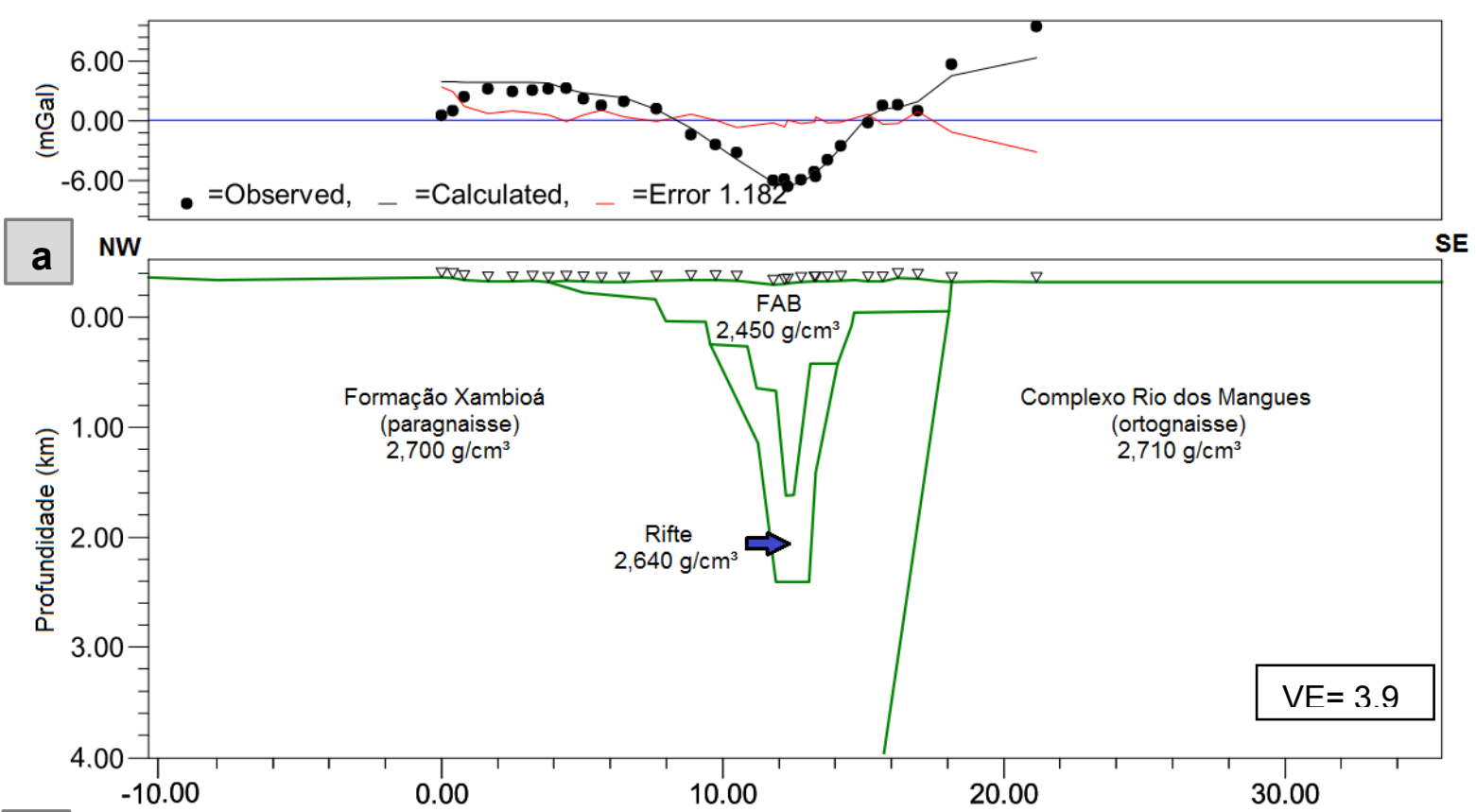

b

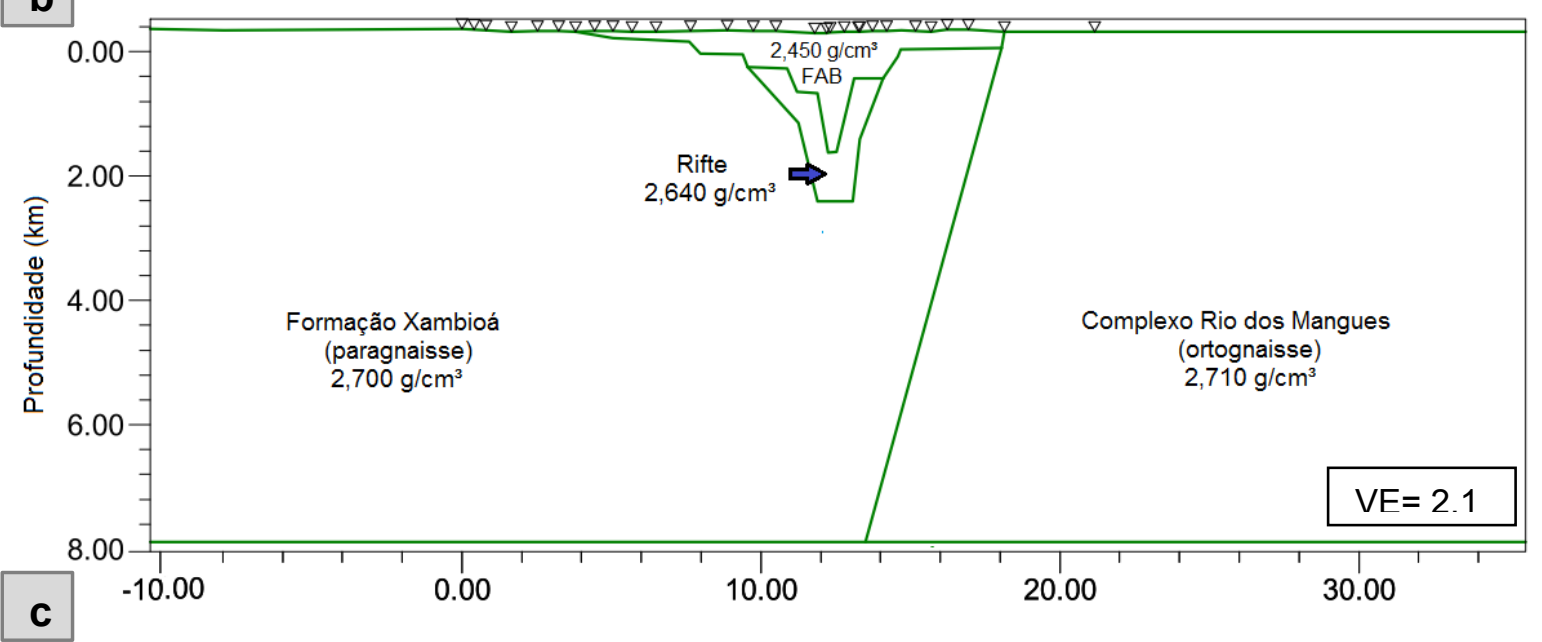

Figura 7.2 - Modelagem gravimétrica do perfil gravimétrico: a) Curva do dado modelado; b) Modelagem vista com profundidade até $4 \mathrm{~km}$; c) Modelagem com a profundidade até $8 \mathrm{~km}$. 
Tabela 7.1 - Diferentes profundidades encontradas com o espectro de potência e o matched filter para a análise de profundidade.

\begin{tabular}{cccc}
\hline \multicolumn{2}{c}{ Magnetometria } & \multicolumn{2}{c}{ Gravimetria } \\
\hline Esp. De Potência $(\mathbf{k m})$ & Matched Filter $(\mathbf{k m})$ & Esp. De Potência (km) & Matched Filter $(\mathbf{k m})$ \\
18,187 & 28,206 & & \\
8,059 & 8,642 & 9,083 & \\
& & 3,335 & 2,608 \\
2,391 & 1,620 & 2,456 & 1,884 \\
1,652 & & 1,397 & 0,427 \\
1,012 & 0,326 & 0,333 & \\
0,412 & & &
\end{tabular}

\subsection{Modelo Geológico}

Um sistema strike slip teórico (figura 7.3) é formado por falhas retilíneas segmentadas sub paralelamente ao vetor regional de deslocamento com lentes obliquas a ele (Woodcock, 1986; Woodcock e Rickards, 2003). Geralmente são bordejados por duas zonas de falhas contínuas ou duas zonas de alta densidade de fratura e entre estas existem zonas menores com falhas en echelon que definem a estrutura duplex (Woodcock, 1986). A figura 7.4 é uma estrutura em flor no afloramento classificado anteriormente como Fácies C. Esta é uma estrutura que pode ser encontrada em bacias strike slip.

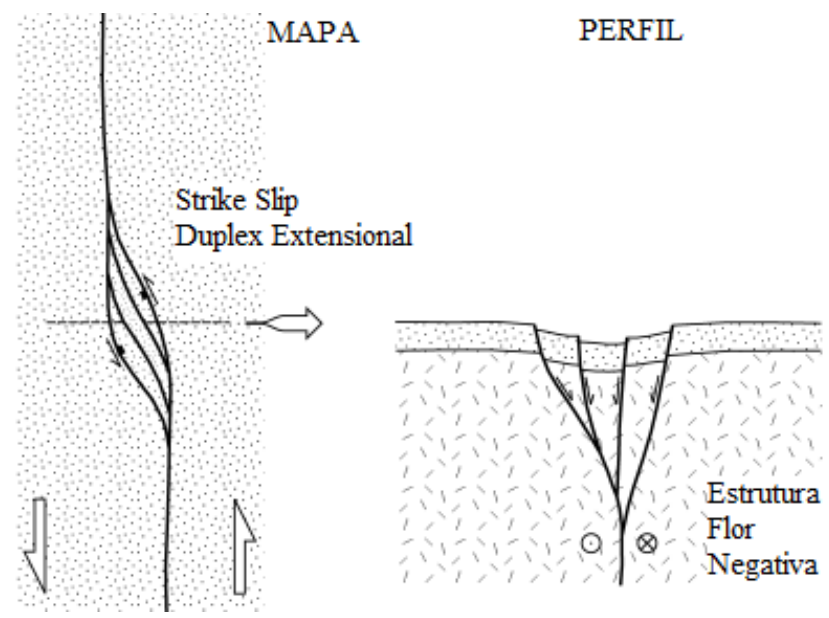

Figura 7.3 - Mapa e seção em perfil de um genérico sistema de falha strike slip, mostrando estrutura em flor e duplexes (Woodcock e Rickards, 2003). 


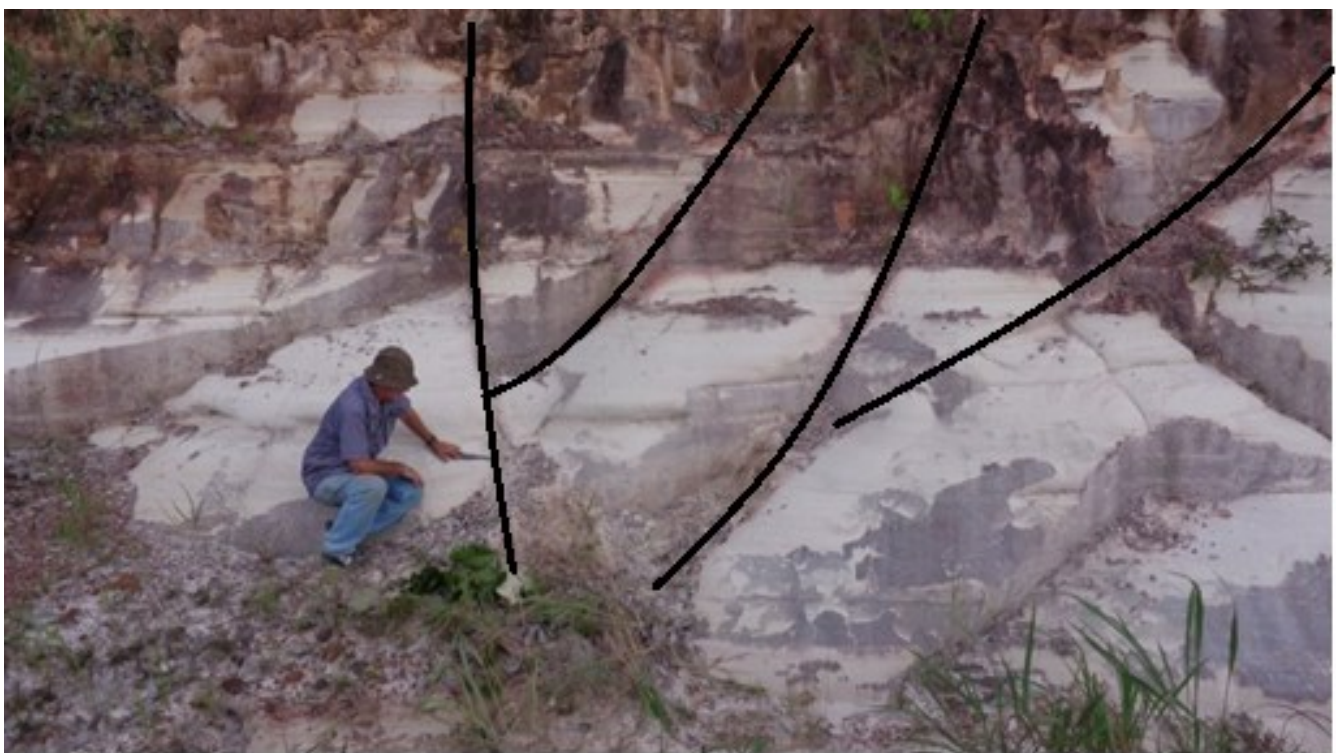

Figura 7.4 - Possível estrutura em flor no afloramento classificado como Fácies C. Esta estrutura pode ser encontrada em bacias strike slip.

Aguiar et al. (2011) descreveu que o embasamento é composto de rochas marcadas por uma foliação milonítica com direção principal de N40E, acompanhando o trend geral do LTB, na zona de cisalhamento dextral. Este mesmo autor afirmou que no embasamento e na $F A B$ foram encontradas estruturas com direção NE/SW que foram reativadas como falhas normais e que as medidas de paleocorrentes apresentaram orientação preferencial na direção NE-SW, sentido NE, indicando que os sedimentos tiveram uma deposição condicionada pelas estruturas do embasamento, que formavam uma calha preferencial de transporte condicionada pelo LTB, também relacionado por Chamani et al. (2011).

Sugere-se então que estruturas com direção NE/SW que foram reativadas a partir de um rifteamento formando uma calha preferencial de transporte com direção preferencial para NE (fácies B do capítulo 3) que foi condicionada pelo LTB (Aguiar et al. 2011; Chamani et al. 2011). Este evento pode ser 
correlacionado ao do Grupo Jaibaras da Bacia do Parnaíba em que foi sugerida a formação de calhas grabenfomes com um pacote sedimentar de provável idade cambro ordoviciana, registrando as atividades finais do Ciclo Brasiliano (Oliveira e Mohriak, 2003). Durante as grandes inundações marinhas silurianas devonianas (Milani et al. 2007) pode ter ocorrido a conexão que culminou na deposição das bacias paleozoicas do Paraná e do Parnaíba, causando a similaridade litológica de base que correlacionada o Grupo Serra Grande, Trombetas e Formação Furnas (Barbosa et al. 1981; Melo et al. 1987). Porém não foram encontrados fósseis na FAB para que se pudesse confirmar esta conexão. A foliação milonítica (Aguiar et al. 2011; Carvalho, 2011) com direção principal de N40E, acompanhando o trend geral do LTB, pode ter sido formada juntamente ao duplex extensional por estar sujeita a movimentos regionais de caráter dextral (Delgado et al. 2003; Zalán, 1989; Chamani et al. 2011). A formação deste duplex acomodou os sedimentos da FAB e do rifte que foram depositados anteriormente. Depois ocorreram cisalhamentos na Formação Xambioá (a oeste) que estão relacionados aos lineamentos que cortam a parte norte do GAB relacionado a um alto gravimétrico que pode estar associado a um soerguimento.

De acordo com os dados de estimativas de profundidade e da modelagem gravimétrica 2D a profundidade máxima interpretada para a Formação Água Bonita é de 1,6 km e do rifte de aproximadamente 2,4 km (figura 7.5). O gráben está bordejado por falhas dextrais com um mergulho mais suave em direção a Formação Xambioá. Possui lineamentos perpendiculares a borda oeste (Xambioá), além dos que cortam o GAB numa direção N65E e separa a parte norte com características diferenciadas nos dados magnéticos, gravimétricos e 
geológicos. O gráben situa-se na região de fraqueza do Lineamento

Transbrasiliano e sua falha principal (a leste) é subvertical com um mergulho para

oeste. Esta falha foi modelada na gravimetria até os $8 \mathrm{~km}$ (figura 7.2c) e também

foi observada no TAHG do resultado do grid do matched filter a aproximadamente

$8 \mathrm{~km}$ (figura 6.7b).

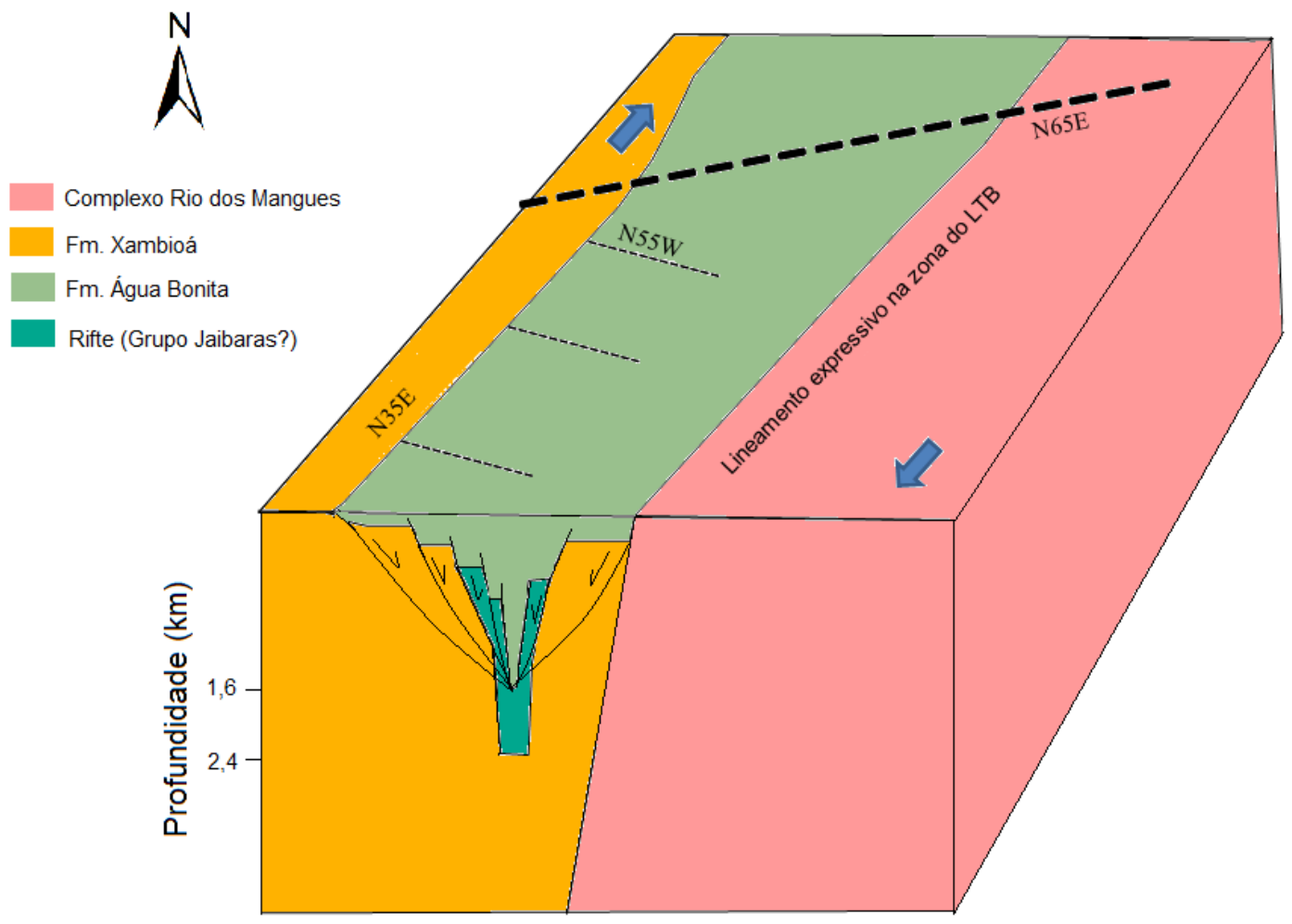

Figura 7.5 - Modelo geológico para o Graben Água Bonita onde se sugeriu que um rifte precursor (que pode ser relacionado ao Grupo Jaibaras) formou uma calha preferencial de transporte com direção preferencial para NE (Aguiar et al. 2011; Chamani et al. 2011) e depois a deposição da Fm. Água Bonita (FAB) pode ter ocorrido ao mesmo tempo das bacias do Paraná e Parnaíba. A partir de reativações do LTB uma bacia pull-apart foi gerada acomodando os sedimentos préexistentes da FAB e do rifte. A Faixa Araguaia em amarelo está a oeste do gráben; a FAB, em verde claro; o rifte precursor em verde escuro; na borda leste do GAB o contato com o Complexo Rio dos Mangues do Arco Magmático de Goiás (rosa). Neste contato há um lineamento expressivo situado na zona de influência do LTB que tem um mergulho subvertical para oeste. A profundidade máxima do rifte é de $2,4 \mathrm{~km}$ e da $F A B$ é de $1,6 \mathrm{~km}$. O GAB com suas falhas principais de direção principal N35E e perpendicular a borda oeste possui falhas de direção N55W, além disso, foi cortado com lineamentos de direção N65E que separa a parte norte da sul com características diferenciadas nos dados magnéticos, gravimétricos e geológicos. 


\section{Discussões e Conclusões}

As associações de fácies da Formação Água Bonita, descritas no cap. 3, indicaram a possibilidade de ter havido o retrabalhamento de depósitos aluviais conglomeráticos, por ação de correntes, possivelmente de maré, em uma situação de mar transgressivo (fácies A), predomínio de estratificações onduladas, truncamentos suaves e rara estratificação cruzada tabular (paleocorrentes para $\mathrm{NE}$ ) sugerem que a deposição de tais facies processou-se em plataforma rasa com ação de ondas de tempestades que retrabalharam sedimentos previamente depositados (fácies B) e predomínio de estratificações cruzadas por ondas, onde ambiente deposicional foi de plataforma rasa com ação de ondas de tempestades, à frente de ambiente de praia, evidenciando uma progradação deposicional (fácies C).

Para a interpretação dos dados geológicos foram utilizadas a imagem de satélite e o relevo sombreado. A composição Landsat 8 mostrou que a vegetação é menos densa e a densidade de drenagem é menor na região do GAB do que na região ao redor. As rochas a oeste do GAB são mais friáveis que a do leste; há ainda drenagens que demarcam bem a borda oeste do GAB e perpendicular a esta borda tem drenagens secundárias e retilíneas adentrando o GAB. O relevo sombreado foi interpretado a partir dos lineamentos primários e secundários com a direção principal do lineamento primário foi de aproximadamente N35E, N55W, N70W e os secundários na direção EM além de lineamentos N65E que cortam o GAB. 
A partir dos lineamentos traçados nos mapas magnéticos foi feita uma integração da interpretação individual dos produtos onde foi possível observar as direções preferencias de NE/SW e E/W, além de lineamentos que cortam o GAB numa direção N65E. A direção N55W representada na interpretação dos dados geológicos não está representada nos dados magnéticos, o que pode ser explicado pela falta de contraste da magnetização, direção da linha de vôo em relação à direção da anomalia ou resolução dos dados.

A separação dos diferentes domínios magnéticos resultou em nove domínios determinados de acordo com a densidade e magnitude dos lineamentos (descritos anteriormente no cap. 4). O domínio 4 é marcado por uma zona com lineamentos sigmoidais e baixo magnético. O domínio 5 localiza-se na região do GAB e caracteriza-se com um baixo magnético e poucos lineamentos sendo segmentado pelo domínio 7 que tem uma maior densidade de lineamentos. 0 domínio 6 é caracterizado pelo maior alto magnético na área de estudo e por ser cortado por vários lineamentos de direção E/W e N65E.

O mapa de anomalia Bouguer Completa possui efeitos regionais que resultam em valores mais baixos a oeste representados pela Faixa Araguaia, e outros mais altos a leste, no Complexo Rio dos Mangues. Com a retirada dos efeitos regionais observaram-se baixos gravimétricos mais definidos na região do gráben cujo baixo com maior amplitude dentro de seus limites está localizado na porção centro sul. Como a anomalia apresenta gradiente mais elevado a leste, esta borda deve ser mais verticalizada que a borda oeste, que varia mais suavemente, além disso, lineamentos N65E cortam o GAB e o segmentam com um alto gravimétrico. 
A análise de profundidade dos dados magnéticos e gravimétricos foi feita utilizando os métodos do espectro de potência, matched filter e Deconvolução de Euler. As principais fontes encontradas na análise do espectro de potência e matched filter estão a aproximadamente $8 \mathrm{~km}$, a 2,4 km e 1,6 km.

$\mathrm{Na}$ deconvolução de Euler da magnetometria as profundidades máximas encontradas foram, aproximadamente, $9 \mathrm{~km}$. Observou-se uma boa relação da interpretação dos lineamentos juntamente com o resultado do Euler em profundidades mais rasas e mais profundas. Os lineamentos descritos no domínio 4 da magnetometria como zona com lineamentos sigmoidais que cortam o GAB possuem profundidades até $3 \mathrm{~km}$ e próximo a Novo Planalto localizam-se fontes profundas bem aglomeradas que alcançam $9 \mathrm{~km}$. No GAB o resultado da deconvolução de Euler da gravimetria resultou em até 2,8 km e no matched filter da gravimetria observou-se um baixo na mesma região com profundidade de 1,8 $\mathrm{km}$ e também a 2,6 km. Portanto, o modelo criado pode estar relacionado com essas diferenças entre as profundidades encontradas e as informações adquiridas na interpretação, integração e modelagem gravimétrica. A partir disto foi criado um modelo geológico com um rifteamento precursor, que pode ser relacionado ao Grupo Jaibaras, e que está associado ao baixo gravimétrico a aproximadamente 2,4 km e um duplex extensional num sistema strike slip com profundidade de até 1,6 km onde foram acomodados os sedimentos pré-existentes da FAB e do rifte.

A utilização do TAHG em grids resultantes do matched filter aparenta ser uma boa ferramenta para o estudo de fontes mais profundas, considerando sua função de separar comprimentos de onda. Desta forma foi possível observar 
lineamentos de grande expressão na região do Gráben Água Bonita e se obteve mais informações sobre o Lineamento Transbrasiliano.

$\mathrm{Na}$ integração dos dados geofísicos e geológicos a Formação Xambioá e o Complexo Rio dos Mangues foram separados em unidades menores não mapeadas no mapa geológico de Goiás com escala de 1:500.000 (Moreira et al. 2008) e na folha SD-22 da Carta Geológica do Brasil ao Milionésimo (Lacerda Filho et al. 2004), desta forma não foi possível fazer uma associação à litologia conhecida. Foi separada uma faixa milonítica que foi definida por Carvalho (2011) na borda oeste do gráben que em função das características nos dados geofísicos e dados de campo adquiridos neste trabalho permitiu que esta fosse estendida até a borda norte do GAB. Os principais lineamentos interpretados foram adicionados ao mapa, mas não foi possível defini-los como falhas ou fraturas e cinemática por causa da falta de dados estruturais de campo.

Sugeriu-se que estruturas com direção NE/SW que foram reativadas a partir de um rifteamento formando uma calha preferencial de transporte com direção preferencial para NE (fácies B do capítulo 3) que foi condicionada pelo LTB (Aguiar et al. 2011; Chamani et al. 2011). Este evento pode ser correlacionado ao do Grupo Jaibaras da Bacia do Parnaíba em que foi sugerida a formação de calhas grabenfomes com um pacote sedimentar de provável idade cambro ordoviciana, registrando as atividades finais do Ciclo Brasiliano (Oliveira e Mohriak, 2003). Durante as grandes inundações marinhas silurianas devonianas (Milani et al. 2007) pode ter ocorrido a conexão que culminou na deposição das bacias paleozoicas do Paraná e do Parnaíba, causando a similaridade litológica de base que correlacionada o Grupo Serra Grande, Trombetas e Formação Furnas 
(Barbosa et al. 1981; Melo et al. 1987). Porém não foram encontrados fósseis na FAB para que se pudesse confirmar esta conexão. A foliação milonítica (Aguiar et al. 2011; Carvalho, 2011) com direção principal de N40E, acompanhando o trend geral do LTB, pode ter sido formada juntamente ao duplex extensional por estar sujeita a movimentos regionais de caráter dextral (Delgado et al. 2003; Zalán, 1989; Chamani et al. 2011). A formação deste duplex acomodou os sedimentos da $F A B$ e do rifte que foram depositados anteriormente. Depois ocorreram cisalhamentos na Formação Xambioá (a oeste) que estão relacionados aos lineamentos que cortam a parte norte do GAB relacionado a um alto gravimétrico que pode estar associado a um soerguimento.

De acordo com os dados de estimativas de profundidade e da modelagem gravimétrica 2D a profundidade máxima interpretada para a Formação Água Bonita é de 1,6 km e do rifte de aproximadamente 2,4 km (figura 7.5). O gráben é bordejado por falhas dextrais com um mergulho mais suave em direção a Formação Xambioá. Possui lineamentos perpendiculares a borda oeste (Xambioá), além dos que cortam o GAB numa direção N65E e separa a parte norte com características diferenciadas nos dados magnéticos, gravimétricos e geológicos. O grabén está situado na região de fraqueza do Lineamento Transbrasiliano e sua falha principal (a leste) é subvertical e mergulha para oeste. Esta falha foi modelada na gravimetria até os $8 \mathrm{~km}$ (figura $7.2 \mathrm{c}$ ) e também foi observada no TAHG do resultado do grid do matched filter a aproximadamente 8 km (figura 6.7b). 


\section{Referências Bibliográficas}

Aguiar M. P., Chamani M. A. C., Riccomini C., 2011. O "Graben" de Água Bonita TO-GO e seu significado tectônico. Anais do $13^{\circ}$ Simpósio Nacional de Estudos Tectônicos e do VII International Symposium on Tectonics. Campinas, Sociedade Brasileira de Geologia, Núcleo São Paulo, p. 443-446.

Almeida, F. F. M., 1967. Origem e Evolução da Plataforma Brasileira. Rio de Janeiro, DNPM, Boletim 241, 36 p.

Almeida, F. F. M., 1974. Sistema tectônico marginal do Craton do Guaporé. In: SBG, Congresso Brasileiro de Geologia, 28, Porto Alegre, Anais, 4:9-17.

Almeida, F.F.M., Hasui, Y., Brito Neves, B.B., Fuck, R.A., 1977. Províncias Estruturais Brasileiras. In: SBG, Simp. de Geol. do Nordeste, 8, Campina Grande - PB, Atas, 363-391.

Almeida, F.F.M., Hasui, Y., Brito Neves, B.B., Fuck, R.A., 1981. Brazilian Structural Provinces: an introduction. Earth Science Review, 17:1-19.

Alvarenga, C.J.S., Moura, C.A.V., Gorayeb, P. S. S., Abreu, F.A.M., 2000. Paraguay and Araguaia Belts. In: Cordani, U.G., Milani, E.J., Thomas Filho, A., Campos, D. A. (ed.). Tectonic evolution of South America. Rio de Janeiro, $31^{\text {st }}$ IGC, p. 183-193.

Alves, C. L., 2006. Petrografia, geoquímica e geocronologia do Granito Ramal de Lontra e sua relação com a tectônica e metamorfismo do Cinturão Araguaia, Xambioá-TO. Dissertação de mestrado, Universidade Federal do Pará, Centro de Geociências, Universidade do Pará, 138 p.

Andrade, S. M. e Camarço, P. E. N., 1982. Sequencias sedimentares pre-carboniferas dos flancos nordeste da bacia do Paraná e sudoeste da bacia do Parnaíba e suas possibilidades uraníferas. In: 32 Congresso Brasileiro de Geologia, Salvador, Sociedade Brasileira de Geologia, 5:2132-2144.

Baptista, M. B. e Cartner-Dyer, R., 1966. Ocorrência singular de sedimentos médio-paleozóicos no Centro-Oeste de Goiás. Divisão de Geologia e Mineralogia, Notas preliminares e estudos, $135,11 \mathrm{p}$.

Barbosa, O., Ramos, J. R. A., Gomes, F. A., Helmbold, R., 1966. Geologia Estratigráfica, Estrutural e Econômica da área do "Projeto Araguaia". Rio de Janeiro, DNPM, 1-94.

(Monografia DGM 18/19).

Barbosa, O., Baptista M. B., Dyer, R.C., Braun. O. P. G., Cotta, J.C., 1981. Geologia e Inventário dos Recursos Minerais da Região Central do Estado de Goiás - Projeto Brasília: Série Geologia 18, Seção Geologia Básica 13, DNPM, Brasília.

Bizzi, L. A., Schobbenhaus, C., Vidotti, R.M., Gonçalves, J.H., 2003. Geologia, Tectônica e Recursos Minerais do Brasil. Textos, Mapas e Gis. Serviço Geológico do Brasil - CPRM. Brasília. 692 p.

Blakely, R. J., 1995. Potential theory in gravity and magnetic applications. Cambridge University Press, $436 \mathrm{p}$. 
Blakely, R.J., 2005. Utility of aeromagnetic studies for mapping of potentially active faults in two forearc basins: Puget Sound, Washinton, and Cook Inlet, Alaska, Earth Planets Space, 57:781-793.

Blum, M. L. B., 1999. Processamento e Interpretação de Dados de Geofísica Aérea no Brasil Central e sua Aplicação à Geologia Regional e à Prospecção Mineral.Instituto de Geociências, Universidade de Brasília, Brasília. Tese de doutoramento. 229 pp.

Brito Neves, B. B. e Cordani, U. C., 1991. Tectonic evolution of South America during the Late Proterozoic. Precambrian Research, 53: 23-40.

Brito Neves, B. B. e Fuck, R. A., 2014. The basement of the South American platform: Half Laurentian (N-NW) + half Gondwanan (E-SE) domains. Precambrian Research, 244:75-86

Carvalho, D. L. O., 2011. Mapeamento geológico e gravimetria da porçãoo central do Gráben de Água Bonita, sudoeste de Tocantins e noroeste de Goiás. Dissertação de mestrado, Universidade de Brasília, $79 \mathrm{p}$.

Castro, D. L., Fuck, R. A., Phillips, J. D., Vidotti, R. M., Bezerra, F. H. R., Dantas, E. L., 2014. Crustal structure beneath the Paleozoic Parnaíba Basin revealed by airbone gravity and magnetic data, Brazil. Tectonophysics, 614:128-145.

Cavendish H., 1798. Experiments to determine the density of the Earth. Philosophical Transactions of the Royal Society of London, 88:460-526.

Chamani, M. A. C., 2011, Tectônica Intraplaca e Deformação sinsedimentar induzida por abalos sísmicos: o Lineamento Transbrasiliano e estruturas relacionadas na Província Parnaíba, Brasil. Dissertação de Mestrado, Instituto de Geociências, Universidade de São Paulo, 206 p.

Chamani, M. A. C., Riccomini, C., Aguiar, M. P., Grohmann, C. H., 2011 . Tectônica sinsedimentar fanerozóica associada ao Lineamento Transbrasiliano no Brasil central. In: XIII Simpósio Nacional de Estudos Tectônicos, Campinas, SP.

Clotfelter, B. E., 1987. The Cavendish experiment as Cavendish knew it. American Journal of Physic, 55(3):210-213.

Cordani, U. G e Sato, K., 1999. Crustal Evolution of the South American Platform, based on Nd Isotopic Systematics on Granitic Rocks. Episodes, 22(3):167-173.

Cordani, U. G., Sato, K., Teixeiro, W., Tassinari C. C. G., Basei M. A. S., 2000. Crustal Evolution of the South American Platform. In Cordani, U. G., Milani, E. J., Thomaz Filho A., Campos D. A., Rio de Janeiro, $31^{\text {ST }}$ International Geological Congress, p. 19-40.

Cordell, L., e V. J. S. Grauch, 1985, Mapping basement magnetization zones from aeromagnetic data in the San Juan Basin, New Mexico,in W. J. Hinze, ed., The utility of regional gravity and magnetic anomalies maps: SEG, 181-197.

Cooper, G. R. J. e Cowan, D. R., 2005. Differential reduction to the pole. Computers and Geoscience, 3: 989-999.

Costa J. B. S., Gorayeb P.S.S., Bemerguy R.L., Gama Jr. T., Kotschoubey B., Lemos R. L., 1983. Projeto Paraíso do Norte: relatório final. Belém. DNPM/UFPA. 125 p.

Collela, A. e Prior, D.B., 1990. Coarse grained deltas. Oxford: International Association of Sedimentologists, Special publication, n10. DOI: 10.1017/S0016756800017933. 
Curto, J. B., Vidotti, R. M., Fuck, R. A., Blakely, R. J., Alvarenga, C. J. S., Dantas, E. L., 2014. The tectonic evolution of the Transbrasiliano Lineament in northern Paraná Basin, Brazil, as inferred from aeromagnetic data. Journal of Geophysical Research:Solid Earth. AGU Publications, 19p, doi:10.1002/2013JB010593.

Delgado, I. M., Dalton, J.S., Carlos, L.S., Custódio, N.S.F., Alves, R.S., José, A. P., Torres, J. G., Alberto, L. A. A., Maurílio, A.V., Paiva, I.G., Lacerda, J.V.F., Rodrigues, C.V., Perotta, M. M., Heineck. C. A., 2003. Geotectônica do Escudo Atlântico. In: Bizzi, L. A., Schobbenhaus, C., Vidotti, R.M., Gonçalves, J.H. Geologia, Tectônica e Recursos Minerais do Brasil. Textos, Mapas eGis. Serviço Geológico do Brasil - CPRM. Brasília: p.: 227- 334.

DNPM, 1981. Projeto Geofísico Brasil-Canadá: histórico e atividade até 30/09/77. MME/DNPM, Goiânia, GSC, Canadá.

European Space Agency, 2014. http://www.esa.int/spaceinimages/Images/2014/06/June_2014_magnetic_field. Acessado em 19 de agosto de 2014.

Ferreira, F. J. F., Souza, J., Bongiolo, A. B. S., Castro, L. G., 2010. Realce do gradiente horizontal total de anomalias magnéticas usando a inclinação do sinal analítico. Parte I Aplicação a dados sintéticos. IV Simpósio Brasileiro de Geofísica, Brasília, 6p.

Ferreira, F. J. F., Souza, J., Bongiolo, A. B. S., Castro, L. G., 2013. Enhancement of the total horizontal gradiente of magnetic anomalies using the tilt angle. Geophysics, 78(3):J33-J41.

Frasca, A. A. e Araújo, V. A., 2001. Projeto Hidrogeologia no Tocantins -Folha Palmas (TO) SD.22-Z-B. Goiânia: CPRM, 52 p.

Fuck, R. A., Jardim De Sá, E. F., Pimentel, M. M., Dardenne, M. A., Pedrosa-Soares, A. C., 1993. As faixas de dobramentos marginais do Cráton do São Francisco: síntese dos conhecimentos. In: Dominguez, J. M. L., Misi, A. (eds) O Craton do São Francisco, Salvador, SBG-BA/SGM/CNPq, 161-185.

Fuck, R. A., Dantas, E. L., Vidotti, R. M., Roig, H. L., Almeida, T., 2013. Deformação intracontinental em sistemas transcorrentes: $O$ caso do Lineamento Transbrasiliano: geometria, idade e significado. In: XIV Simpósio Nacional de Estudos Tectônicos, Chapada dos Guimarães. XIV Simpósio Nacional de Estudos Tectônicos. São Paulo: SBG.

Fuck, R. A., Dantas E. L., Pimentel M. M., Botelho, N. F., Armstrong R., Laux, J. H., Junges, S.L., Soares, J. E., Praxedes, I. F., (2014). Paleoproterozoic crust-formation and reworking events in the Tocantins Province, central Brazil: A contribution for Atlantica supercontinente reconstruction. Precambrian Research 244:53-74.

Gorayeb, P. S. S., Moura, C. A. V., Calado, W. M., 2001. Idades Paleoproterozóicas em Zircão dos Pillows Basaltos da Serra do Tapa (Cinturão Araguaia) - Município de Sapucaia - PA. In: SBG, Simpósio de Geologia da Amazônia, Belém. Resumos Expandidos, 1 CD-ROM.

Hasui, Y., Sadowski, G.R., Suguio, K., Fuck, G. F., 1975.The Phanerozoic Tectonic Evolution of the Western Minas Gerais State. Anais da Academia Brasileira de Ciências, 47: 431-438.

Hasui, Y., Abreu, F. A. M., Rangel, J. M. R., 1977. Estratigrafia da Faixa de Dobramentos Paraguai Araguaia no centro norte do Brasil. Boletim do IG - USP, 8:107-118.

Hasui, Y. e Costa, J.B.S., 1990. O Cinturão Araguaia: um novo enfoque estrutural estratigráfico. In: SBG, Congresso Brasileiro de Geologia, 36, Natal, Anais, 6:2535-2549. 
Herz, N., Hasui Y., Costa J. B. S., Matta M. A. S., 1989. The Araguaia fold belt, Brazil: A reactivated brasiliano - pan-african cycle (550 Ma) Geosuture. Precambrian Research 42: 371386.

Hinze, P. W. J.; Frese R. R.B., Saad A. H., 2013. Gravity and magnetic exploration: principles, practices, and applications. Cambridge: Cambridge University Press, 525 p.

Inpe, 2014. http://www.dsr.inpe.br/topodata/, acessado em 17 de janeiro.

Isles, D. J. e Rankin, L. R., 2013. Geological Interpretation of Aeromagnetic Data. Australia, CSIRO Publising, $365 \mathrm{p}$.

Kane, M. F., 1962. Comprehensive system of terrain corrections using a digital computer, Geophysics, 27(4):455-462.

Kearey, P., Vine, F. J. 1996. Global Tectonics. 2 ed. Osney Mead, Blackwell, 333p.

Kingston, D. R., Dishroom, C.P., Williams, P. A. 1983. Global basin classification system. AAPG Bulletin, 67: 2175-2193.

Klein, G. V., 1995. Intracratonic Basins. In: Busby, C. J.; Ingersoll R. V. (eds.). Tectonics of Sedimentary Basins. Blackwell Science, Cambridge, p. 459-478.

Kotschoubey B., Hieronymous, B., Albuquerque, C. A. R., 2005. Disrupt peridotites and basalts from the Neoproterozoic Araguaia belt (northern Brazil): Remnants of a poorly evolved oceanic crust? Journal of South American Earth Sciences 20:211-230.

Lacerda Filho J. V., Valente, C. R., Bahia, R. B. C., Lopes, R. C., Romanini, S. J., Oliveira, I. W. B., Oliveira, C. C., Sachs, L.L.B., Silva, V. A., Batista, I. H., 2004. Folha SD-22-Goiás. In: Schobbenhaus, C., Gonçalves, J. H., Santos, J.O.S.; Abram, M. B.; Leão Neto, R., Matos; G. M. M.; Vidotti, R. M.; Ramos, M. A. B.; Jesus, J.D.A. (eds). Carta Geológica do Brasil ao Milionésimo, Sistema de Informações Geográficas, Programa Geológico do Brasil, CPRM, Brasília. CD ROM.

LaFehr, T. R.; Nabiguian, M. N., 2012. Fundamentals of Gravity Exploration. Society of Exploration Geophysicists, 218 p.

Li, X. 2006. Understandig 3D analytic signal amplitude. Geophysics, 71(2): L13-L16.

Longman, I. M., 1959. Formulas for computing the tidal acceleration due to the moon and the sun: Journal of Geophysical Research, 64(12):2351-2355.

Luyendik, A. P. J., 1997. Processing of airbone magnetic data. AGSO Journal of Australian Geology e Geophysics, 17(2):31-38

Melo, J. H. G., Quadros, L. P. Janvier, P., 1987, Ocorrência de peixes actinopterígios no Devoniano Superior da bacia do Alto Amazonas, e suas implicações estratigráficas. Boletim de Geociências da Petrobrás, 1:114-115 (Abstract).

Melo, S.S.V., 2006, Razão de Poisson da Crosta Superior da Região de Porangatu, Goiás, Província Tocantins: um estudo por refração sísmica, Dissertação de Mestrado, Instituto de Geociências, Universidade de Brasília, 102 p.

Milani, E.J., Melo, J.H.G., Souza, P.A., Fernandes, L.A., França, A.B., 2007. Bacia do Paraná. Bol Geoc. Petrobras 15(2):265-287. 
Miller, H. G., e V. Singh., 1994, Potential field tilt-A new concept for location of potential field sources: Journal of Applied Geophysics, 32(2):213-217, doi:10.1016/0926-9851(94)90022-1.

Minty, B. R. S., 1991. Simple Micro-Levelling for Aeromagnetic Data. Expl. Geoph. 22:591-592

Moraes Rego, L. F. 1933. Notas Geograficas e Geológicas sobre o Rio Tocantins. Boletim do Museu Paraense Emílio Goeldi, Belém, 9:271-288.

Moreira M. L. O., Moreton L. C., Araújo V. A., Lacerda Filho J. V., Costa H.F., 2008. Geologia do Estado de Goiás e do Distrito Federal: texto Explicativo do Mapa Geológico de Goiás e Distrito Federal. Escala 1:500.000. Goiânia: CPRM; SIC-FUNMINERAL, 143 p.

Moura C. A. V. e Souza S. H. P., 1996. Síntese dos dados geocronológicos das rochas do embasamento do Cinturão Araguaia e suas implicações estratigráficas. Atas. XXXIX In: Congresso Brasileiro de Geologia, 39. , Salvador. Atas .. Salvador, SBG. 6: 31-34.

Nabighian, M. N., 1972, The analytic signal of two-dimensional magnetic bodies with polygonal cross-section: Its properties and use for automated anomaly interpretation. Geophysics, 37:507-517, doi: 10.1190/1.1440276.

Nabighian M. N., Ander M. E., Grauch V.J.S., Hansen R. O., LaFehr T. R., Li Y., Pearson W.C., Peirce J.W., Phillips J. D., Ruder M. E., 2005. Historical development of the magnetic method in exploration, Geophysics, 70(6):33-61.

Nagy, D., 1966. The prism method for terrain corrections using digital computers. Pure Appl. Geophys, 63:31-39.

Nilsen, T. H.; Sylvester, A. G. 1995. Strike-Slip Basins. In: Busby, C. J., Ingersoll, R. V. (eds.). Tectonics of Sedimentary Basins. Cambridge, Blackwell Science, 425-457.

Oliveira, D. C. e Mohriak, W. U., 2003. Jaibaras trough: an important element in the early tectonic evolutionof the Parnaíba interior sag basin, Northern Brazil, Marine and Petroleum Geology 20:351-383.

Pedreira, A. J. S., Cunha, R.L., Maurílio, A. V., Bahia, R.B.C., 2003. Bacias Sedimentares Paleozóicas e Meso-Cenozoicas Interiores In: Bizzi, L. A., Schobbenhaus, C., Vidotti, R.M., Gonçalves, J.H., Geologia, Tectônica e Recursos Minerais do Brasil. Textos, Mapas e Gis. Serviço Geológico do Brasil - CPRM, Brasília, p. 55-85.

Pimentel M. M., Fuck, R. A., 1994. Neoproterozoic crustal accretion in central Brazil. Geology, 20:375-379.

Pimentel, M. M., Jost, H., Fuck, R. A., 2004. O embasamento da faixa Brasília e o Arco Magmático de Goiás . In: Montesso-Neto, V., Bartorelli A., Carneiro C.D.R., Brito-Neves B.B. Geologia do Continente Sul-Americano - evolução da obra de Fernando Flávio Marques de Almeida. Ed. Becca, p. 354-368.

Phillips J.D., 2001. Designing matched bandpass and azimuthal filters for the separation of potential-field anomalies by source region and source type. 15th ASEG Geophysical Conference and Exhibition, Expanded Abstracts, 4 p.

Plint, A.G., 2010. Wave-and storm-dominated shoreline and shallow marine systems, p 167-199. In: James, N.P. \& Dalrymple R.W. (eds) Facies Models 4, Geological Society of Canada, 586p.

Popowsky, T., Connard, G., French R., 2009. GM-SYS Profile Modeling, Gravity and magnetic modeling software for Oasis montaj ${ }^{\mathrm{TM}}$, . Geosoft Inc., guia do usuário v 4.1, 107 p. 
Reeves, C., 2005 - Aeromagnetic Surveys: Principles, Practice e Interpretation- Geosoft -155 p.

Reid A. B., Allsop J. M., Granser H., Millett A. J., Somerton I. W., 1990. Magnetical interpretation in three dimensions using Euler deconvolution, Geophysics, 55(1):80-91.

Reynolds, J.M., 1997. An Introduction to Applied and Environmental Geophysics, John Wiley and Sons Ltd, Chichester, $796 \mathrm{p}$.

Rodrigues, T. J. A., 2012. Observatório Nacional, 185 anos. Rio de Janeiro. Observatório Nacional, $180 \mathrm{p}$.

Schobbenhaus, C., Ribeiro, C.L., Oliva, L.A., Takanohashi, J.T.,Lindenmayer, Z.G., Vasconcelos, J.B., Orlandi, V., 1975. Folha Goiás (SD-22). In: Carta Geológica do Brasil ao Milionésimo, DNPM, Brasília, $113 p$.

Schobbenhaus, C., Brito Neves. B. B., 2003. A Geologia do Brasil no contexto da Plataforma Sul In: Bizzi, L. A., Schobbenhaus, C., Vidotti, R.M., Gonçalves, J.H., Geologia, Tectônica e Recursos Minerais do Brasil. Textos, Mapas eGis. Serviço Geológico do Brasil - CPRM. Brasília: p. 5-55.

Sheriff S. D., 2010. Matched filter separation of magnetic anomalies caused by scattered surface debris at archaeological sites. Near Surface Geophysics, 8:145-150.

Sousa J. O., Moreton, L. C., 1995. Folha Xambioá - SB.22-Z-B. Escala 1:250.000. Programa Levantamentos Geológicos Básicos do Brasil - PLGB Goiânia, CPRM, 84p. Programa Grande Carajás, Convenio CPRM/DNPM.

Souza, L. F., 2013. Projeto Grabén Água Bonita: Geologia, Magnetometria e EM. Trabalho Final de Graduação. Universidade de Brasília. 80p

Spector A., e Grant F. S., 1970. Statistical models for interpretation aeromagnetic data, Geophysics, 35:293-302.

Syberg F. J. R., 1972. A Fourier method for the regional-residual problem of potencial fields. Geophysycal Prospeting, 20:47-75.

Talwani, M. e Heirtzler, J. R., 1964. Computation of magnetic anomalies caused by twodimensional bodies of arbitrary shape, in Parks, G. A., ed. Computers in the mineral industries, Part 1: Stanford Univ. Publ., Geological Sciences, 9:464-480.

Talwani, M., Worzel, J. L., Landisman, M., 1959, Rapid gravity computations for two-dimensional bodies with application to the Mendocino submarine fracture zone: Journal Geophysics, 64:4959.

Telford, W. M., Geldart L. P., Sheriff R. E., 1990. Applied Geophysics, Cambridge University Press, Cambridge,. $2^{\text {nd }}$ edition. $770 p$.

Verduzco, B., Fairhead, J. D., Green, C. M., Mackenzie C., 2004. New insights into magnetic derivatives for structural mapping: The Leading Edge, 23:116-119, doi:10.1190/1.1651454.

Vogado, G. A., 2013. Projeto Gráben Água Bonita: Geologia e Gravimetria. Trabalho Final de Graduação. Universidade de Brasília. 80p.

Vidotti, R. M., Fuck, R. A., Dantas, E. L., Almeida, T., Roig, H. L., Curto, J. B., Pedrosa Jr, N. C., Santos, R. D., Castro, D. L., Bezerra, F. H. R., 2012. Lineamento Transbrasiliano: 
interpretação de dados aerogeofísicos. In: 46 Congresso Brasileiro de Geologia, Santos. Anais 46 Congresso Brasileiro de Geologia. São Paulo: SBG, 2012.

Zalán, P.V., 1989. A tectônica transcorrente na exploração de Petróleo: uma revisão. Revista Brasileira de Geociências, 16: 245-257.

Withehead, N., 2009. Montaj Geophysics, tutorial e guia do usuário, v. 7.1, Geosoft Inc., 39p.

Withehead, N., 2010. Montaj Grav/Mag Interpretation, Sistema de processamento, análise e visualização para a inversão 3D de dados de campos potenciais para o Oasis Montaj v. 7.1, Geosoft Inc., 79p.

Won, I. J., and Bevis, M., 1987, Computing the gravitational and magnetic anomalies due to a polygon: Algorithms and Fortran subroutines: Geophysics, 52:232-238.

Woodcock, N. H., 1996. Strike Slip Duplexes. Journal of Strutural Geology, 8(7):725-735.

Woodcock, N. H. e Rickards, B., 2003. Transpressive duplex and flower structure: Dent Fault System, NW England. Journal of Structural Geology, 25:1981-1992. 